Universidade De SÃo PaUlo

Instituto de Física de SÃo Carlos

\title{
Análise de Formas 3D usando Wavelets 1D, 2D e 3D
}

\author{
SÍlvia CRistina Dias Pinto ${ }^{\dagger}$ \\ Orientador: \\ Prof. Dr. Roberto Marcondes CeSAR Junior \\ Co-orientador: \\ Prof.Dr. LuCIANO DA Fontoura Costa \\ Tese apresentada ao Instituto de Física de São Carlos da Universidade \\ de São Paulo para obtenção do título de Doutor em Ciências, sub-área:
} Física Computacional.

\section{São Carlos \\ Outubro de 2005}

${ }^{\dagger}$ Este trabalho contou com apoio financeiro da CAPES. 
Dedico a minha família, que sempre acreditou no meu potencial intelectual para realizar este trabalho. 


\section{Agradecimentos}

Gostaria de deixar registrado meu profundo agradecimento às pessoas que, direta e indiretamente, me ajudaram na elaboração desta tese.

À Deus, por tudo que ele já me ofereceu nesta vida.

Ao meu orientador, Dr. Roberto Marcondes Cesar Junior, que acreditou nesta parceria e me deu a oportunidade de trabalhar com um grande profissional.

Ao meu co-orientador, Dr. Luciano da Fontoura Costa, pela orientação e a oportunidade de realizar este trabalho em ótima infra-estrutura.

Aos meus amigos do Grupo de Visão Cibernética que por aqui já passaram: Daniela Ushizima, Andréa Campos, Leandro Estrozi, Carlos Rodrigues, Luiz Rios, Edson Nakamura, Ricardo Fabbri, Renata Arantes, Cristian Montagnoli, Luis Diambra, Katia Waldemarin e Célia Cortez; E aos que ainda fazem parte desta família cibernética: Linder Candido, Bruno Travençolo, Thomas Chalumeau, Cesar Castanon, Luis Rocha, Matheus Viana, Dilson da Silva, Michelle Horta, Marcos Roberto e Leandro Carrijo.

Aos professores e pesquisadores que contribuíram direto e indiretamente com discussões e colaborações neste trabalho: PhD. Pete E. Lestrel (UCLA), Didem Gokcay, Dra. Maria Cristina Ferreira de Oliveira (ICMC-USP), Dr. Luis Gonçalvez Neto (EESC-USP), Dr. Luis Diambra (UNIVAP) e Dra. Míriam Manoel (ICMCUSP).

Aos funcionários do IFSC, que me auxiliaram durante o programa de doutorado: Marcos Roberto, Leandro C. P., Paulo Blandino, Claudia Amato, Wladerez Gounella, Cristiane Estella, as bibliotecárias do IFSC, além de outros.

À minha professora de inglês e grande amiga Ivani Albert, pelas aulas, companheirismo e confiança que ela me dedicou. 
Aos amigos que fiz durante o meu doutorado, que foram muitos, e que serão representados por: Sonia e José Bachega, Josiane Viana, Juliana Monferdini, Thais Vanzella, Eugênia Dajer, Thatyana Piola, Enzo Serafim, Celio Borges, Allan Rodrigues, Thalita Asperti, Juliana Visioli, Clodis Boscarioli, Celina Takemura, Silvia Calbo, Reinaldo Lopes e Tania, Rodrigo Bianchi, Barbara Estrozi, além de muitos outros.

Às amigas que vêm me acompanhando há mais tempo: Alessandra Riposati, Simone Falconi e Gercina Angelo.

À Comissão de Pós-graduação do IFSC, principalmente aos professores Dr. Richard Garratt e Dr. Tito Bonagamba, pelo incentivo, confiança e a oportunidade de trabalharmos juntos em pró da pós-graduação.

À CAPES pelo apoio financeiro.

Ao IFSC pelo suporte e infra-estrutura. 


\section{Conteúdo}

1 Introdução 1

1.1 Considerações Preliminares . . . . . . . . . . . . . . . . . 1

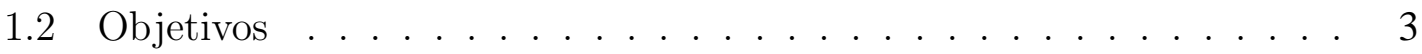

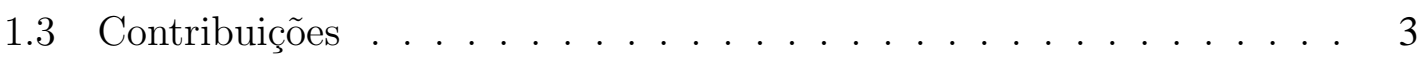

1.4 Organização do Texto . . . . . . . . . . . . . . . . 4

2 Conceitos em Análise de Formas $\quad 7$

2.1 Visão Computacional e a Análise de Formas . . . . . . . . . . . . . . 7

2.2 Tarefas de Análise de Formas Desempenhadas neste Trabalho . . . . 9

2.2.1 Pré-Processamento de Formas . . . . . . . . . . . . . . . . . 9

2.2.2 Transformações de Formas . . . . . . . . . . . . . . . . . . . . 9

2.3 Formas 3D e a Geometria Diferencial . . . . . . . . . . . . . . . . 11

2.3.1 Curvas Espaciais . . . . . . . . . . . . . . . . 12

2.3.2 Superfícies Regulares . . . . . . . . . . . . . . . 14

3 Wavelets $\quad 16$

3.1 Análise Multi-escala e a Wavelet . . . . . . . . . . . . . . . . 16

3.2 Wavelets e suas Propriedades . . . . . . . . . . . . . . . . 18

3.2.1 Transformada Wavelet Contínua 1D . . . . . . . . . . . . . . . 19

3.2.2 Transformada Wavelet Contínua 2D . . . . . . . . . . . . . 21

3.2.3 Transformada Wavelet Contínua 3D . . . . . . . . . . . . . . 22

3.3 Escolha da Wavelet Analisadora . . . . . . . . . . . . . . . . . 22

4 Análise de Formas 3D usando Wavelets 26

4.1 Análise de Formas: Wavelets 1D . . . . . . . . . . . . . . . . . . 27

4.1.1 Pré-processamento . . . . . . . . . . . . . . . . . . . . 27

4.1 .2 Extração de Características . . . . . . . . . . . . . . . . 27

4.2 Análise de Formas: Wavelets 2D . . . . . . . . . . . . . . 31 
4.2.1 Pré-processamento . . . . . . . . . . . . . . . . 31

4.2.2 Extração de Características . . . . . . . . . . . . . . 36

4.3 Análise de Formas: Wavelets 3D . . . . . . . . . . . . . . . . . 38

4.3.1 Pré-processamento . . . . . . . . . . . . . . . . . . 38

4.3.2 Extração de Características . . . . . . . . . . . . . . 39

5 Resultados $\quad 46$

5.1 Curvas Espaciais Parametrizadas e Wavelet 1D . . . . . . . . . . 46

5.1.1 Espaço de Características Obtido . . . . . . . . . . . . . 48

5.2 Superfícies do tipo $z=f(x, y)$ e Wavelet 2D . . . . . . . . . . 50

5.2.1 Espaço de Características Obtido . . . . . . . . . . . 53

5.2.2 Avaliação de Desempenho das Características . . . . . . . . 54

5.3 Superfícies do tipo $w=f(x, y, z)$ e Wavelet 3D . . . . . . . . . 58

5.3 .1 Espaço de Características Obtido . . . . . . . . . 58

6 Conclusão $\quad 64$

6.1 Considerações Finais . . . . . . . . . . . . . . . . . . 64

6.1 .1 Desenvolvimentos Futuros . . . . . . . . . . . . 65

$\begin{array}{ll}\text { Bibliografia } & 67\end{array}$

A Rotinas Aplicadas no Pré-processamento das Imagens $\quad 74$

$\begin{array}{ll}\text { B Conjunto das Curvas Espaciais } & 78\end{array}$

C Conjuntos das Superfícies do tipo $z=f(x, y) \quad \mathbf{8 2}$

D Conjunto das Superfícies do tipo $w=f(x, y, z) \quad 87$

E Trabalhos Produzidos durante o Programa de Doutorado $\quad 89$ 


\section{Lista de Figuras}

1.1 Organização da Tese. . . . . . . . . . . . . . . . . . . . . . 6

2.1 Tarefas de análise de formas e sua organização em três classes principais. As tarefas destacadas foram trabalhadas neste doutorado. . . . 8

2.2 Representação do Triedro de Frenet-Serret para a curva $f(s) \ldots$. . . . 13

3.1 (a) Ondas senoidais e (b) a wavelet conhecida como Chapéu Mexicano em diferentes freqüências e localização no espaço. . . . . . . . . . . . 17

3.2 Derivada de primeira ordem da função gaussiana como wavelet $\psi_{1}$. . . 23

3.3 As wavelets $\psi_{x}$ em (a) e $\psi_{y}$ em (b) definidas pela equação (3.13). . . . 24

3.4 A wavelet mãe $\psi_{x} 3 \mathrm{D}$ em (a) e em (b) a fatia central da função em (a). 25

4.1 (a) Representação da órbita por marcos; e em (b) representação por uma curva fechada do tipo $f(s)=(x(s), y(s), z(s))$, a partir de uma interpolação dos marcos pelo Método de Bresenham. . . . . . . . . . 28

4.2 Pontos gerados para uma circunferência em (a); (b) o campo tangente; (c) o campo normal; (d) o campo binormal; e em (e) a composição dos vetores do triedro de Frenet-Serrat. . . . . . . . . . . . . . 30

4.3 Gráfico da curvatura e da torção para a circunferência da Figura 4.2(a), a partir do triedro de Frenet-Serrat. . . . . . . . . . . . . . 31

4.4 (a) Marcos da órbita analisada; (b) o seu campo tangente; (b) o seu campo normal; (c) o seu campo binormal; e (d) os seus vetores para a representação do triedro de Frenet-Serrat. . . . . . . . . . . . . 32

4.5 Gráficos da curvatura e da torção para a curva referente a Figura 4.4(a), a partir do triedro de Frenet-Serrat. Alguns pontos são marcados para facilitar a leitura dos gráficos com a curva original. . . . . . . . . . 33

4.6 Exemplo de uma superfície da classe fissura de Sylvius conforme os dados originais. . . . . . . . . . . . . . . . . . 33 
4.7 Superfície da Figura 4.6 apresentada a partir do valor médio $\hat{z}=$ $f(x, y)$ dos pontos. . . . . . . . . . . . . . . . 34

4.8 (a) Imagem 2D da superfície $\hat{z}=f(x, y)$ apresentada na Figura 4.7;

(b) Imagem 2D da superfície extrapolada; e em (c) a sua versão como uma superfície tri-dimensional. . . . . . . . . . . . . . . . . 35

4.9 (a) Imagem da superfície extrapolada e periódica, e sua versão como uma superfície 3D em (b). . . . . . . . . . . . . . . . . 36

4.10 (a) Gradiente da superfície referente à Figura 4.7 e o seu histograma da dispersão da orientação do gradiente em (b). . . . . . . . . . . . . 37

4.11 (a) Pontos da estrutura morfológica original; e em (b) a curva de pontos de uma fatia da estrutura original. . . . . . . . . . . . . 38

4.12 Uma das fatias de pontos originais interpolada pelo método de Bresenham em (a); e em (b) o conjunto de pontos originais vistos através de curvas de nível depois da interpolação. . . . . . . . . . . . . . . 39

4.13 Contorno dos pontos em (a); dilatação do contorno em (b); escolha da região de interesse em (c), e a região considerada em (d). . . . . . 40

4.14 Volume obtido através do empilhamento das regiões dilatadas. . . . . 40

4.15 Visualização de alguns intervalos do campo normal de uma esfera sintética em (a)-(c) . . . . . . . . . . . . . . . . . . . . 442

4.16 Versão suavizada pela aplicação da TWC do volume da Figura 4.14

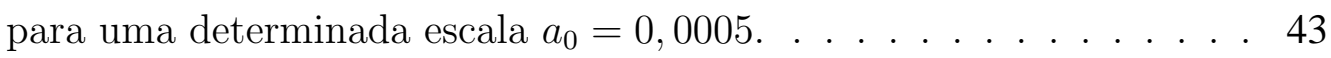

4.17 Ilustração do campo normal obtido através da versão suavizada da estrutura volumétrica da Figura 4.16. . . . . . . . . . . . . . . 43

4.18 Modelo da distribuição dos voxels vizinhos-de-1-voxel (em cinza escuro) de um ponto $(x, y, z)$ da superfície em (a); e em (b) a medida do ângulo $\theta$ de um dos voxels da vizinhança em relação ao vetor normal do ponto $(x, y, z) \ldots \ldots \ldots \ldots \ldots$

5.1 O crânio do coelho visualizado por uma perspectiva que mostra a relação da margem orbital e sua orientação no sistema de coordenadas cartesianas. Figura retirada do livro [38] . . . . . . . . . . . . . . . 4

5.2 Perspectiva 3D da curva orbital do coelho. Os três grupos médios: (1) infantil (MEANINFC3); (2) juvenil (MEANJUVC3); e (3) adulto (MEANADUC3), estão sobrepostos pelo centróide. Ambas diferenças de tamanho e forma estão envolvidas nesta representação. . . . . . . . 48 
5.3 Perspectiva 3D da curva orbital do coelho. Os três grupos médios: (1) infantil (MEANINFC1); (2) juvenil (MEANJUVC1); e (3) adulto (MEANADUC1), estão sobrepostos pelo centróide. Apenas as diferenças em relação à forma estão envolvidas nesta representação. . . . . .

5.4 Resultados obtidos para a curvatura em (a) e a torção em (b) para as curvas da Figura 5.2, conforme a análise de forma e tamanho para as diferentes idades do contorno orbital. . . . . . . . . . . . 50

5.5 Resultados obtidos para a curvatura em (a) e a torção em (b) para as curvas da Figura 5.2, conforme a análise que considera apenas a forma das diferentes idades do contorno orbital. . . . . . . . . . . 50

5.6 Normalização da curvatura para as duas diferentes análises. . . . . . . 51

5.7 Regiões de destaque na curva onde ocorrem os valores de picos no gráfico de curvatura da Figura 5.6. . . . . . . . . . . . . 51

5.8 Regiões de destaque no gráfico de torção. . . . . . . . . . . . . . 52

5.9 Regiões de destaque na curva, conforme o gráfico da Figura 5.8. . . . 52

5.10 Fossa (ou sulco) lateral localizada na visão lateral do Lobos do telencéfalo (Adaptado de [56]). . . . . . . . . . . . . . . . 53

5.11 Sulco do cíngulo (Adaptado de $[56]$ ). . . . . . . . . . . . . . 54

5.12 Espaços de características obtidos pelo método que utiliza a transformada wavelet (a)-(c) para as escalas de análise $\mathrm{a}=0.00006, \mathrm{a}=0.005 \mathrm{e}$ $\mathrm{a}=0.01$, respectivamente; e em (d) o espaço de características obtido pelo método de diferenciação de Sobel. . . . . . . . . . . . . . . . . 55

5.13 Medidas de qualidade dos espaços de características para uma série de escalas: (a) Distância de Mahalanobis; (b) Distância de Battacharyya; (c) Dispersão total; (d) Dispersão Intra classes; (e) Dispersão Inter classes; (f) Coeficiente de Correlação (valores deslocados para o eixo positivo do gráfico). . . . . . . . . . . . . . 60

5.14 A distância de Mahalanobis em relação às escalas espaciais, considerando várias reconstruções a partir dos auto-vetores na Análise dos Componentes Principais. . . . . . . . . . . . . . . 61

5.15 Melhor combinação de uma (a), duas (b) e três (c) características considerando o valor da distância de Mahalanobis. . . . . . . . . . . 62

5.16 Três espaços de características obtidos pela análise visual entre todas as combinações de 1,2 e 3 características. . . . . . . . . . . . 63 
B.1 Perspectivas 3D da curva orbital do coelho. Os três grupos médios: (1) infantil (MEANINFC1); (2) juvenil (MEANJUVC1); e (3) adulto (MEANADUC1), estão sobrepostos pelo centróide. Também são apresentadas as projeções ortogonais nos planos xy, xz e yz. Ambas diferenças de tamanho e forma estão envolvidas nesta representação. . 78

B.2 Perspectiva 2D das três vistas da curva orbital para os três grupos médios: (1) infantil (MEANINFC1); (2) juvenil (MEANJUVC1); e (3) adulto (MEANADUC1), que estão sobrepostos pelo centróide. Em (a) vista lateral ou plano xy; em (b) vista superior ou plano xz; e (c) plano yz, respectivamente, conforme as projeções das curvas orbitais apresentadas na Figura 5.2 no Capítulo 5. Ambas diferenças de tamanho e forma estão envolvidas nestas representações. . . . . . . 79

B.3 Perspectivas 3D da curva orbital do coelho. Os três grupos médios: (1) infantil (MEANINFC3); (2) juvenil (MEANJUVC3); e (3) adulto (MEANADUC3), estão sobrepostos pelo centróide. Também são apresentadas as projeções ortogonais nos planos xy, xz e yz. Apenas as diferenças em relação à forma estão envolvidas nesta representação. 80

B.4 Perspectiva 2D das três vistas da curva orbital para os três grupos médios: (1) infantil (MEANINFC3); (2) juvenil (MEANJUVC3); e (3) adulto (MEANADUC3), que estão sobrepostos pelo centróide. Em (a) vista lateral ou plano xy; em (b) vista superior ou plano xz; e (c) plano yz, respectivamente, conforme as projeções das curvas orbitais apresentadas na Figura 5.3 no Capítulo 5. Apenas as diferenças em relação à forma estão envolvidas nesta representação. . . . . . . . 81

C.1 Estruturas do tipo fissura de Sylvius. . . . . . . . . . . . . 83

C.2 Superfícies suavizadas das estruturas referentes à figura C.1 para $a=$ $5.10^{-4} \ldots \ldots \ldots \ldots . \ldots \ldots$. . . . . . . . . . . . . . . . . . . . . . 84

C.3 Estruturas do tipo sulco de cíngulo. . . . . . . . . . . . . . . 85

C.4 Superfícies suavizadas das estruturas referentes à figura C.3 para $a=$

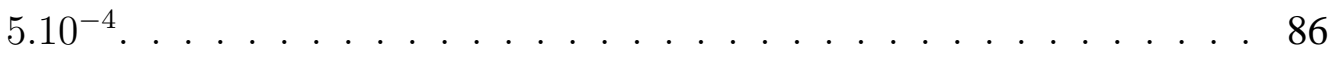

D.1 Superfícies analisadas: as superfícies da coluna (a) pertencem à classe de Giros de Heschl de hastes em comum; as superfícies da coluna (b) pertencem à classe de Giros de Heschl posteriormente duplicado; e as superfícies da coluna (c) pertencem à classe de Giros de Hesch simples. 88 


\section{Lista de Tabelas}

5.1 Coeficientes de correlação entre as medidas de qualidade de clusters. . 57

5.2 Distância de Mahalanobis para diferentes escalas considerando a combinação de características conforme explicado na Seção 5.2.1. Os valores em destaque são referentes aos gráficos da Figura 5.12(a)-(c). . . 57

5.3 Distância de Mahalanobis para os espaços de características apresentados na Figura 5.15 . . . . . . . . . . . . . . . . . . 58 


\section{Lista de Símbolos}

\begin{tabular}{ll}
$x, y$ e $z$ & coordenadas cartesianas \\
$t$ e $w$ & números reais \\
$s$ & comprimento de arco \\
$f(t)=(x(t), y(t), z(t))$ & curva espacial qualquer \\
$f(s)=(x(s), y(s), z(s))$ & curva espacial parametrizada pelo comprimento de arco \\
$f(x, y)=z$ & superfície \\
$f(x, y, z)=w$ & superfície \\
$\mathbf{T}$ & vetor tangente \\
$\mathbf{N}$ & vetor normal \\
$\mathbf{B}$ & vetor binormal \\
$k$ & curvatura \\
$\tau$ & torção \\
$S$ & superfície regular \\
$N$ & campo normal de $S$ \\
$f_{x}$ & derivada da função $f$ em relação a $x$ \\
$f_{y}$ & derivada da função $f$ em relação a $y$ \\
$f_{z}$ & derivada da função $f$ em relação a $z$ \\
$a$ & parâmetro de escala \\
$\mathbf{b}$ & vetor de translação ou deslocamento mãe \\
& wavelet \\
\hline & \\
&
\end{tabular}




$\begin{array}{ll}W_{\psi} & \text { transformada wavelet contínua } \\ C_{\psi} & \text { constante numérica para a transformada wavelet inversa contínua } \\ \mathbf{x} & \text { vetor posição } \\ \theta & \text { ângulo de rotação no espaço bidimensional } \\ \alpha & \text { ângulo de rotação no espaço tridimensional } \\ \psi_{1} & \text { wavelet como a primeira derivada da função gaussiana 1D } \\ \phi & \text { função gaussiana } \\ \psi_{x} & \text { wavelet como a primeira derivada parcial com respeito a } x \\ \psi_{y} & \text { wavelet como a primeira derivada parcial com respeito a } y \\ \psi_{z} & \text { wavelet como a primeira derivada parcial com respeito a } z \\ \nabla_{W} & \text { magnitude média do gradiente } \\ \mathbb{E}_{\nabla W} & \text { entropia da distribuição de orientação } \\ V & \text { superfície orientável } \\ R_{1} \text { e } R_{2} & \text { razões dos auto-eixos } \\ \mu & \text { valor médio } \\ \tilde{M} & \text { momento central }\end{array}$




\section{Resumo}

Este trabalho apresenta novos métodos para análise de formas tridimensionais dentro do contexto de visão computacional, destacando-se o uso das transformadas wavelets $1 \mathrm{D}, 2 \mathrm{D}$ e $3 \mathrm{D}$, as quais proporcionam uma análise multi-escala das formas estudadas. As formas analisadas se dividem em três tipos diferentes, dependendo da sua representação matemática: $f(t)=(x(t), y(t), z(t)), f(x, y)=z$ e $f(x, y, z)=w$. Cada tipo de forma é analisado por um método melhor adaptado. Primeiramente, tais formas passam por uma rotina de pré-processamento e, em seguida, pela caracterização por meio da aplicação das transformadas wavelet 1D, 2D e 3D para as respectivas formas. Esta aplicação nos permite extrair características que sejam invariantes à rotação e translação, levando em consideração alguns conceitos matemáticos da geometria diferencial. Destaca-se também neste trabalho a não obrigatoriedade de parametrização das formas. Os resultados obtidos a partir de formas extraídas de imagens médicas e dados biológicos, que justificam este trabalho, são apresentados. 


\section{Abstract}

This work presents new methods for three-dimensional shape analysis in the context of computational vision, being emphasized the use of 1D, 2D and 3D wavelet transforms, which provide a multiscale analysis of the studied shapes. The analyzed shapes are divided in three different types depending on their representation: $f(t)=(x(t), y(t), z(t)), f(x, y)=z$ and $f(x, y, z)=w$. Each type of shape is analyzed by a more suitable method. Firstly, such shapes undergo a pre-processing procedure followed by the characterization using the $1 \mathrm{D}, 2 \mathrm{D}$ or $3 \mathrm{D}$ wavelet transform, depending on its representation. This application allows to extract features that are rotation- and translation-invariant, based on some mathematical concepts of differential geometry. In this work, we emphasize that it is not necessary to use the parameterized version of the $2 \mathrm{D}$ and $3 \mathrm{D}$ shapes. The experimental results obtained from shapes extracted from medical and biological images, that corroborate the introduced methods, are presented. 


\section{Capítulo 1}

\section{Introdução}

\subsection{Considerações Preliminares}

Inquestionavelmente, a extração de medidas para caracterização de formas tem grande importância no desenvolvimento tecnológico e científico em nossa sociedade. Existe um grande número de áreas de pesquisa em que a caracterização de formas é fundamental, sejam elas de interesse teórico, como em estudos em física ou biologia, quanto práticos, como automatização de diagnósticos médicos ou de produção industrial. Uma das maneiras de analisar e caracterizar estas formas, por meio de medidas, é utilizando suas imagens. Em geral, empregam-se computadores para processar estas imagens e extrair delas medidas importantes para sua caracterização.

Existem diversos tipos de medidas que podem ser extraídas de uma imagem e a criação e o aperfeiçoamento destas contribuem para o desenvolvimento das áreas de pesquisa que se utilizam do processamento de imagens. Uma área de pesquisa que está fortemente vinculada à análise de imagens é a visão computacional, que tem como uma de suas principais linhas de pesquisa, desenvolver e aplicar técnicas de medidas em formas.

Pesquisadores têm dado grande importância à análise de formas e uma atenção especial às técnicas de processamento de sinais $[2,14]$. Por exemplo, descritores de Fourier e Wavelets têm sido aplicados com êxito em diferentes situações em análise de formas 2D [20, 23, 34, 38, 68]. A transformada wavelet, sendo particularmente explorada por causa das suas propriedades multi-escala, pode ser usada para anali- 
sar estruturas de formas cujas características são dependentes da escala. Métodos de análise de formas bidimensionais utilizando a transformada wavelet $2 \mathrm{D}$ foram desenvolvidos e descritos em [12].

Por outro lado, a análise de formas 3D tem atraído crescente interesse nos últimos anos e, portanto, novos métodos e aplicações têm freqüentemente sido registrados na literatura científica [59]. De qualquer forma, há ainda importantes problemas em aberto restringindo algumas situações práticas e requerendo o desenvolvimento de técnicas mais poderosas e flexíveis.

\section{Aplicações Médicas}

A análise de formas é particularmente promissora no campo de análise de imagens médicas, onde um grande número de dados é gerado e armazenado todos os dias em hospitais e centros de pesquisa. Atualmente, por exemplo, embora as análises morfológicas de estruturas neuroanatômicas sejam realizadas através de medidas volumétricas e estatísticas, há uma carência de métodos em análises morfológicas, apesar da sensibilidade espacial de imagens de ressonância magnética (MRI, para a sigla em inglês) ter avançado.

Dois estudos publicados em deficiência de leitura [36] e geração de palavras [18] mostraram que as diferenças de formas básicas em neuroanatomia devem ser indicativo da variabilidade funcional no cérebro. Outros dois novos estudos [54, 55] de delineamento funcional do córtex auditivo em populações normais revelam que há uma enorme relação entre a topografia de anatomia e a função. Estes estudos destacam várias possíveis funções para análises morfológicas 3D, tal como o estudo da correlação anatômica da função, predição de disfunção através da evolução da anatomia e investigação precisa de neuroanotomia desenvolvida.

\section{Aplicações Biológicas}

Outra área de comparável importância é a análise de formas biológicas, tendo como uma das principais disciplinas a morfometria, que realiza medidas quantitativas da forma biológica. Estas medidas têm como função elucidar questões taxonômicas e classificar as formas em relação à estrutura e função, assim como fornecer informações para melhor compreensão dos processos biológicos [39, 60]. 


\subsection{Objetivos}

Em virtude da necessidade de dispor de técnicas para análise de formas 3D, conforme discutido anteriormente, este trabalho tem como objetivo apresentar uma nova abordagem em análise de formas, desenvolvendo técnicas que possibilitem a extração de características (informações significativas) de formas 3D.

Devido à importância de realizar medidas das formas de uma maneira mais representativa e assumindo a possibilidade de que uma forma possa apresentar detalhes relevantes de sua estrutura em diferentes escalas de observação, nós adotamos como principal ferramenta de análise a transformada wavelet, cuja principal característica é a sua propriedade multi-escala.

De acordo com as técnicas encontradas na literatura, geralmente há uma necessidade de que se construa primeiramente uma parametrização da superfície da forma para que então se possa aplicar técnicas de análise na mesma. Uma das técnicas mais utilizadas para a realização da parametrização é a triangularização [45], bem como por contorno ativo [30, 63]. Estas técnicas, além de apresentarem algumas dificuldades computacionais, ainda não garantem resultados satisfatórios.

Um dos objetivos deste trabalho é o desenvolvimento de métodos que evitam a necessidade de parametrização, a fim de que se possa extrair propriedades diferenciais da forma analisada.

Devido à grande variedade de tipos de formas, daremos ênfase neste trabalho à aplicação do método proposto em formas 3D, as quais representaremos matematicamente como superfícies do tipo $f(x, y)=z$ e $f(x, y, z)=w$, e como uma curva no espaço $\mathbb{R}^{3}$ do tipo $f(t)=(x(t), y(t), z(t))$.

\subsection{Contribuições}

De um modo geral, esta tese introduz novas técnicas de análise de formas 3D. Essas contribuições para a pesquisa em visão computacional podem ser divididas como:

1. Desenvolvimento de uma abordagem baseada na transformada wavelet 1D e obtenção dos três vetores componentes de Frenet para caracterização de curvas fechadas espaciais parametrizadas do tipo $f(t)=(x(t), y(t), z(t))$. Este 
método foi aplicado em um conjunto de marcos ${ }^{1}$ de formas biológicas (ver Apêndice B) com o propósito de analisá-los e caracterizá-los através de características invariantes à translação e rotação como, por exemplo, análise da curvatura e torção da curva. Esta parte do trabalho teve a contribuição do Prof. Pete Lestrel, da Universidade da California de Los Angeles (UCLA), o qual nos forneceu o conjunto de dados trabalhados.

2. Desenvolvimento de uma abordagem baseada na transformada wavelet $2 \mathrm{D}$ e obtenção do campo gradiente de superfícies do tipo $f(x, y)=z$. Este método foi aplicado em um conjunto de estruturas neuroanatômicas (ver Apêndice C) com o objetivo de caracterizá-las através de características que sejam invariantes à translação e rotação como, por exemplo, análise da magnitude e da dispersão da orientação do campo gradiente. Esta aplicação contou com a colaboração da cientista Didem Gokcay, do centro de pesquisa Swartz Center for Computational Neuroscience-USA, a qual nos forneceu o conjunto de dados trabalhados.

3. Desenvolvimento de uma abordagem baseada na transformada wavelet 3D e obtenção do campo normal de superfícies do tipo $f(x, y, z)=w$. Este método foi aplicado em um conjunto de estruturas neuroanatômicas (ver Apêndice D) a fim de caracterizá-las através de características que sejam invariantes à translação e rotação como, por exemplo, análise dos auto-eixos e da distribuição da orientação local do campo normal. Esta aplicação também contou com a colaboração da cientista Didem Gokcay, do centro de pesquisa Swartz Center for Computational Neuroscience-USA, pelo fornecimento do conjunto de dados trabalhados.

Os métodos introduzidos nesta tese foram descritos previamente em [46, 47, 48, $49,50,51]^{2}$.

\subsection{Organização do Texto}

O texto da tese organiza-se inicialmente com um capítulo sobre as abordagens de análise de formas e suas ferramentas (capítulo 2), cuja intenção é apresentar, de

\footnotetext{
${ }^{1}$ Tradução para a palavra landmarks em inglês

${ }^{2}$ As conferências DSP 2002 e ISSPA 2003 são classificadas como Qualis Internacional A pela Capes
} 
uma maneira resumida, os principais conceitos trabalhados neste projeto, e também introduz alguns conceitos da Geometria Diferencial, dando ênfase para curvas espaciais e superfícies regulares. O capítulo 3 tem como objetivo apresentar a idéia da análise multi-escala e uma das suas principais ferramentas, a transformada wavelet, que ocupa um papel central para a realização deste trabalho. O capítulo 4 apresenta as três diferentes versões do método desenvolvido, suas respectivas ferramentas de processamento de imagens e formas para extração de características e caracterização de formas analisadas. Os resultados de tais aplicações são então apresentados no capítulo 5, finalizando com um capítulo de discussão e conclusão do trabalho (ver capítulo 6). O esquema da Figura 1.1 esclarece como esta tese esta organizada. 


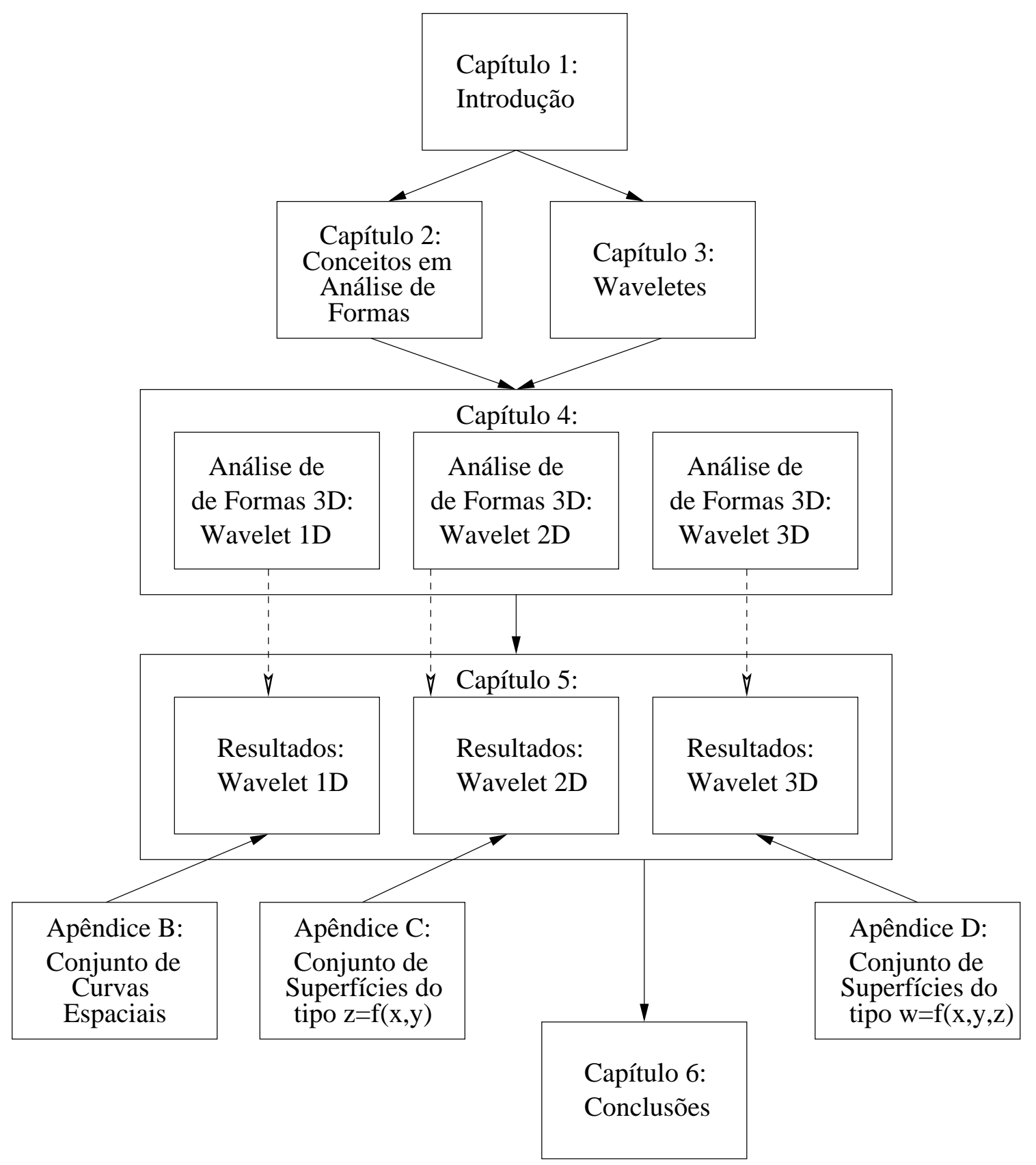

Figura 1.1: Organização da Tese. 


\section{Capítulo 2}

\section{Conceitos em Análise de Formas}

\subsection{Visão Computacional e a Análise de Formas}

Visão computacional é a disciplina de computação que tenta fazer computadores "enxergarem" através de análise de imagens e/ou vídeo [43]. Conhecendo a geometria da imagem, as propriedades da câmera de aquisição e as propriedades do mundo físico, é possível (no mínimo em alguns casos) inferir informações úteis sobre o mundo como, por exemplo, o tamanho de um obstáculo na frente do robô em Marte, a identidade de uma pessoa num sistema de vigilância, ou a localização de um tumor numa imagem de ressonância magnética. A visão computacional estuda como tais tarefas podem ser desenvolvidas de maneira robusta e eficiente.

A visão computacional tem sido uma área de pesquisa de grande importância por quase 40 anos e tende a continuar sendo instigante em ambas perspectivas científica e tecnológica, principalmente em certas áreas de aplicações, tais como: modelagem de visão biológica, navegação e manipulação de robô, análise de imagens médicas, além de tarefas de inspeção, detecção e reconhecimento de objetos.

Uma das principais tarefas da visão computacional é a representação e análise de formas. De fato, procedimentos de neuromorfometria [20, 21, 22], reconhecimento de impressões digitais [16], casamento de contornos para reconstrução tridimensional de imagens biomédicas [11], inspeção visual em ambientes industriais e muitas outras tarefas visuais podem ser realizadas por processos baseados em reconhecimento e análise de formas. 
Existem ainda problemas no contexto de análise de formas e reconhecimento computacional. Realmente, a análise computacional de formas envolve várias tarefas importantes, desde a aquisição de imagens até a classificação de suas formas. Em alguns casos, numa típica aplicação, a forma de interesse é digitalizada, produzindo uma imagem digital, a qual, às vezes, deve passar por uma rotina de pré-processamento, em que um conjunto de técnicas são aplicadas a fim de extrair informações da forma, para então ser analisada e (eventualmente) classificada. A figura 2.1 ilustra as tarefas freqüentemente exigidas para análise de formas, as quais podem ser brevemente divididas em 3 classes: (1) pré-processamento; (2) transformações; e (3) classificação. É Pré-Processamento Transformações $\quad$ Classificação

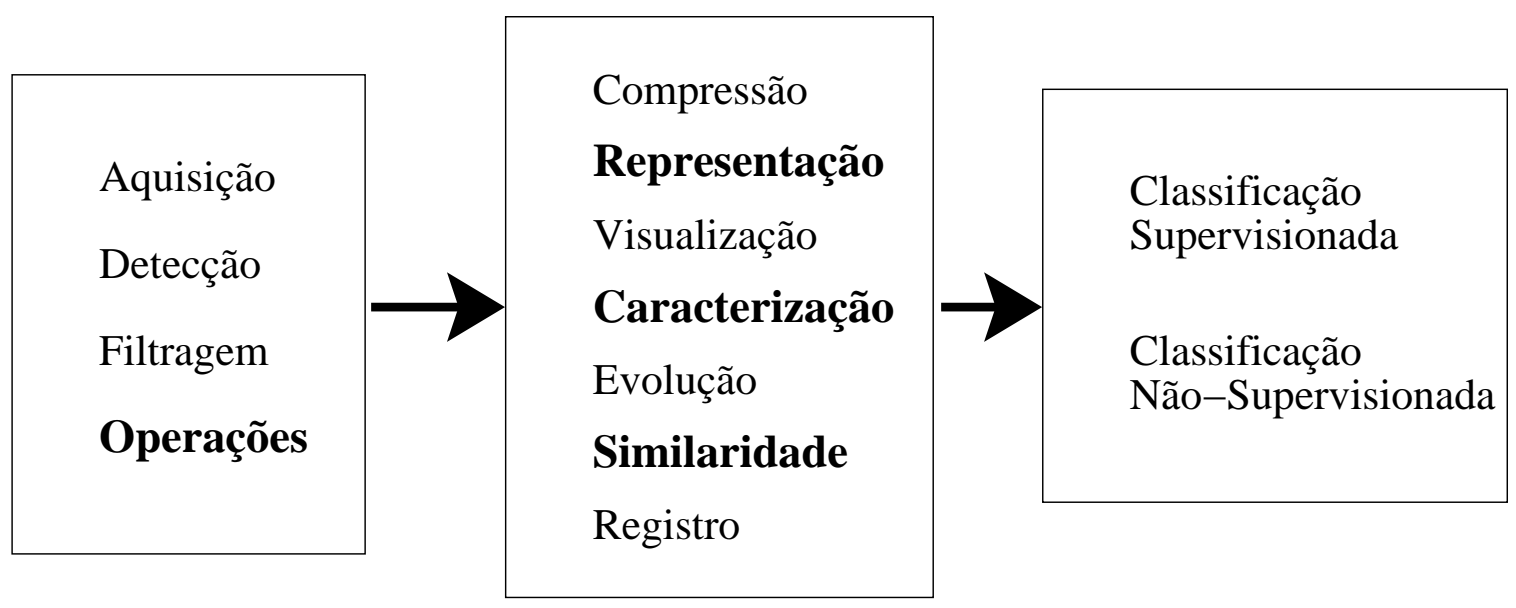

Figura 2.1: Tarefas de análise de formas e sua organização em três classes principais. As tarefas destacadas foram trabalhadas neste doutorado.

importante salientar que neste trabalho foi necessário trabalharmos apenas com uma parte destas tarefas, as quais se encontram destacadas na Figura 2.1 e detalhadas na Seção 2.2 seguinte.

Devido aos tipos de formas 3D trabalhadas nesta tese e à proposta de as analisarmos sem necessariamente ter que parametrizá-las, foi dada uma maior atenção de como representá-las de uma maneira matematicamente aceitável para que então pudéssemos caracterizá-las. Assim, a Seção 2.3 apresenta alguns conceitos da geometria diferencial, que foram adotados para explicar e validar as representações das formas 3D analisadas neste doutorado. 


\title{
2.2 Tarefas de Análise de Formas Desempenhadas neste Trabalho
}

\subsubsection{Pré-Processamento de Formas}

- Operações:

\begin{abstract}
Algumas vezes existe a necessidade de aplicar um certo número de operações nas formas de interesse antes de realizar uma análise nas mesmas. Por exemplo, num caso que envolve uma análise de comparação de duas ou mais formas, existe a necessidade de normalização dessas, abrangendo parâmetros tais como escala, rotação e translação dos dados. Outra operação altamente utilizada é a interpolação de pontos quando há necessidade de uma aproximação e/ou geração de formas intermediárias [1, 64], ou até mesmo a eliminação de porções da forma para um melhor tratamento e/ou manipulação dos dados. No capítulo 4, apresentaremos detalhadamente os métodos de operações utilizadas no pré-processamento dos diferentes dados trabalhados nesta tese.
\end{abstract}

\subsubsection{Transformações de Formas}

Após a aplicação da rotina de pré-processamento, um conjunto de técnicas pode ser aplicado para extrair informações da forma a ser analisada. Normalmente estas informações podem ser obtidas aplicando rotinas de transformações nas formas. Estas transformações são mapeamentos que permitem representar a forma de uma maneira mais apropriada (com respeito a uma determinada tarefa) e extrair medidas que são utilizadas em rotinas de classificação.

- Representação: Uma vez que o objeto de interesse tenha sido localizado na imagem (por detecção e/ou segmentação), temos um conjunto de pontos que pertencem ao objeto. Algumas vezes a maneira como esta forma é representada originalmente gera um certo tipo de insatisfação por causa do grande número de dados que é necessário para armazená-la. Além disso, um outro problema a ser enfrentado é o de como representar corretamente a forma, e isto implica num esquema de representação no qual a forma deve ser definida com base em tarefas específicas. 
Tal esquema pode permitir ou não a reconstrução da forma original, pois existem técnicas de preservação de informação (o que permite a reconstrução da forma original) e de não-preservação da informação. É importante enfatizar que representações que preservam informações são particularmente importantes devido ao fato de que diferentes formas são mapeadas em diferentes representações, enquanto técnicas de não-preservação podem produzir representações iguais para diferentes formas (mapeamento degenerado). Tais técnicas de não-preservação são, apesar de tudo, adotadas como medidas de formas que são úteis para caracterização e classificação. Portanto, ambas as abordagens apresentam suas vantagens e desvantagens.

De uma maneira geral, existem três abordagens básicas para a representação e análise de formas: a abordagem baseada em contornos, regiões e transformadas. Das abordagens baseadas em regiões se destacam: as "quadtrees" [6], a decomposição morfológica [52, 53], os esqueletos e os eixos de simetria [7, 20]. Por outro lado, a aproximação poligonal [13], o código da cadeia [10], as primitivas geométricas [25], as curvas paramétricas são alguns exemplos de representações de formas baseadas em contornos; os descritores de Fourier [27] e a transformada de Hough [19, 20] são alguns exemplos de representações de formas baseadas em transformada.

- Descrição ou Caracterização: Alguns dos mais importantes problemas envolvendo técnicas de análise de formas requerem uma extração de informações sobre objetos na vida real. Deve-se observar que freqüentemente alguns aspectos da forma são mais importantes que outros, dependendo da tarefa a ser resolvida pelo sistema de análise de formas. Por exemplo, muitos problemas de reconhecimento de objetos podem ser resolvidos primeiramente detectando alguns pontos dominantes que geralmente ocorrem na forma. Normalmente, o tipo de característica que deve ser detectada depende de cada problema específico, assim como das formas envolvidas. Existem diferentes abordagens para extrair informações sobre formas [20], as quais podem ser organizadas como segue:

- Medidas da forma: Uma das maneiras mais comuns de descrever formas envolve definir e medir características específicas tais como área, perímetro, número de vértices, número de buracos, medidas baseadas em curvatura, etc. A idéia básica da descrição de uma forma por meio de um conjunto de medidas (isto é, números) é que as medidas obtidas são sufi- 
cientes para representar razoavelmente as informações relevantes sobre a forma analisada.

- Transformadas realizadas na forma: As técnicas baseadas em transformadas são conhecidas em diversas áreas, desde processamento de sinais até telecomunicação, sendo muito utilizadas em análise de formas.

A transformada de um sinal é uma ferramenta matemática que expressa o sinal original de uma maneira alternativa, a qual é muitas vezes mais apropriada para uma certa tarefa do que a representação original. Existem diferentes transformadas que podem ser usadas, embora a transformada de Fourier seja a mais conhecida, por ser uma das mais versáteis. Outros exemplos de transformada são as wavelets, a Gabor e a de KarhunenLoève.

- Decomposição de formas: Esta técnica é baseada em decompor a forma em partes mais simples, as quais algumas vezes são chamadas de primitivas. Uma das abordagens mais versáteis e adequadas em diversas aplicações envolve ajustar primitivas geométricas em porções de um contorno, sendo conhecida como aproximação poligonal.

- Similaridade: Refere-se a estabelecer critérios que permitem medidas objetivas de quanto duas ou mais formas são similares (ou diferentes) uma(s) da(s) outra(s). É digno observar que os critérios de similaridade de formas, os quais são fundamentais para a classificação de formas, são geralmente dependentes de problemas específicos. De uma maneira mais clara, as características adotadas da forma analisada representam um papel importante no que diz respeito a definir o quão similares são duas formas.

\subsection{Formas 3D e a Geometria Diferencial}

A análise de formas realizada neste trabalho levou em consideração, algumas vezes, alguns conceitos da geometria diferencial. O propósito desta seção é introduzir algumas idéias da teoria diferencial clássica de curvas e superfícies regulares [9, 62]. 


\subsubsection{Curvas Espaciais}

A partir de uma determinada parametrização da curva espacial, podemos introduzir conceitos básicos como curvatura, torção, triedro de Frenet-Serret, etc.

Uma curva espacial é representada por uma correspondência $f: I \rightarrow \mathbb{R}^{3}, f(t)=$ $(x(t), y(t), z(t))$, em que $t \in I \subset \mathbb{R}$ e $x: I \rightarrow \mathbb{R}, y: I \rightarrow \mathbb{R}$ e $z: I \rightarrow \mathbb{R}$ são as funções componentes de $f$.

Considerando $f: I \rightarrow \mathbb{R}^{3}$ uma curva espacial parametrizada por $s$, sendo $s$ o comprimento de arco da curva, temos que $\mathbf{T}(s)=f^{\prime}(s)=\left(x^{\prime}(s), y^{\prime}(s), z^{\prime}(s)\right)$ indica o vetor espacial tangente unitário da curva. A velocidade com que as retas tangentes mudam de direção é denominada curvatura de $f$, isto é, se $\mathbf{T}^{\prime}(s) \neq 0$, então podemos definir

$$
k(s)=\left|\mathbf{T}^{\prime}(s)\right|
$$

como a curvatura e $\mathbf{N}(s)=\mathbf{T}^{\prime}(s) / k(s)$ o vetor normal unitário da curva, se $k(s) \neq 0$.

O produto vetorial de $\mathbf{T}(s)$ por $\mathbf{N}(s)$ define um outro vetor

$$
\mathbf{B}(s)=\mathbf{T}(s) \times \mathbf{N}(s),
$$

o qual é chamado de vetor binormal da curva.

Portanto, para cada valor de $s$, tem-se uma base ortonormal do espaço euclidiano $\mathbb{R}^{3}$, constituída pelos vetores $\mathbf{T}(s), \mathbf{N}(s)$ e $\mathbf{B}(s)$, chamada de Triedro de FrenetSerret, onde cada vetor da base é o produto vetorial dos outros dois, com orientação positiva (veja Figura 2.2):

$$
\begin{aligned}
\mathbf{T}(s) & =\mathbf{N}(s) \times \mathbf{B}(s) \\
\mathbf{N}(s) & =\mathbf{B}(s) \times \mathbf{T}(s) \\
\mathbf{B}(s) & =\mathbf{T}(s) \times \mathbf{N}(s) .
\end{aligned}
$$

Derivando a expressão de 2.2 e usando a primeira relação de Frenet-Serret $\mathbf{T}^{\prime}(s)=k(s) \mathbf{N}(s)$ tem-se que

$$
\mathbf{B}^{\prime}(s)=\mathbf{T}(s) \times \mathbf{N}^{\prime}(s),
$$

pois $\mathbf{B}^{\prime}(s)=\mathbf{T}^{\prime}(s) \times \mathbf{N}(s)+\mathbf{T}(s) \times \mathbf{N}^{\prime}(s)$, onde $\mathbf{T}^{\prime}(s)$ e $\mathbf{N}(s)$ são paralelos. Como $\mathbf{N}(s)$ é um vetor unitário, $\mathbf{N}^{\prime}(s)$ é ortogonal a $\mathbf{N}(s)$, portanto $\mathbf{N}^{\prime}(s)$ é uma combinação linear de $\mathbf{B}(s)$ e $\mathbf{T}(s)$

$$
\mathbf{N}^{\prime}(s)=\alpha(s) \mathbf{T}(s)+\tau(s) \mathbf{B}(s) .
$$




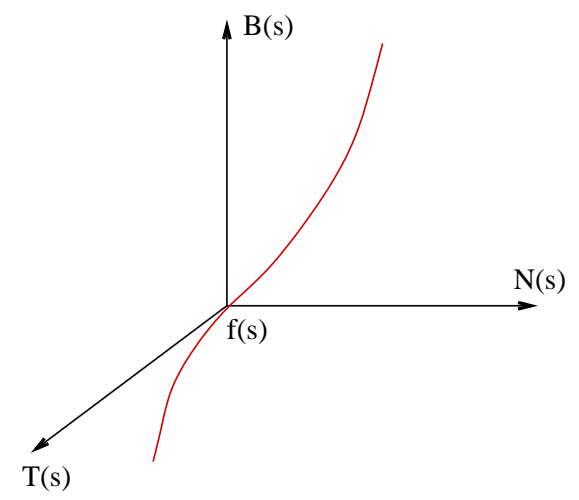

Figura 2.2: Representação do Triedro de Frenet-Serret para a curva $f(s)$.

Substituindo a equação (2.5) em (2.4), obtemos a segunda relação de Frenet-Serret:

$$
\begin{aligned}
\mathbf{B}^{\prime}(s) & =\mathbf{T}(s) \times(\alpha(s) \mathbf{T}(s)+\tau(s) \mathbf{B}(s)) \\
& =\tau(s)(-\mathbf{N}(s)) \\
\mathbf{B}^{\prime}(s) & =-\tau(s) \mathbf{N}(s)
\end{aligned}
$$

sendo que o escalar $\tau(s)$ recebe o nome de torção de $f$ em $s$.

Derivando a segunda expressão de (2.3):

$$
\mathbf{N}^{\prime}(s)=\mathbf{B}^{\prime}(s) \times \mathbf{T}(s)+\mathbf{B}(s) \times \mathbf{T}^{\prime}(s),
$$

e usando a segunda relação de Frenet-Serret, obtemos a terceira relação de FrenetSerret:

$$
\begin{aligned}
& \mathbf{N}^{\prime}(s)=k(s)(\mathbf{B}(s) \times \mathbf{N}(s))-\tau(s)(\mathbf{N}(s) \times \mathbf{T}(s)) \\
& \mathbf{N}^{\prime}(s)=-k(s) \mathbf{T}(s)+\tau(s) \mathbf{B}(s)
\end{aligned}
$$

O Sistema de equações

$$
\begin{aligned}
\mathbf{T}^{\prime}(s) & =k(s) \mathbf{N}(s) \\
\mathbf{N}^{\prime}(s) & =-k(s) \mathbf{T}(s)+\tau(s) \mathbf{B}(s) \\
\mathbf{B}^{\prime}(s) & =-\tau(s) \mathbf{N}(s)
\end{aligned}
$$

é conhecido como Equações ou Fórmulas de Frenet-Serret de uma curva parametrizada pelo comprimento de arco.

No capítulo 4 analisaremos curvas espaciais de dados biológicos, utilizando os conceitos de curvas regulares apresentados acima. 


\subsubsection{Superfícies Regulares}

De uma maneira simplificada, uma superfície regular do $\mathbb{R}^{3}$ é obtida a partir de porções do plano, deformando-as e colocando-as entre si, de tal modo que a figura resultante não apresente pontas, arestas ou auto-intersecções, tendo sentido, portanto, falar em plano tangente nos pontos dessa superfície [9].

Segundo a definição encontrada em [62] sabemos que uma superfície parametrizada regular, ou simplesmente uma superfície, é uma aplicação $X: U \subset \mathbb{R}^{2} \rightarrow \mathbb{R}^{3}$, onde $U$ é um aberto de $\mathbb{R}^{2}$, tal que

a) $X$ é diferenciável de classe $C^{\infty}$;

b) Para todo $q=(u, v) \in U$, a diferencial de $X$ em $q, d X_{q}: \mathbb{R}^{2} \rightarrow \mathbb{R}^{3}$, é injetora.

As variáveis $u, v$ são os parâmetros da superfície. O subconjunto $S$ de $\mathbb{R}^{3}$, ou seja, a superfície $S$ é obtida pela aplicação $X$.

Podemos observar no item $a)$ que a aplicação $X(u, v)=(x(u, v), y(u, v), z(u, v))$ é diferenciável de classe $C^{\infty}$ quando as funções $x, y, z$ têm derivadas parciais de todas as ordens. Já a condição do item $b$ ) garante a existência de plano tangente em cada ponto da superfície.

A definição apresentada acima trata então de superfícies parametrizadas pelas variáveis $u, v$, mas nem sempre trabalhamos com superfícies parametrizadas. Portanto, sem fugir dos conceitos da geometria diferencial, podemos tratar uma superfície a partir da seguinte proposição:

Seja $f: \mathbb{R}^{3} \rightarrow \mathbb{R}$ uma aplicação diferencial. Consideremos o conjunto $S=$ $\left\{(x, y, z) \in \mathbb{R}^{3} ; f(x, y, z)=c\right\}$, em que c é um número real. Se $p_{0}=\left(x_{0}, y_{0}, z_{0}\right) \in S$ é tal que $f^{2}{ }_{x}\left(p_{0}\right)+f^{2}{ }_{y}\left(p_{0}\right)+f_{z}^{2}\left(p_{0}\right) \neq 0$ então, o conjunto dos pontos $(x, y, z) \in S$, suficientemente próximos de $p_{0}$, é um traço ${ }^{1}$ de uma superfície regular [62].

Ao mesmo tempo quando tratamos de uma superfície sobre o ponto de vista da proposição acima, podemos afirmar que $S$ é uma superfície orientável, ou seja, existe um campo diferenciável de vetores normais unitários $N: S \rightarrow \mathbb{R}^{3}$ em $S$, o qual é definido como [9]:

$$
N(x, y, z)=\left(\frac{f_{x}}{\sqrt{f_{x}^{2}+f_{y}^{2}+f_{z}^{2}}}, \frac{f_{y}}{\sqrt{f_{x}^{2}+f_{y}^{2}+f_{z}^{2}}}, \frac{f_{z}}{\sqrt{f_{x}^{2}+f_{y}^{2}+f_{z}^{2}}}\right)
$$

\footnotetext{
${ }^{1}$ Dizer que é um traço de uma superfície significa que é uma região que pertence ao gráfico de uma superfície.
} 
Uma das principais vantagens desta formulação é que o campo normal da superfície pode ser calculado para uma representação implícita, evitando assim a necessidade de uma parametrização, isto é,

$$
N(x, y, z)=\left(\frac{\partial f}{\partial x}, \frac{\partial f}{\partial y}, \frac{\partial f}{\partial z}\right)
$$

No capítulo 4 iremos tratar com formas volumétricas, no qual usaremos os conceitos de superfície regular orientável apresentados nesta seção. 


\section{Capítulo 3}

\section{Wavelets}

\subsection{Análise Multi-escala e a Wavelet}

Conforme o nome diz, análise multi-escala preocupa-se com a representação e análise de sinais (ou imagens) em mais de uma escala, ou seja, características que não poderiam ser detectadas em uma determinada escala de resolução poderiam ser localizadas em outras. É como se pudéssemos "examinar" essas informações por um microscópio e ver seu comportamento em várias escalas.

Em rotinas de processamento de imagens, uma borda, por exemplo, pode ser detectada como uma transição de pontos preto e branco ou uma transição que ocorre gradualmente em níveis de cinza em relação a uma distância considerável. Em geral, o paradigma de multi-escala para representação ou análise de imagens procura explorar esta idéia.

Na cartografia, mapas são desenhados em diferentes escalas de resolução. A escala de um mapa cartográfico é o tamanho de um território real em relação a sua representação no mapa. Em grandes escalas, como num globo, características maiores tais como continentes e oceanos são visíveis, enquanto detalhes tais como ruas e cidades são despercebidos nesta resolução do mapa. Em escalas pequenas, os detalhes tornam-se visíveis e as grandes características são perdidas. Assim, para ser capaz de navegar por um trecho (caminho) em uma locação distante, precisamos de um conjunto de mapas extraídos de diferentes escalas.

O surgimento da transformada wavelet deu-se na década de 80, tendo como 
precedentes as idéias desenvolvidas principalmente no campo de análise multi-escala. A nova e poderosa ferramenta em análise e processamento de sinais e imagens foi introduzida por Morlet e Grossmann [29], cuja principal meta era contornar as limitações da tão conhecida análise de Fourier.

Diferente da transformada de Fourier, onde as funções de base são senoidais, a transformada wavelet tem como funções de base pequenas ondas chamadas wavelets, as quais apresentam variações de freqüência e duração limitada no tempo.

A Figura 3.1 ilustra a diferença entre ondas senoidais e wavelets. A Figura 3.1(a) apresenta funções senos que diferem na freqüência, mas não no espaço. Por outro lado, a Figura 3.1(b) apresenta wavelets (neste caso a wavelet conhecida como Chapéu Mexicano) que diferem tanto na freqüência quanto ao longo do eixo de posição.

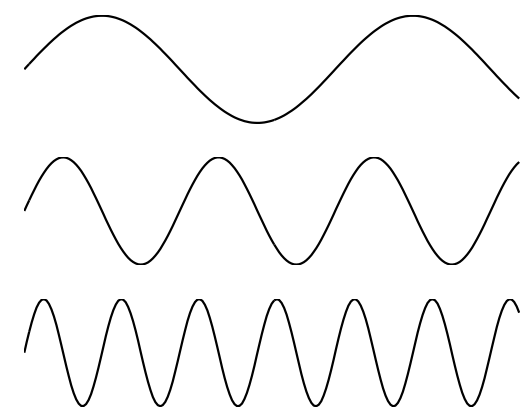

(a)

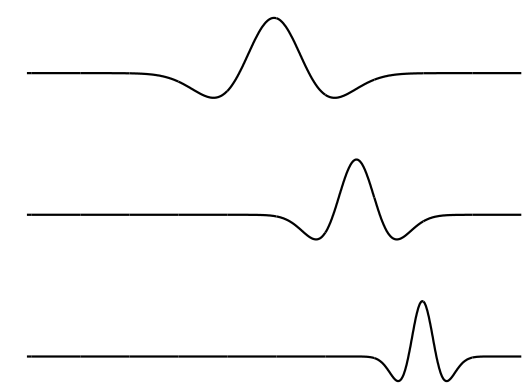

(b)

Figura 3.1: (a) Ondas senoidais e (b) a wavelet conhecida como Chapéu Mexicano em diferentes freqÜências e localização no espaço.

A modificação de tamanho da função é alcançada dilatando ou contraindo a wavelet básica $\psi$, ou mais conhecida como wavelet mãe. Conforme o seu parâmetro de escala $a$, a wavelet mãe $\psi(x / a)$ é ampliada se $a>1$ e/ou contraída se $0<a<1$ a fim de formar o conjunto de funções de base. A posição da função no espaço varia com o parâmetro de deslocamento (translação) $b$, conforme a wavelet mãe $\psi\left(\frac{x-b}{a}\right)$.

A seguir, é introduzido o conceito da wavelet referente a uma dimensão. Generalizaremos para duas e três dimensões e então finalizaremos dando ênfase para a wavelet escolhida para desenvolver este trabalho. 


\subsection{Wavelets e suas Propriedades}

Wavelets são funções de energia finita com propriedades de localização que podem ser usadas com muita eficiência para representar sinais de pequena duração no domínio do tempo, ou seja, sinais breves. A eficiência significa que somente um número finito de coeficientes é necessário para representar um sinal complexo. Em contraste com as funções senoidais de extensão infinita (ondas longas), as wavelets implicam em ondas breves (curtas). Isso significa que a área sob o gráfico da wavelet $\psi(x)$ é zero, isto é, $\int_{-\infty}^{\infty} \psi(x) d x=0$. No domínio do espectro, esta propriedade é equivalente a $\hat{\psi}(0)=0^{1}$, ou seja, o espectro da wavelet tem um valor de zero em $u=0$ [15].

Pode-se verificar, para qualquer wavelet e seu espectro, que a energia da wavelet é concentrada em certa região de ambos os eixos de tempo e de freqüência (ou tempo e escala). Esta propriedade de localização é uma importante caracterização das wavelets. Se a wavelet é mais localizada (isto é, a energia da wavelet é concentrada numa pequena região), ela fornece uma melhor representação do sinal no plano tempo-freqüência (ou tempo-escala). No nosso caso, melhor significa alta resolução e exige menos coeficientes na representação [15].

Para a análise de Fourier, toda função periódica, de período $2 \pi$ quadrática integrável, ou seja, definida no espaço $L^{2}(0,2 \pi)$, é produzida por uma superposição de funções exponenciais complexas, $w_{n}(x)=e^{i n x}, n=0, \pm 1, \ldots$, obtidas por dilatações da função $w_{n}(x)=e^{i x}: w_{n}(x)=w(n x)$. O objetivo é estender essa idéia para o espaço $L^{2}(\mathbb{R})^{2}$, ou seja, gerar esse espaço a partir de uma única função $\psi$, por exemplo. Isto é obtido por dilatações (ou compressões) e translações de uma determinada wavelet $\psi(x)[44]$ :

$$
\psi_{a, b}(x)=\frac{1}{\sqrt{a}} \psi\left(\frac{x-b}{a}\right), \quad a, b \in \mathbb{R}, a \neq 0 .
$$

Sendo que o parâmetro $a$ corresponde à escala e deve obedecer à condição de $a>0$ enquanto b é o parâmetro de translação.

É importante notar que a forma da wavelet permanece a mesma sob translação e mudança de escala (veja Figura 3.1 (b)). Mantendo o conceito de base em mente, pode-se concluir que a idéia de processamento de sinais usando wavelets não é muito diferente do processamento usando Fourier. No lugar de decompor um sinal em funções senoidais de diferentes freqüências (conforme as bases de Fourier), o proces-

\footnotetext{
${ }^{1} \hat{\psi}$ é a transformada de Fourier da função $\psi$

${ }^{2}$ Espaço de todas as funções uni-dimensionais quadráticas integráveis e limitadas.
} 
samento de sinais usando wavelets procura decompor um sinal em uma combinação linear de versões transladadas da wavelet mãe em diferentes escalas [15].

\subsubsection{Transformada Wavelet Contínua 1D}

A Transformada Wavelet Contínua (TWC) 1D de um sinal $f(x)$ é uma transformada linear definida [15] pela integral:

$$
\begin{aligned}
W_{\psi}[f](\mathbf{b}, a) & =\int_{-\infty}^{\infty} f(x) \bar{\psi}_{a, b}(x) d x \\
& =\frac{1}{\sqrt{a}} \int_{-\infty}^{\infty} f(x) \bar{\psi}\left(\frac{x-\mathbf{b}}{a}\right) d x \\
& =<f(x), \psi_{a, b}(x)>
\end{aligned}
$$

sendo que $\mathbf{b} \in \mathbb{R}$ representa o parâmetro de translação, enquanto $a>0$ define o parâmetro de escala da transformada wavelet. Além disso, $\bar{\psi}$ é o complexo conjugado da wavelet $\psi$. A última expressão de (3.2) representa o produto interno das duas funções, definido no espaço $L^{2}$ por

$$
<f, h>=\int_{-\infty}^{\infty} f(x) \bar{h}(x) d x .
$$

Referindo-se a (3.2), a TWC calcula, através da fórmula do produto interno, o coeficiente da wavelet do sinal $f(x)$ associado com a wavelet $\psi_{b a}(x)$. Este coeficiente indica a correlação entre a função $f(x)$ e a $\psi_{b a}(x)$. Alta correlação fornece um coeficiente de valor alto.

Cada coeficiente numa transformada é determinado pelo produto interno entre a função de entrada e uma das funções de base. Este valor representa, de algum modo, o grau de similaridade entre a função de entrada e sua função de base particular. Se as funções de base são ortogonais (ou ortonormais), um produto interno entre duas funções de base será zero, indicando que estas funções são dissimilares entre si. Já, se um sinal é constituído de componentes que são similares a uma função — ou um número pequeno de funções — de base, então teremos todos os coeficientes menos um — ou um número pequeno de coeficientes — com valores pequenos.

Similarmente, a transformada inversa pode ser vista como a reconstrução do sinal original somando as funções de base, que são ponderadas em amplitudes pelos coeficientes da transformada. Dado $W_{\psi}[f](a, \mathbf{b}), f(x)$ pode ser obtida usando a 
transformada wavelet contínua inversa

$$
f(x)=\frac{1}{C_{\psi}} \int_{0}^{\infty} \int_{-\infty}^{\infty} W_{\psi}[f](a, \mathbf{b}) \frac{\psi_{a, b}(x)}{a^{2}} d \mathbf{b} d a
$$

sendo que $C_{\psi}$ é uma constante dada pela integral

$$
C_{\psi}=\int_{-\infty}^{\infty} \frac{|\hat{\psi}(u)|^{2}}{|u|} d u
$$

com $\hat{\psi}(u)$ sendo a transformada de Fourier de $\psi(x)$.

As equações (3.4) e (3.5) definem uma transformada inversa, contanto que o critério de admissibilidade $C_{\psi}<\infty$ seja satisfeito. Na maioria dos casos, a exigência de que $\hat{\psi}(0)=0$ e $\psi(u) \rightarrow 0$, quando $u \rightarrow \infty$, é o bastante para fazer $C_{\psi}$ limitada.

Então, se o sinal é constituído por componentes que são similares a uma função de base ou a um número pequeno delas, a soma precisa só de poucos termos da amplitude significante. Muitos dos termos podem então ser ignorados e o sinal pode ser representado compactamente por somente uma pequena parte dos coeficientes da transformada. Esta característica é um dos motivos pelos quais a transformada wavelet é usada para fazer compressão de dados (sinais ou imagens) [58].

Além disso, se as componentes de interesse no sinal ou imagem são similares a uma ou a um número pequeno de funções de base, então esses componentes manifestarão a si mesmos em grandes valores de coeficientes para aquelas funções de base. Em relação a estes coeficientes, a possibilidade de identificá-los na transformada é grande.

Finalmente, se um componente indesejável (ruído) é similar a um ou a um número pequeno de funções de base, então será fácil de identificá-lo. Será fácil de removê-los também, eliminando os coeficientes da transformada correspondente.

Conforme as propriedades da transformada wavelet, a função $\psi$ deve satisfazer as condições que são [44]:

i) $\int_{-\infty}^{\infty} \psi(x) d x=0$ (admissibilidade).

ii) $\int_{-\infty}^{\infty}|\psi(x)| d x<\infty$.

iii) $\int_{-\infty}^{\infty} \frac{|\hat{\psi}(u)|^{2}}{|u|} d u<\infty$, em que $\hat{\psi}(u)$ é a transformada de Fourier de $\psi(x)$. Uma condição necessária para (iii) valer é que $\hat{\psi}(0)=0$, que é equivalente a (i). 
iv) Os primeiros $r-1$ momentos de $\psi$ anulam-se, isto é,

$$
\int_{-\infty}^{\infty} x^{j} \psi(x) d x=0, \quad j=0,1, \ldots, r-1,
$$

para algum $r \geq 1 \mathrm{e}$

$$
\int_{-\infty}^{\infty}\left|x^{r} \psi(x)\right| d x<\infty
$$

Esta condição determina a capacidade da TW detectar singularidades.

\subsubsection{Transformada Wavelet Contínua 2D}

Seja $f(\mathbf{x}) \in L^{2}\left(\mathbb{R}^{2}\right)^{3}$ uma imagem, em que $\mathbf{x}=(x, y)$. A transformada wavelet contínua $2 \mathrm{D} W_{\psi}[f]$ é definida em função do produto escalar de $f(\mathbf{x})$ com a wavelet $\psi_{a \theta b}(\mathbf{x})$, considerada como uma função de parâmetros $(a, \theta, \mathbf{b})$, sendo definida como:

$$
\begin{aligned}
W_{\psi}[f](a, \theta, \mathbf{b}) & =\left\langle f(\mathbf{x}), \psi_{a \theta b}\right\rangle \\
& =\frac{1}{a} \int f(\mathbf{x}) \bar{\psi}\left(\frac{1}{a} r_{-\theta}(\mathbf{x}-\mathbf{b})\right) d^{2} \mathbf{x}
\end{aligned}
$$

em que $\mathbf{b} \in \mathbb{R}^{2}, \theta$ e a são, respectivamente, o vetor de translação, o ângulo de rotação e o parâmetro de escala. Note que o operador de rotação age em $\mathbf{x}=(x, y)$ como:

$$
r_{\theta}(\mathbf{x})=(x \cos \theta-y \operatorname{sen} \theta, x \operatorname{sen} \theta+y \cos \theta), \quad 0 \leq \theta<2 \pi .
$$

A transformada inversa é então dada por:

$$
f(\mathbf{x})=\frac{1}{C_{\psi}} \iiint \frac{1}{a^{3}} \psi_{a \theta b}(\mathbf{x}) W_{\psi}[f](a, \theta, \mathbf{b}) d a d \theta d^{2} \mathbf{b}
$$

sendo que

$$
C_{\psi}=(2 \pi)^{2} \int_{-\infty}^{\infty} \frac{|\hat{\psi}(\mathbf{u})|^{2}}{|\mathbf{u}|^{2}} d^{2} \mathbf{u}<\infty
$$

Conforme a TWC 1D, a TWC 2D também tem suas propriedades, como o fato de ser covariante sobre translação, dilatação e rotação [3], que significa que a correspondência $W_{\psi}: f(x) \longrightarrow W_{\psi}[f](a, \theta, \mathbf{b})$ implica o seguinte:

$$
\begin{aligned}
f\left(\mathbf{x}-\mathbf{b}_{\mathbf{0}}\right) & \longrightarrow W_{\psi}[f]\left(a, \theta, \mathbf{b}-b_{0}\right) \\
W_{\psi}: a_{0}^{-1}[f]\left(a_{0}^{-1} \mathbf{x}\right) & \longrightarrow W_{\psi}[f]\left(a_{0}^{-1} a, \theta, a_{0}^{-1} \mathbf{b}\right) \\
f\left(r_{-\theta}(\mathbf{x})\right) & \longrightarrow W_{\psi}[f]\left(a, \theta-\theta_{0}, r_{-\theta_{0}}(\mathbf{b})\right)
\end{aligned}
$$

\footnotetext{
${ }^{3}$ A notação $L^{2}\left(\mathbb{R}^{2}\right)$ define o espaço das funções bi-dimensionais quadráticas, integráveis e limitadas.
} 


\subsubsection{Transformada Wavelet Contínua 3D}

A transformada wavelet contínua 3D é bastante similar em relação à TWC $2 \mathrm{D}$ quando se trata de ser covariante em função de translações, dilatações e rotações.

Então, dado um sinal $f(\mathbf{x}) \in L^{2}\left(\mathbb{R}^{3}\right)^{4}$, em que $\mathbf{x}=(x, y, z)$, sua TWC $3 \mathrm{D}$ com respeito à wavelet mãe $\psi$ é dada por [4]:

$$
W_{\psi}[f](a, \alpha, \mathbf{b})=a^{-\frac{3}{2}} \int f(\mathbf{x}) \bar{\psi}\left(a^{-1} r(\alpha)^{-1}(\mathbf{x}-\mathbf{b})\right) d^{3} \mathbf{x}
$$

sendo que $a>0$ é o parâmetro de escala , $\alpha \in S O(3)^{5}$ é o ângulo de rotação, $\mathbf{b} \in \mathbb{R}^{3}$ é o parâmetro de translação e $r(\alpha) \in S O(3)$ é uma matriz de rotação $3 \times 3$. Conforme comparado com (3.6), as únicas diferenças estão na normalização dos fatores e a matriz de rotação. Portanto, a estrutura das fórmulas é a mesma das outras dimensões.

O elemento $\alpha \in S O(3)$ pode ser parametrizado, por exemplo, em termos dos três ângulos de Euler $[4,65]$.

\subsection{Escolha da Wavelet Analisadora}

Segundo Arnéodo e colaboradores [5], na maioria das vezes, as características mais importantes numa imagem ou forma se concentram nas bordas (da imagem) ou na superfície (da forma volumétrica). É por este motivo que, em visão computacional [43], uma grande classe de detectores de bordas procuram por pontos onde o gradiente da intensidade da imagem tem um módulo que é localmente máximo na sua direção. No caso de formas representadas por contornos espaciais, a atenção maior está na análise de variação dos vetores tangente e normal à curva.

Conforme o trabalho de Mallat e colaboradores [41, 42], pode-se, a partir de uma escolha apropriada da wavelet analisada, trabalhar com um detector de bordas multi-escala em termos de uma transformada wavelet.

Podemos analisar um sinal 3D, representado por uma curva parametrizada no espaço $f(t)=(x(t), y(t), z(t))$, a partir das características extraídas da distribuição dos principais vetores (tangente e normal). Conforme mostrado no Capítulo 2, na

\footnotetext{
${ }^{4}$ A notação $L^{2}\left(\mathbb{R}^{3}\right)$ define o espaço das funções tri-dimensionais quadráticas, integráveis e limitadas.

${ }^{5} S O(3)$ é o grupo de rotação [66] para o espaço tri-dimensional.
} 
seção 2.3, a partir da representação dos vetores pelo triedro de Frenet-Serret, podemos obter características importantes para uma curva espacial como, por exemplo, curvatura e torção.

Para obter estes vetores, utilizaremos a propriedade da transformada wavelet unidimensional como sendo a n-ésima derivada da função gaussiana $\phi$ de $f(t)$, ou seja, a wavelet utilizada para obter os vetores tangente e normal da curva analisada $f(t)$ é representada pela:

- Derivada de primeira ordem da função gaussiana:

$$
\psi_{1}=\phi^{(1)}=\frac{d \phi(x)}{d x}
$$

Sendo que a função gaussiana unidimensional é dada por:

$$
\phi(x)=e^{-\frac{\left(x^{2}\right)}{2}} .
$$

A Figura 3.2 apresenta o gráfico da wavelet $\psi_{1}$.

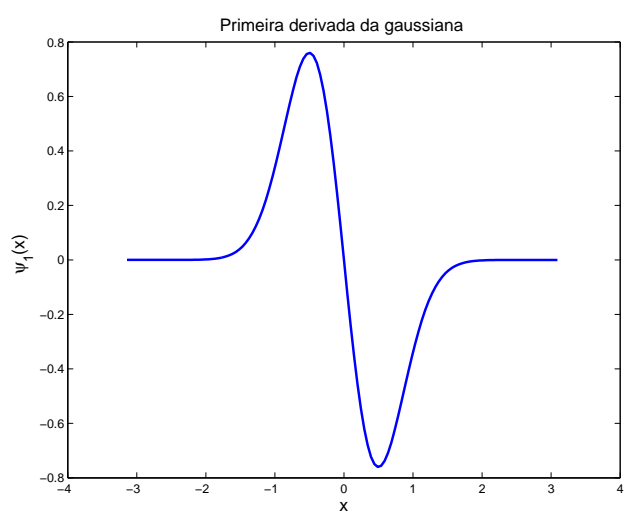

Figura 3.2: Derivada de primeira ordem da função gaussiana como wavelet $\psi_{1}$.

A idéia é decompor o sinal tridimensional $f(t)=(x(t), y(t), z(t))$ em três sinais unidimensionais $x(t), y(t)$ e $z(t))$, e realizar a análise multi-escala a partir da wavelet unidimensional apresentada.

Para o caso de trabalharmos com superfícies representadas por uma função $f(x, y)$, vamos considerar duas wavelets que são, respectivamente, as derivadas parciais com respeito a $x$ e $y$ de uma função suave $2 \mathrm{D} \phi(x, y)$ :

$$
\psi_{x}(x, y)=\frac{\partial \phi(x, y)}{\partial x} \quad \text { e } \quad \psi_{y}(x, y)=\frac{\partial \phi(x, y)}{\partial y}
$$


Assumimos que $\phi$ é uma função bem localizada (em torno de $x=y=0$ que depende de $|\mathbf{x}|$ somente). Adotamos $\phi$ como a função gaussiana bidimensional dada por:

$$
\phi(x, y)=e^{-\frac{\left(x^{2}+y^{2}\right)}{2}}=e^{-\frac{|\mathbf{x}|^{2}}{2}},
$$

As wavelets analisadas correspondentes a $\psi_{x}$ e $\psi_{y}$ estão ilustradas na Figura 3.3(a) e (b) respectivamente.

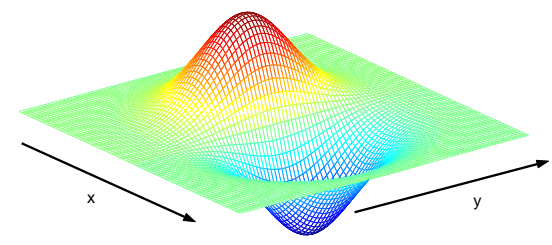

(a)

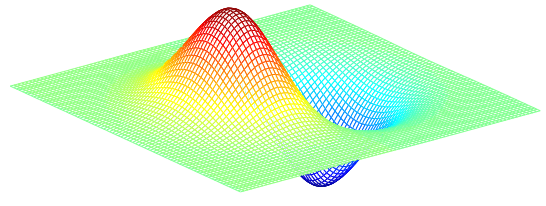

(b)

Figura 3.3: As wavelets $\psi_{x}$ em (a) e $\psi_{y}$ em (b) definidas pela equação (3.13).

Para qualquer função $f(x, y) \in L^{2}\left(\mathbb{R}^{2}\right)$, a transformada wavelet com respeito a $\psi_{x}$ e $\psi_{y}$ tem dois componentes, e portanto pode ser expressa de uma forma vetorial [5]:

$$
W_{\psi}[f](\mathbf{b}, a)=\left(\begin{array}{l}
W_{\psi_{x}}[f]=a^{-2} \int f(\mathbf{x}) \psi_{x}\left(a^{-1}(\mathbf{x}-\mathbf{b})\right) d^{2} \mathbf{x} \\
W_{\psi_{y}}[f]=a^{-2} \int f(\mathbf{x}) \psi_{y}\left(a^{-1}(\mathbf{x}-\mathbf{b})\right) d^{2} \mathbf{x}
\end{array}\right)
$$

Então, depois de uma integração simples em partes, tem-se:

$$
W_{\psi}[f](\mathbf{b}, a)=a^{-2}\left(\begin{array}{c}
\frac{\partial}{\partial b_{x}}\left[\int \phi\left(a^{-1}(\mathbf{x}-\mathbf{b})\right) f(\mathbf{x}) d^{2} \mathbf{x}\right] \\
\frac{\partial}{\partial b_{y}}\left[\int \phi\left(a^{-1}(\mathbf{x}-\mathbf{b})\right) f(\mathbf{x}) d^{2} \mathbf{x}\right]
\end{array}\right),
$$

as quais podem ser escritas como:

$$
\begin{aligned}
W_{\psi}[f](\mathbf{b}, a) & =a^{-2} \nabla\left\{\int \phi\left(a^{-1}(\mathbf{x}-\mathbf{b})\right) f(\mathbf{x}) d^{2} \mathbf{x}\right\} \\
& =\nabla\left\{W_{\phi}[f](\mathbf{b}, a)\right\} \\
& =\nabla\left\{\phi_{\mathbf{b}, a} * f\right\} .
\end{aligned}
$$

Se $\phi(\mathbf{x})$ é simplesmente um filtro suavizante conforme a função gaussiana (3.14), então a equação (3.16) equivale a definir a transformada wavelet $2 \mathrm{D}$ desta forma 
como o vetor gradiente $(\nabla)$ de $f(\mathbf{x})$, suavizado pela versão dilatada $\phi\left(a^{-1} \mathbf{x}\right)$ deste filtro.

No entanto, para o caso de trabalharmos com superfícies representadas por uma função $f(x, y, z)$, e a partir do que concluímos para o caso da wavelet $2 \mathrm{D}$, a transformada wavelet contínua 3D pode explorar a primeira derivada parcial da função gaussiana tridimensional dada por:

$$
\phi(x, y, z)=e^{-\frac{\left(x^{2}+y^{2}+z^{2}\right)}{2}}=e^{-\frac{|\mathbf{x}|^{2}}{2}},
$$

para extrair características da borda de superfícies de formas 3D como, por exemplo, de formas volumétricas, sendo que para este caso obteremos o campo normal. Com este objetivo, as wavelets mãe são consideradas como:

$$
\psi_{x}(x, y, z)=\frac{\partial \phi(x, y, z)}{\partial x}, \quad \psi_{y}(x, y, z)=\frac{\partial \phi(x, y, z)}{\partial y} \text { e } \psi_{z}(x, y, z)=\frac{\partial \phi(x, y, z)}{\partial z} .
$$

A wavelet $\psi_{x} 3 \mathrm{D}$, por exemplo, está ilustrada na Figura $3.4^{6}$ a seguir.

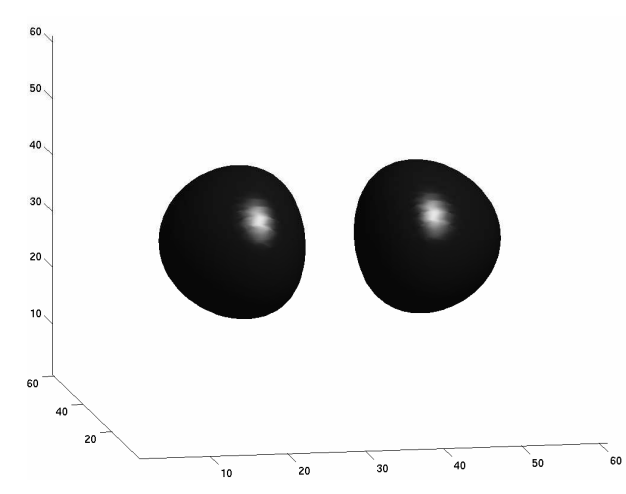

(a)

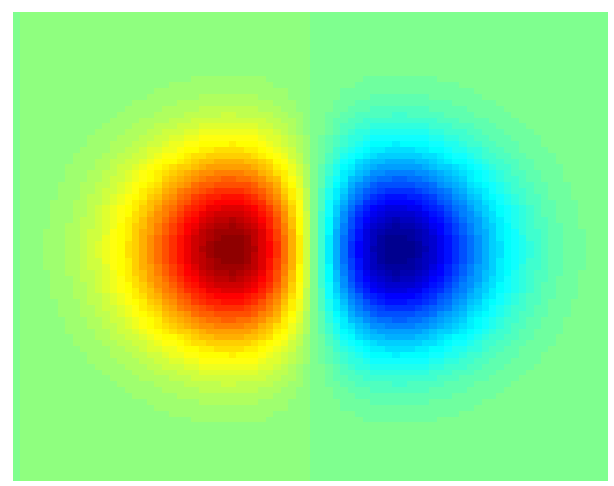

(b)

Figura 3.4: A wavelet mãe $\psi_{x} 3 \mathrm{D}$ em (a) e em (b) a fatia central da função em (a).

Uma importante observação a ser feita tanto para a transformada wavelet 2D quando para a 3D é que os parâmetros $\theta$ e $\alpha$ (de rotação), dados nas Equações (3.6) e (3.10), respectivamente, são considerados fixos, já que adotamos um número de wavelets mãe dependente da dimensão da wavelet.

\footnotetext{
${ }^{6}$ Para visualizar a Figura 3.4(a), nós utilizamos uma função do YAW Toolbox [32] para o Matlab.
} 


\section{Capítulo 4}

\section{Análise de Formas 3D usando Wavelets}

Este capítulo foi criado com a intenção de expor as contribuições deste trabalho, tanto na área de processamento de imagens como na área de análise de formas. Neste trabalho, tivemos a oportunidade de desenvolver e aplicar métodos de análise em três diferentes tipos de formas 3D.

O primeiro tipo de forma analisada trata-se de marcos (landmarks) espaciais representando uma curva parametrizada do tipo $f(t)=(x(t), y(t), z(t))$, conforme apresentaremos na Seção 4.1. Nas Seções 4.2 e 4.3, as formas analisadas são estruturas neuroanatômicas adquiridas de imagens de MRI, as quais se dividem em dois tipos: a primeira é representada como uma superfície do tipo $z=f(x, y)$ e a segunda como uma superfície do tipo $w=f(x, y, z)$.

O propósito deste capítulo é explicar quais os passos tomados em relação ao tratamento computacional destes dados e expor os métodos usados para extrair características destas formas.

Fica claro que todo processamento de imagens aplicado neste trabalho teve a intenção de tornar a forma inicial (dados originais) conveniente para que pudéssemos trabalhar com a ferramenta multi-escala, ou seja, a transformada wavelet. A partir da etapa de pré-processamento de imagens executada, há então a aplicação da transformada wavelet seguida de uma extração de características da forma a fim de caracterizá-la e classificá-la conforme a classe de estruturas analisadas. 


\subsection{Análise de Formas: Wavelets 1D}

\subsubsection{Pré-processamento}

Um estudo direcionado sobre o desenvolvimento e evolução do crânio indica que existe um certo grau de dependência em relação ao tamanho e forma da órbita ${ }^{1}$ e a matéria que a envolve. A órbita tem sido um objeto de interesse de especialistas que estudam o crescimento do olho humano em relação às estruturas que o cercam. Experimentos têm demonstrado que a remoção de certas partes da matéria orbital está relacionada a um crescimento orbital e também de outras regiões do crânio [38]. A fim de investigar como estão relacionadas às informações de forma e tamanho da órbita em relação a sua evolução, nós propomos um método de caracterizar a forma analisada.

A órbita é uma estrutura morfológica tridimensional, a qual pode ser representada a partir dos seus marcos, de acordo com a Figura 4.1(a). Para minimizar o efeito de descontinuidade provocado pela aplicação da transformada wavelet na representação por marcos, foi necessário aplicar uma interpolação dos marcos a fim de poder representar estes dados através de uma curva fechada no $\mathbb{R}^{3}$ do tipo $f(s)=(x(s), y(s), z(s))$, conforme explicado no Capítulo 2, Seção 2.3.

A interpolação dos marcos foi feita através do Método de Bresenham (ver Apêndice A) e o resultado pode ser visualizado na Figura 4.1(b).

\subsubsection{Extração de Características}

Após a rotina de pré-processamento dos dados, podemos aplicar a transformada wavelet para extração de características. Para trabalharmos este tipo de forma utilizando a wavelet 1D será necessário decompor a curva em três sinais unidimensionais, ou seja: $x(s), y(s)$ e $z(s)$, onde o parâmetro $s$ é o comprimento de arco.

Como apresentamos na Seção 3.3, a wavelet $\psi_{1}$ (Equação (3.11)) tem como sua transformada $W_{\psi_{1}}$. A partir da sua aplicação nos sinais $x(s), y(s)$ e $z(s)$, obtemos

\footnotetext{
${ }^{1}$ Cavidade óssea facial onde se situa o olho.
} 


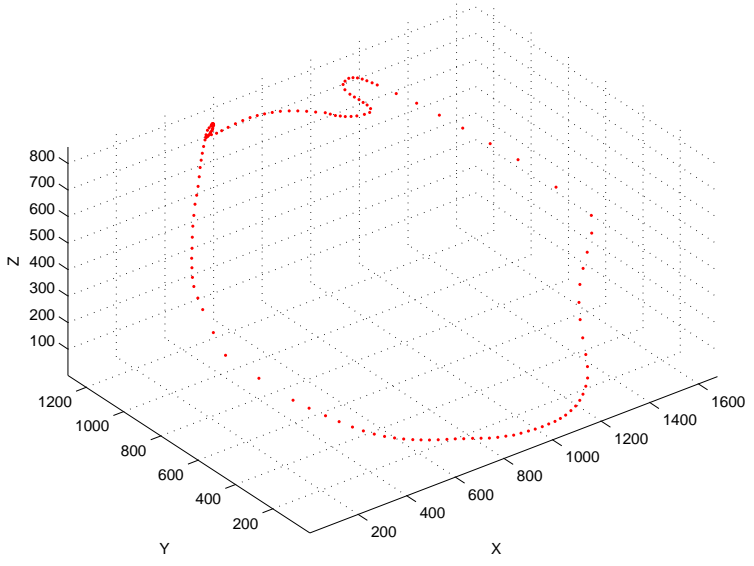

(a)

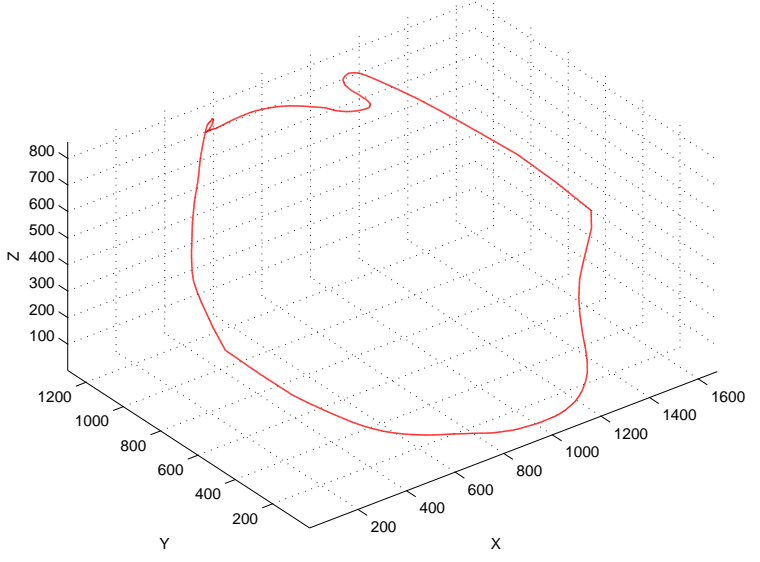

(b)

Figura 4.1: (a) Representação da órbita por marcos; e em (b) representação por uma curva fechada do tipo $f(s)=(x(s), y(s), z(s))$, a partir de uma interpolação dos marcos pelo Método de Bresenham.

a primeira derivada dos mesmos, ou seja, o vetor tangente $\mathbf{T}$ da curva $f(s)$, isto é,

$$
\begin{aligned}
\mathbf{T}(a, b) & =\left(W_{\psi_{1}}[x](a, b), W_{\psi_{1}}[y](a, b), W_{\psi_{1}}[z](a, b)\right) \\
& =\left(\frac{d x(s)}{d s}, \frac{d y(s)}{d s}, \frac{d z(s)}{d s}\right)
\end{aligned}
$$

Para obter o vetor normal à curva, aplicamos novamente a transformada $W_{\psi_{1}}$ em cada componente do sinal $\mathbf{T}(a, b)$. Assim o vetor normal $\mathbf{N}$ de $f(s)$ pode ser representado como:

$$
\begin{aligned}
\mathbf{N}(a, b) & =\left(W_{\psi_{1}}\left[\mathbf{T}_{x}\right](a, b), W_{\psi_{1}}\left[\mathbf{T}_{y}\right](a, b), W_{\psi_{1}}\left[\mathbf{T}_{z}\right](a, b)\right) \\
& =\left(\frac{d^{2} x(s)}{d s^{2}}, \frac{d^{2} y(s)}{d s^{2}}, \frac{d^{2} z(s)}{d s^{2}}\right) .
\end{aligned}
$$

Conforme a teoria dada na Seção 2.3 do Capítulo 2, a partir dos vetores tangente e normal, podemos obter o vetor binormal. Esses vetores compõem o Triedro de Frenet-Serrat, sendo que o vetor binormal B é dado por:

$$
\mathbf{B}(a, b)=\mathbf{T}(a, b) \times \mathbf{N}(a, b) .
$$

Como o objetivo deste trabalho é obter características da forma 3D que sejam principalmente invariantes à translação e à rotação, podemos utilizar os vetores do Triedro de Frenet-Serrat ( $\mathbf{T}, \mathbf{N}$ e $\mathbf{B}$ ) para extrair as seguintes características da curva espacial: 
- Curvatura

$$
k(a, b)=\left|\mathbf{T}^{\prime}(a, b)\right| ;
$$

- Torção

$$
\tau(a, b)=-\frac{\mathbf{B}^{\prime}(a, b)}{\mathbf{N}(a, b)}
$$

Exemplo: Para validar a abordagem proposta, calculamos os vetores tangente, normal e binormal para o caso de uma curva fechada conhecida, ou seja, uma circunferência, conforme ilustrado nas Figuras em 4.2.

A partir dos vetores que compõe o Triedro de Frenet-Serrat, podemos obter a curvatura e a torção para a circunferência. Conforme a literatura [62], o valor de $k$ para a circunferência de raio $r$ é dado por $k=1 / r$, e a torção $\tau$ é zero para uma curva plana.

No nosso caso, para uma circunferência de raio $r=40$ (Figura 4.2(a)), teremos como resultado, a curvatura $k=\frac{1}{40}=0,025$ e a torção $\tau=0$ de acordo com os gráficos obtidos das Figuras 4.3(a) e (b), respectivamente.

A aplicação da WTC na curva parametrizada tem o controle do fator de escala que permite analisá-la. É importante notar que, embora os marcos sejam representados por uma curva espacial fechada, as características extraídas são apresentadas levando em consideração apenas os marcos originais. Nas Figuras 4.4 apresentamos os campos de vetores tangente, normal e binormal referente à Figura 4.4(a), a qual apresenta alguns marcos numerados para facilitar a análise do resultado da extração de características mostrado nos gráficos das Figuras 4.5(a) e (b).

No Capítulo 5 apresentamos os resultados experimentais obtidos para a caracterização deste tipo de forma a partir das características propostas nesta seção. 


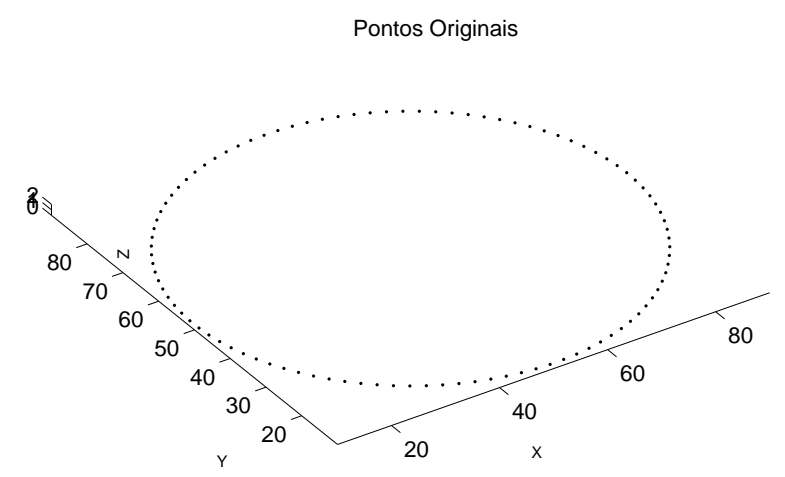

(a)

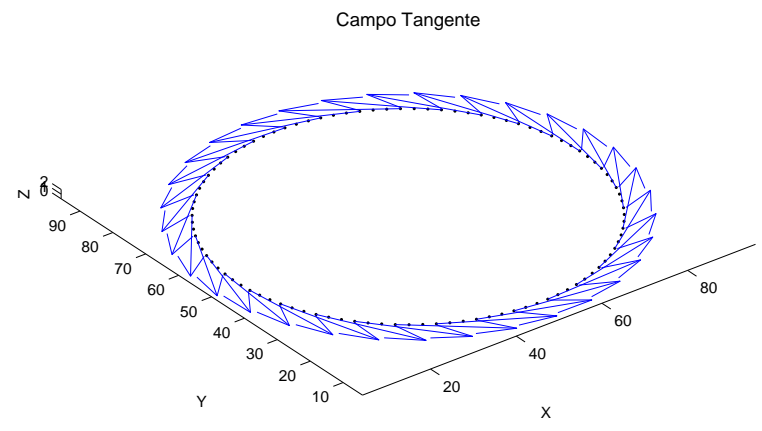

(b)

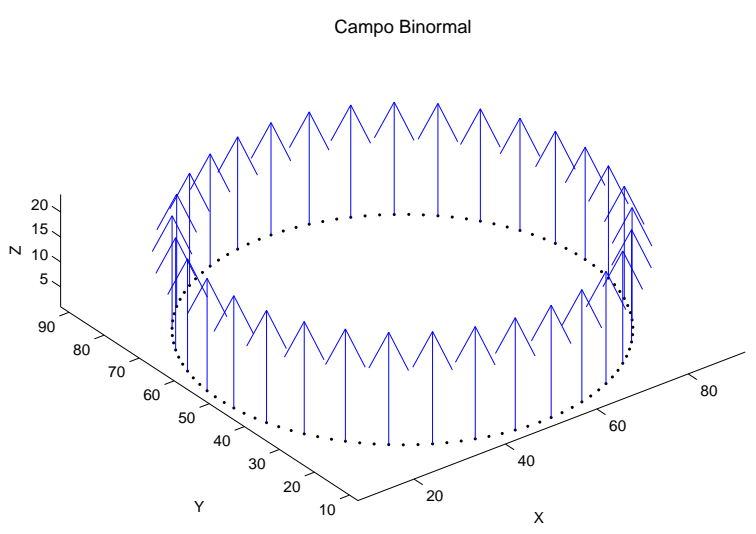

(d)

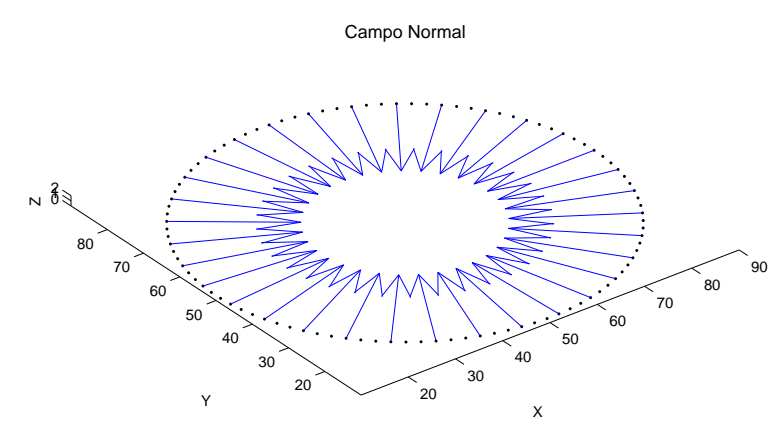

(c)

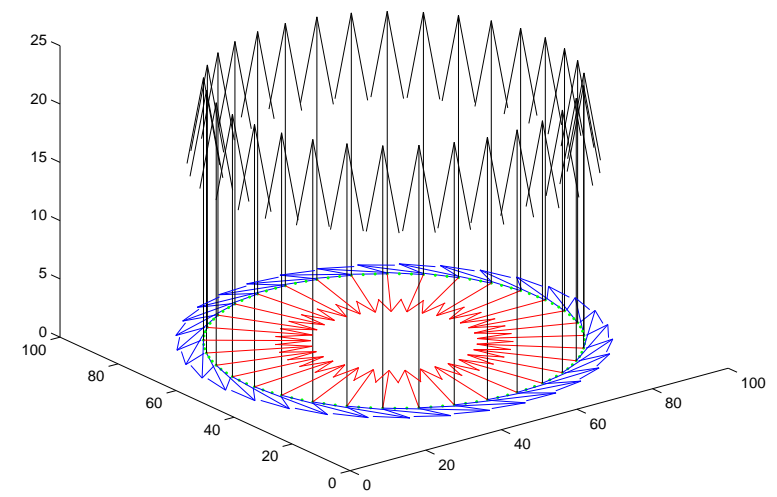

(e)

Figura 4.2: Pontos gerados para uma circunferência em (a); (b) o campo tangente; (c) o campo normal; (d) o campo binormal; e em (e) a composição dos vetores do triedro de Frenet-Serrat. 


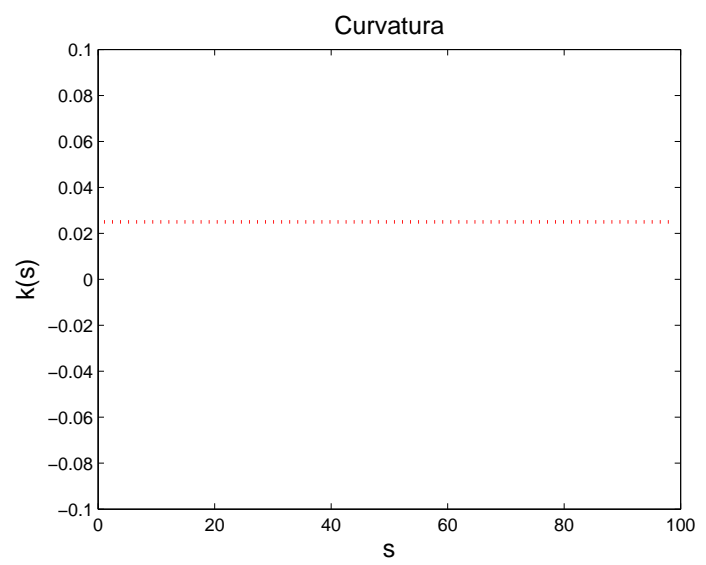

(a)

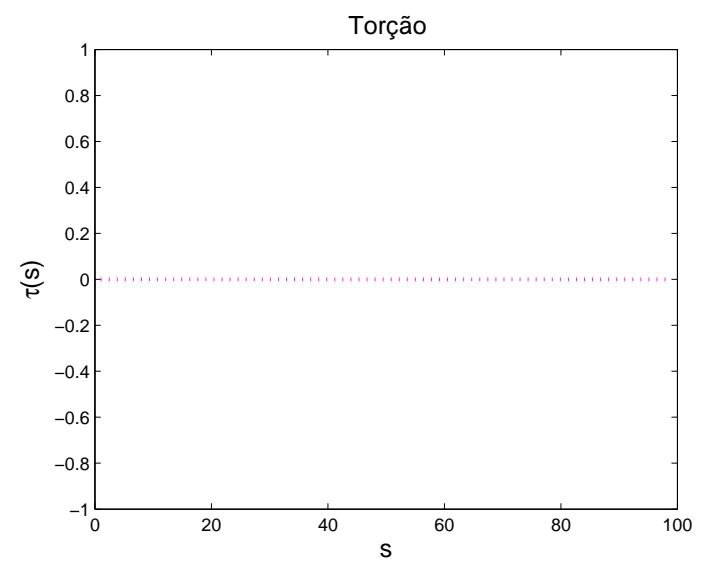

(b)

Figura 4.3: Gráfico da curvatura e da torção para a circunferência da Figura 4.2(a), a partir do triedro de Frenet-Serrat.

\subsection{Análise de Formas: Wavelets 2D}

\subsubsection{Pré-processamento}

Com o desenvolvimento de novas técnicas em neuroimagem e a disponibilidade de novos algoritmos em processamento de imagens, o estudo de anomalias em neuroanatomia tornou-se plausível. Atualmente, existe muitos métodos a este respeito que abrangem desde medidas automáticas via computador até quantificação morfologicas feitas manualmente.

No estudo de variações neuroanatômicas, técnicas de análise de formas não têm sido aplicadas com grande êxito devido a complexidade da anatomia. Neste estudo é proposto um método para distinguir diferenças nas características da forma de diferentes estruturas neuroanatômicas em uma população de pessoas normais, podendo também serem utilizadas na detecção de anomalias neuroanatômicas em dislexios, esquizofrênicos, autistas, além de outros doentes.

Considerando a complexidade de duas diferentes estruturas neuroanatômicas sulco do cíngulo e sulco (ou fissura) de Sylvius, nós decidimos investigar se as características anatômicas dos sulcos estreitos poderiam ser distinguidas dos sulcos largos, respectivamente, de um modo objetivo e quantitativo. 


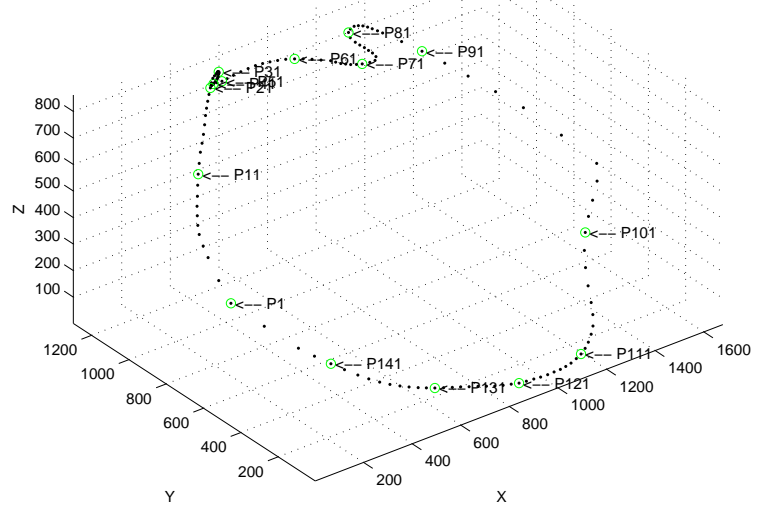

(a)

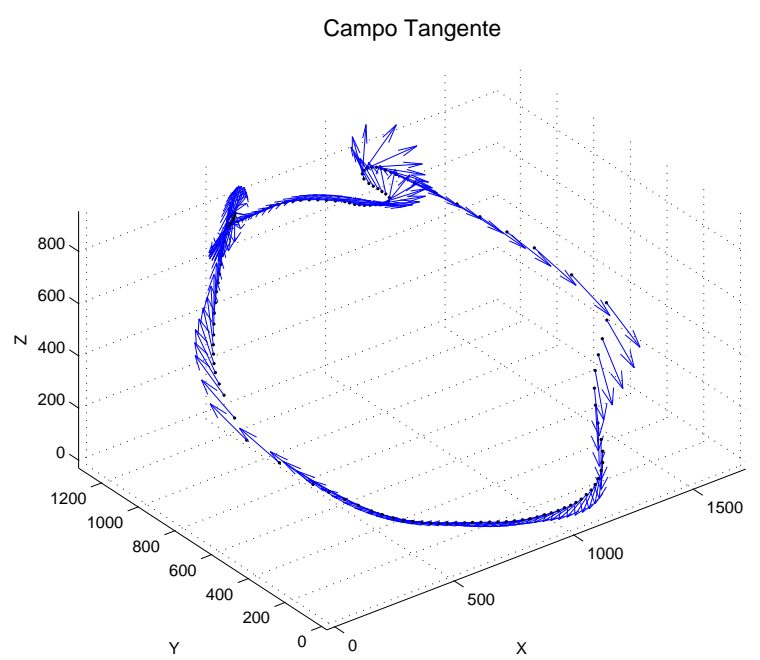

(b)

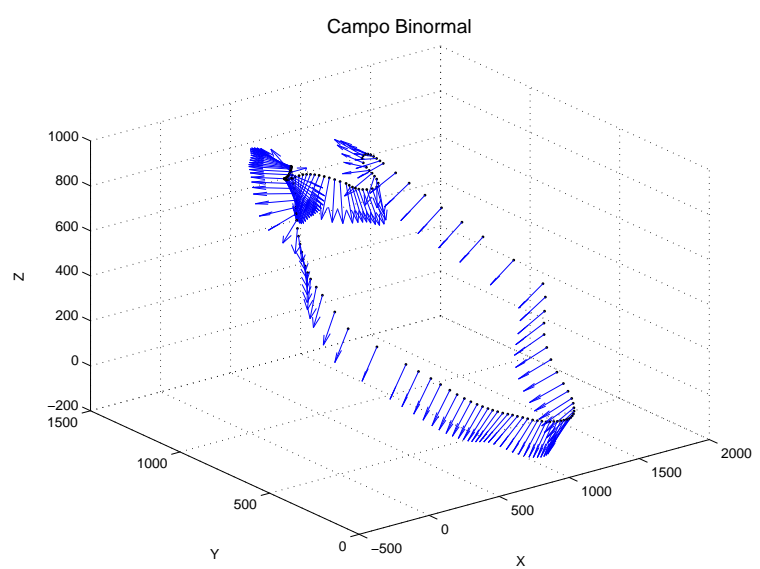

(d)

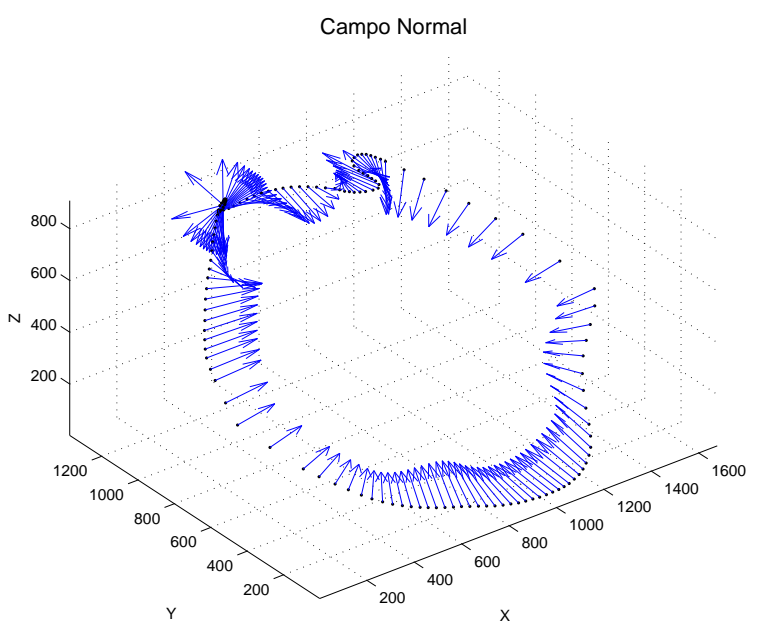

(c)

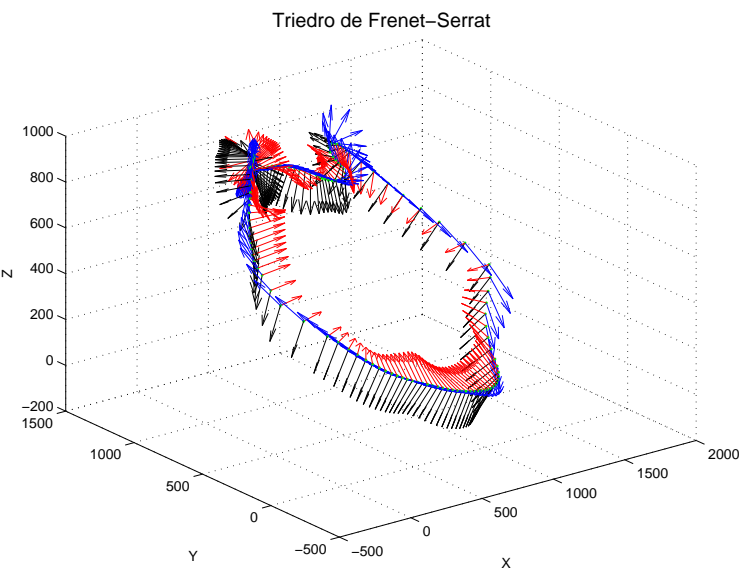

(e)

Figura 4.4: (a) Marcos da órbita analisada; (b) o seu campo tangente; (b) o seu campo normal; (c) o seu campo binormal; e (d) os seus vetores para a representação do triedro de Frenet-Serrat. 


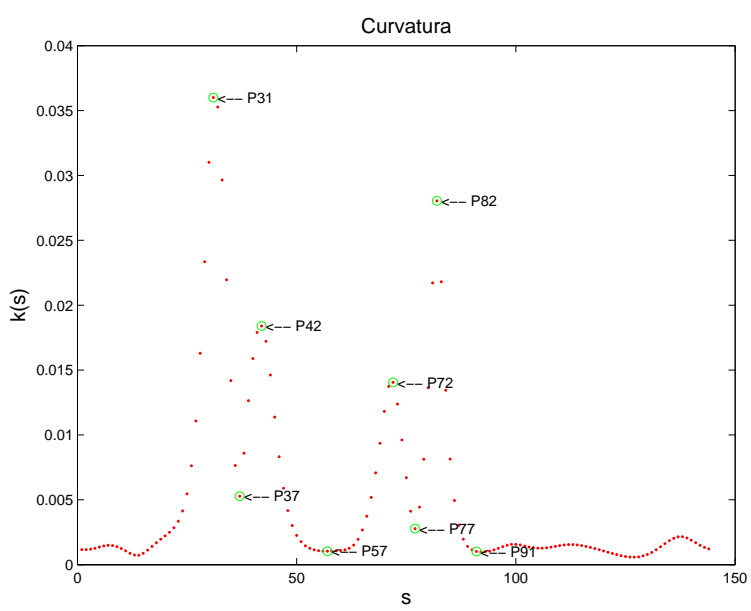

(a)

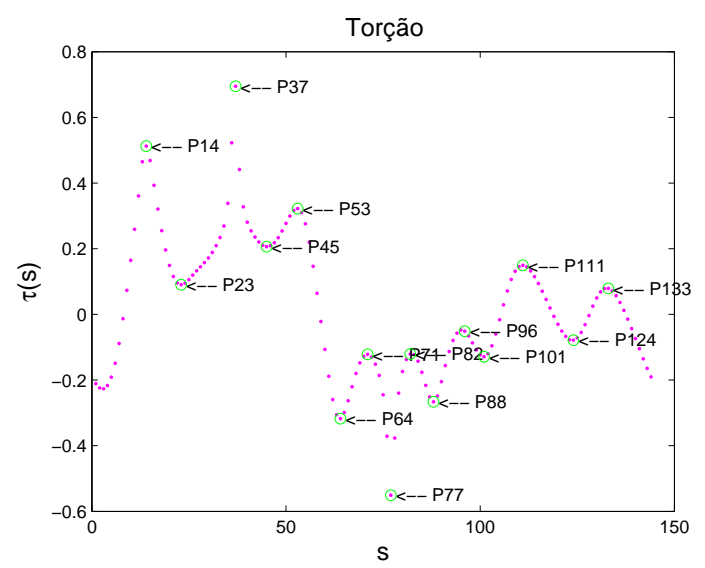

(b)

Figura 4.5: Gráficos da curvatura e da torção para a curva referente a Figura 4.4(a), a partir do triedro de Frenet-Serrat. Alguns pontos são marcados para facilitar a leitura dos gráficos com a curva original.

O primeiro passo então é transformar os dados originais em uma superfície do tipo $z=f(x, y)$, para permitir a aplicação da wavelet 2D. A Figura 4.6 apresenta uma superfície gerada a partir dos dados originais ${ }^{2}$.

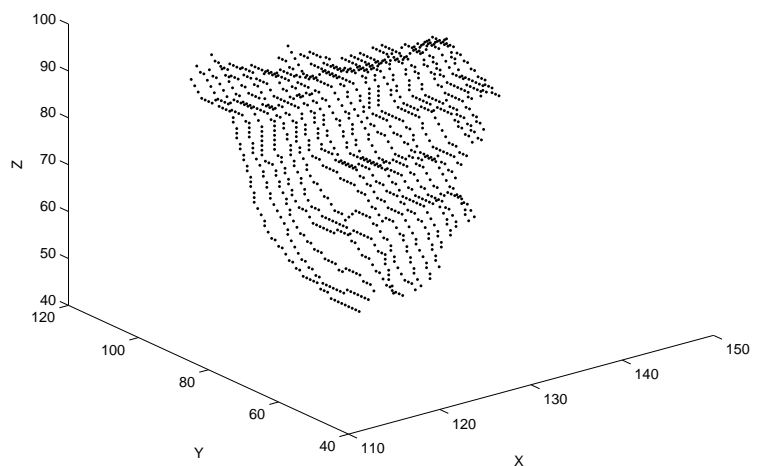

Figura 4.6: Exemplo de uma superfície da classe fissura de Sylvius conforme os dados originais.

\footnotetext{
${ }^{2}$ No Apêndice C são apresentadas todas as superfícies originais de ambas classes de estruturas trabalhadas.
} 
A fase de pré-processamento dos dados tem como objetivo resolver três problemas encontrados nesse tipo de superfície:

(i) Remoção de grupos de voxels conectados verticalmente, tendo as mesmas coordenadas $(x, y)$;

(ii) Preenchimento de "buracos" das superfícies;

(iii) Minimização do efeito de bordas decorrente da transformada wavelet.

Conforme o tipo de superfície que temos na Figura 4.6, existem mais de um valor $z$ para algumas coordenadas $(x, y)$. Como a intenção do nosso trabalho é analisar superfícies do tipo $z=f(x, y)$, temos que eliminar estes grupos de voxels que apresentam diferentes valores de altura $z$ para uma mesma coordenada $(x, y)$. Para resolver este problema, calculamos o valor médio de $z$ para cada ponto $(x, y)$. A Figura 4.7 mostra o resultado obtido em relação à Figura 4.6.

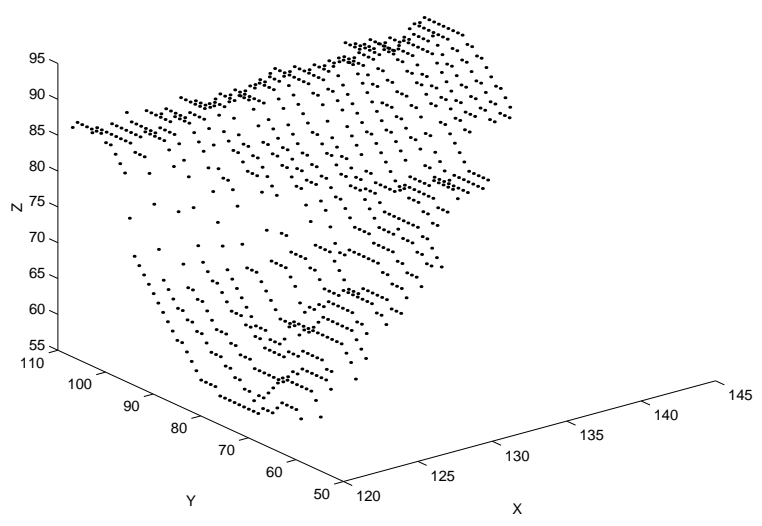

Figura 4.7: Superfície da Figura 4.6 apresentada a partir do valor médio $\hat{z}=f(x, y)$ dos pontos.

Para completar a imagem preenchendo os buracos em relação aos dados originais, aplicamos uma rotina especial em que, para cada pixel vazio, os $n$ pontos mais próximos dos pontos originais são localizados e o valor de $z$ é atribuído como a média dos valores dos $n$ pontos. Para este conjunto de dados nós adotamos trabalhar com $n=3$. Esta rotina utiliza uma estrutura de dados especial chamada SEDR (Sorted Exact Distance Representation) [20], a qual representa, sem omissão ou repetição e em ordem ascendente, todas as possíveis distâncias numa grade digital até um valor de raio máximo. 
Para minimizar o efeito de borda da aplicação da wavelet, tais superfícies são extrapoladas do seu limite (tamanho original) pelo mesmo processo de preenchimento de buracos descrito acima. Esta extrapolação por $n$ vizinhos mais próximos representa uma tentativa para minimizar a descontinuidade ao longo dos limites da superfície original e empurrar os efeitos de borda da wavelet para mais distante dos dados originais. As Figuras 4.8(b) e (c) exibem o resultado do método aplicado na Figura 4.8 (a).

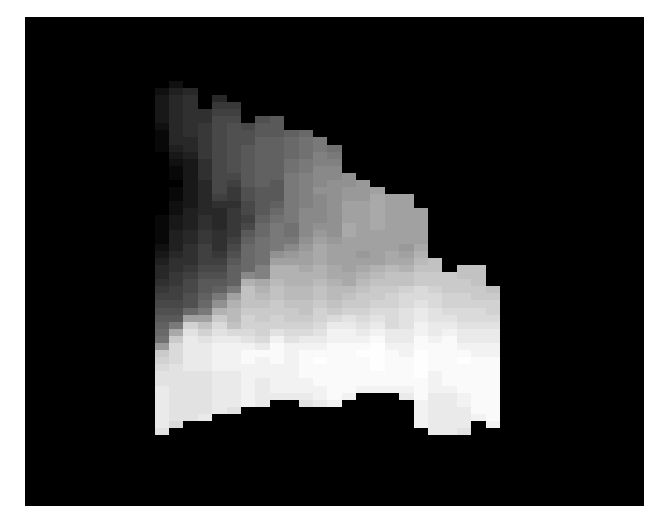

(a)

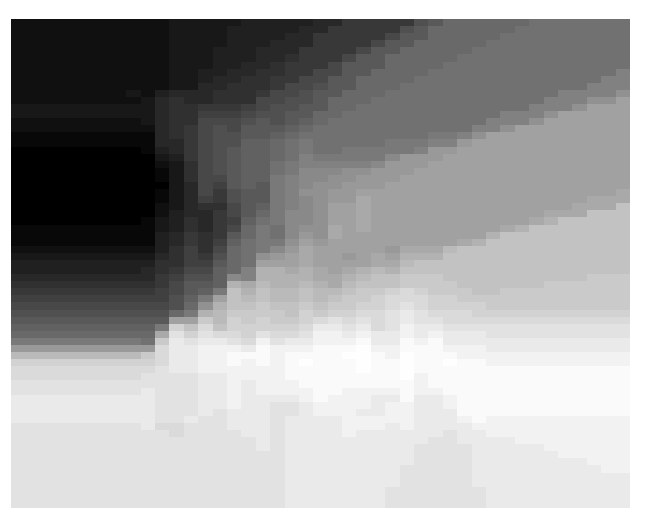

(b)

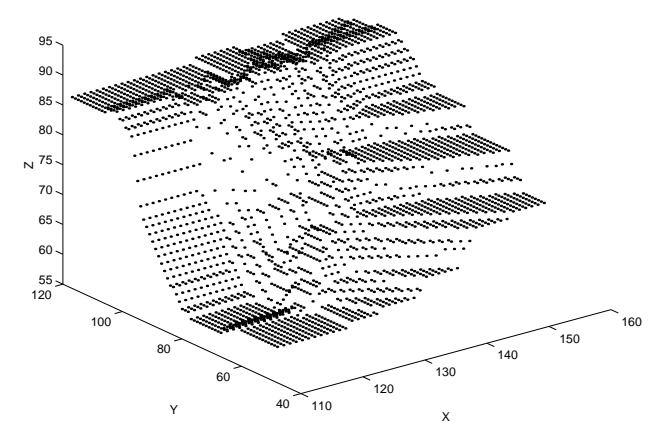

(c)

Figura 4.8: (a) Imagem 2D da superfície $\hat{z}=f(x, y)$ apresentada na Figura 4.7; (b) Imagem 2D da superfície extrapolada; e em (c) a sua versão como uma superfície tri-dimensional.

Finalmente, para obtermos uma imagem "periódica", acrescentamos à imagem extrapolada uma borda de largura de um pixel, levando em consideração o valor médio dos pixels da borda da imagem (superfície) extrapolada. Detalhes desta 
última rotina podem ser vistos no Apêndice A. O resultado mostrado na Figura 4.9 é o que podemos chamar de uma imagem periódica.

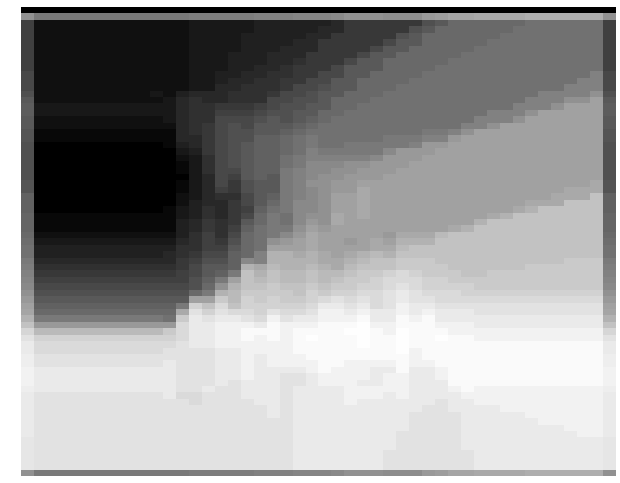

(a)

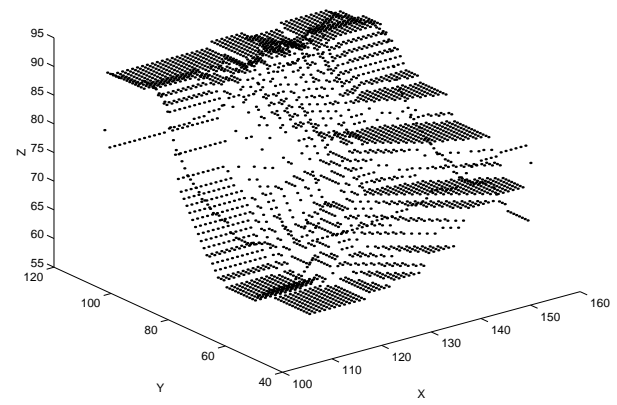

(b)

Figura 4.9: (a) Imagem da superfície extrapolada e periódica, e sua versão como uma superfície 3D em (b).

\subsubsection{Extração de Características}

Após a rotina de pré-processamento dos dados, podemos então aplicar a transformada wavelet para extrair as características da forma analisada. Conforme apresentamos no Capítulo 3, Seção 3.3, as wavelets $\psi_{x}$ e $\psi_{y}$ escolhidas têm como sua transformada wavelet $W_{\psi_{x}}$ e $W_{\psi_{y}}$, respectivamente. Aplicando a transformada wavelet $2 \mathrm{D}$ na superfície, podemos obter o gradiente wavelets $\nabla_{W}(\mathbf{b})$, isto é,

$$
\nabla_{W}(\mathbf{b})=\left(W_{\psi_{x}}[f](\mathbf{b}), W_{\psi_{y}}[f](\mathbf{b})\right)=\left(\frac{\partial f(x, y)}{\partial x}, \frac{\partial f(x, y)}{\partial y}\right) .
$$

A partir do gradiente, duas características particularmente relevantes, invariantes à translação e à rotação, são então extraídas:

A magnitude média do gradiente $\bar{\nabla}_{W}$;

A dispersão da orientação do gradiente medida através da entropia $\mathbb{E}_{\nabla_{W}}$.

Sendo assim, o valor da entropia da distribuição de orientação é definido como [20]:

$$
\mathbb{E}_{\nabla_{W}}=-\sum_{i} p_{i}(\theta) \log p_{i}(\theta)
$$


sendo que $p_{i}(\theta)$ é a probabilidade do ângulo $\theta$ ocorrer.

A entropia é maximizada quando a probabilidade de cada medida é a mesma. Portanto, um valor alto para a entropia significa que os ângulos dos vetores do gradiente estão igualmente distribuídos. Analisando a distribuição do campo gradiente apresentado na Figura 4.10(a), podemos concluir que a probabilidade de alguns ângulos serem observados é mais alta do que de outros num dado intervalo de possibilidades. A partir do histograma de dispersão da orientação do gradiente mostrado na Figura 4.10(b), podemos verificar que o valor da entropia não deve ser muito alto.

É importante notar que, embora a estrutura neuroanatômica original seja representada como um conjunto de pontos dos quais esta superfície extrapolada é derivada, as características obtidas são calculadas levando em consideração apenas as posições $(x, y)$ que correspondem aos pontos que pertencem ao conjunto original, conforme mostramos na Figura 4.10.

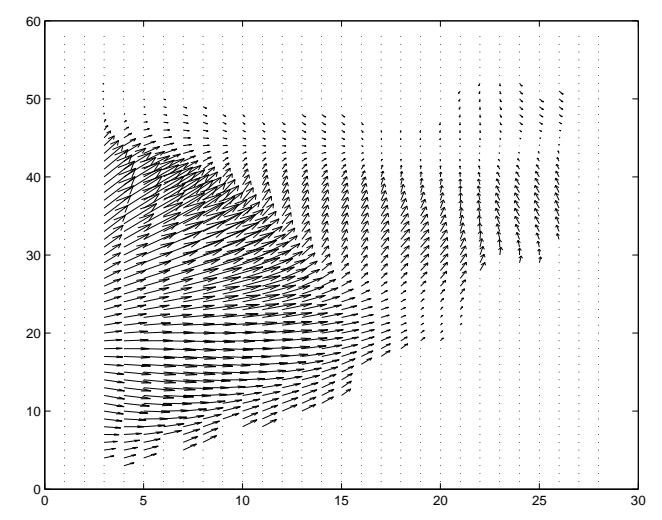

(a)

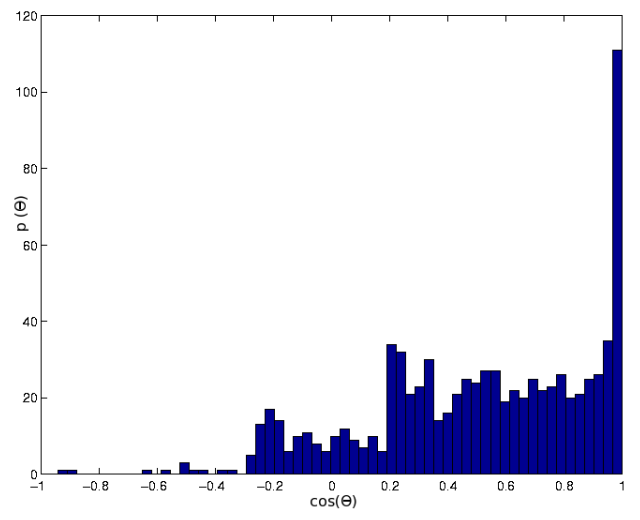

(b)

Figura 4.10: (a) Gradiente da superfície referente à Figura 4.7 e o seu histograma da dispersão da orientação do gradiente em (b).

Um ponto importante a ser enfatizado é que $\nabla_{W}(\mathbf{b})$ e, conseqüentemente, $\bar{\nabla}_{W}$ e $\mathbb{E}_{\nabla_{W}}$ são calculados para uma determinada escala $a=a_{0}$. Sendo assim, variando o parâmetro de escala $a$, obtemos uma família de características que podem ser indexadas como uma função de escala, isto é, $\bar{\nabla}_{W}(b, a)$ e $\mathbb{E}_{\nabla_{W}}(b, a)$.

O resultado dessas características para separar os dois tipos de formas é verificado através das distribuições nos espaços de características obtidos. Esses resultados são 
apresentados no Capítulo 5.

\subsection{Análise de Formas: Wavelets 3D}

\subsubsection{Pré-processamento}

Vários estudos mostraram que as diferenças morfológicas fundamentais em neuroanatomia poderiam ser um indicativo da variabilidade funcional do cérebro. No entanto, acredita-se que o tipo da variabilidade de forma 3D em estruturas neuroanatômicas seja difícil de ser capturada em sua plenitude exclusivamente por suas representações. Motivado por este desafio, desenvolvemos um método baseado em wavelets para a quantificação da variabilidade de forma em estruturas neuroanatômicas 3D. Neste estudo, nosso método será aplicado em uma importante estrutura no córtex auditivo, o giro de Heschl, para a qual a variabilidade de formas complicadas está relatada em [37].

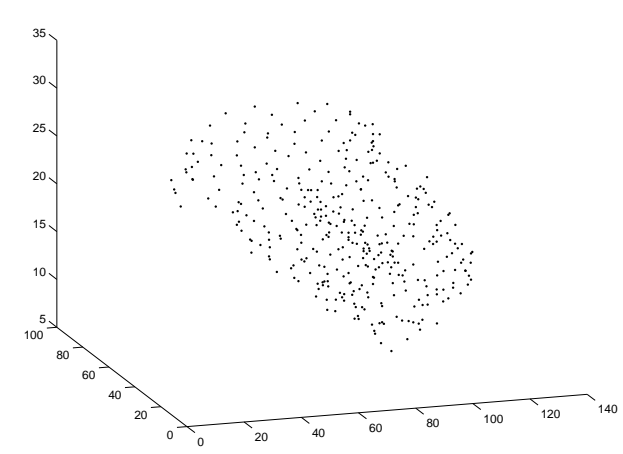

(a)

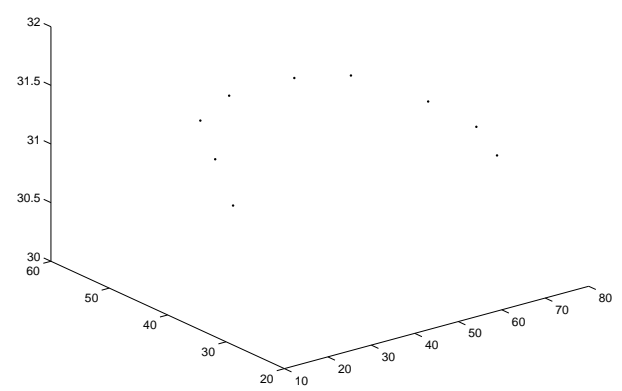

(b)

Figura 4.11: (a) Pontos da estrutura morfológica original; e em (b) a curva de pontos de uma fatia da estrutura original.

Assume-se que a estrutura de interesse (Figura 4.11(a)) é traçada manualmente ou segmentada automaticamente por imagens de ressonância magnética, conforme a sequência de pontos em forma de curvas de nível ao longo de uma série de fatias. Este tipo de estrutura não pode ser representado na forma $z=f(x, y)$, a qual permitiria a aplicação da wavelet 2D para extrair as características da forma, conforme a explicação na Seção 4.2.1. Ao invés disso, desenvolvemos uma aproximação 
para produzir uma representação volumétrica para os contornos, os quais podem ser adequadamente analisados pela transformada wavelet $3 \mathrm{D}$.

A Figura 4.11(b) mostra uma típica curva de pontos de um conjunto a ser processado. O primeiro passo para construir uma representação volumétrica é preencher uma linha poligonal (contorno de pontos) por uma interpolação entre cada par de pontos consecutivos do contorno (ver Método de Bresenham no Apêndice A), conforme mostrado nas Figuras 4.12(a) e (b). O próximo passo é executar uma dilatação do contorno (Figura 4.13(a)) pelo Método de dilatação exata [20], resultando na forma mostrada na Figura 4.13(b).

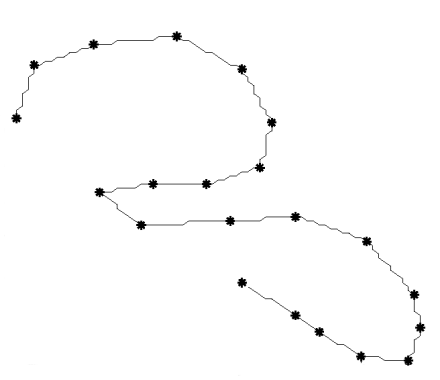

(a)

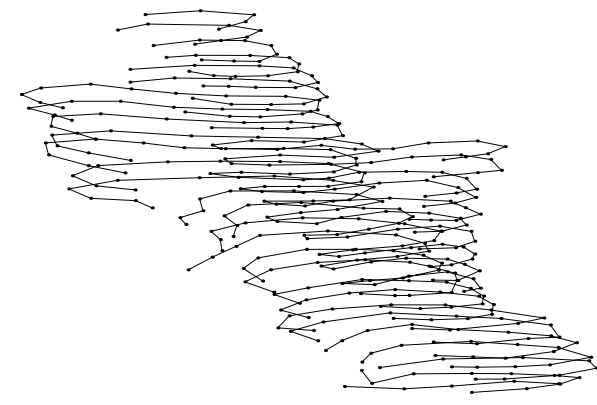

(b)

Figura 4.12: Uma das fatias de pontos originais interpolada pelo método de Bresenham em (a); e em (b) o conjunto de pontos originais vistos através de curvas de nível depois da interpolação.

A forma dilatada é então manualmente dividida em duas partes por dois segmentos ligados aos extremos do contorno inicial, conforme mostramos na Figura 4.13(c), pelas setas. Cada parte consiste de uma região cujo contorno inclui a curva original. A parte correspondente à região externa da estrutura neuroanatômica original é eliminada, restando apenas a região interna e o contorno com os pontos originais (Figura 4.13(d)), os quais são empilhados e transformados em uma forma volumétrica, conforme mostra a Figura 4.14.

\subsubsection{Extração de Características}

Uma importante abordagem para caracterizar superfícies é a estimação do seu campo normal. Trabalhos anteriores já trataram o problema caracterizando estruturas neuroanatômicas usando extração de características do campo normal $[17,33]$. A 


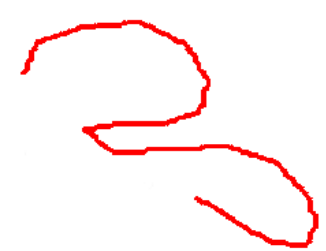

(a)

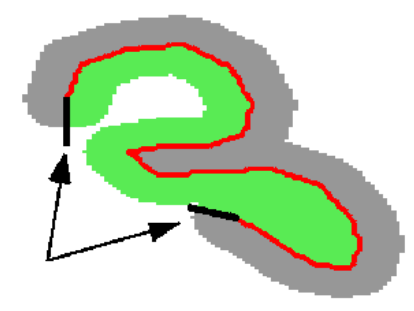

(c)

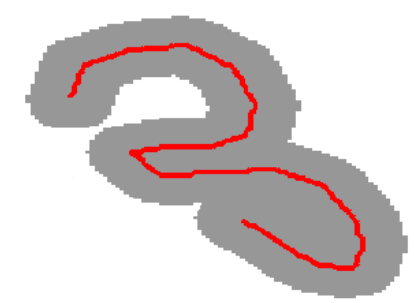

(b)

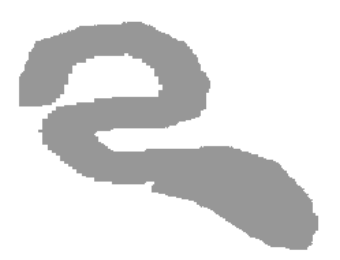

(d)

Figura 4.13: Contorno dos pontos em (a); dilatação do contorno em (b); escolha da região de interesse em (c), e a região considerada em $(\mathrm{d})$.

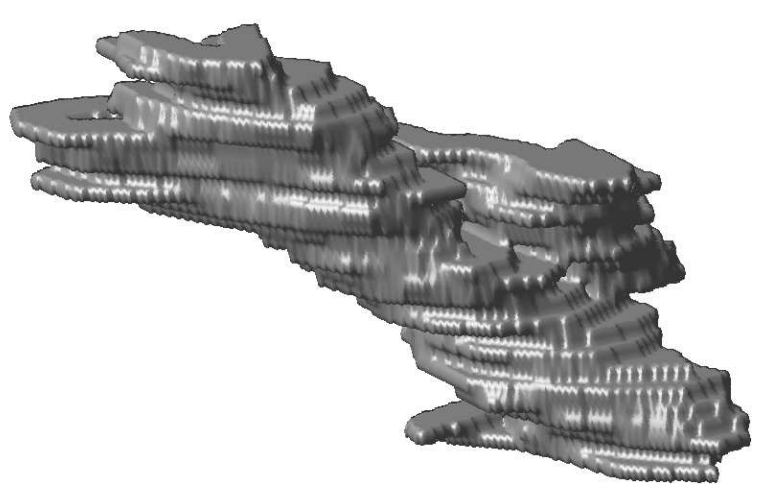

Figura 4.14: Volume obtido através do empilhamento das regiões dilatadas. 
abordagem padrão é obter uma versão parametrizada da superfície, isto é, triangularização ou modelos ativos, os quais podem ser usados para calcular o campo normal e outras medidas diferenciais. O principal problema, com tais abordagens, reside na necessidade de calcular tais representações parametrizadas.

Uma abordagem diferente foi adotada no nosso trabalho a fim de evitar os problemas mencionados. Para isso, resolvemos adotar uma das abordagens em representação de superfícies regulares da geometria diferencial, a qual envolve superfícies orientáveis, conforme expomos no Capítulo 2, Seção 2.3.2.

Portanto, seja $V$ o volume obtido pelo procedimento explicado na seção anterior. Então, podemos construir uma superfície do tipo $w=f(x, y, z)$, tal que

$$
f(x, y, z)= \begin{cases}1, & (x, y, z) \in V \\ 0, & \text { caso contrário. }\end{cases}
$$

Conseqüentemente, o volume $V$ define uma superfície orientável dada por $S=$ $\left\{(x, y, z) \in \mathbb{R}^{3} ; f(x, y, z)=1\right\}$ e da qual podemos obter o seu campo de vetores normais unitários conforme explicado no Capítulo 2, Seção 2.3.2, através da Equação (2.10).

De acordo com o Capítulo 3, Seção 3.3, as wavelets $\psi_{x}, \psi_{y}$ e $\psi_{z}$ têm suas transformadas wavelets representadas por $W_{\psi_{x}}, W_{\psi_{y}}$ e $W_{\psi_{y}}$, respectivamente. Aplicando a TWC 3D na superfície de interesse, podemos estimar o campo normal da forma 3D analisada. Usando esta propriedade, podemos então explorar a capacidade da TWC 3D de realizar a diferenciação numérica conforme feito por Grossmann em [28], ou seja,

$$
N(x, y, z) \simeq\left[W_{\psi_{x}}[f](\mathbf{b}), W_{\psi_{y}}[f](\mathbf{b}), W_{\psi_{z}}[f](\mathbf{b})\right]
$$

Exemplo: Para validar a abordagem usada acima, calculamos o campo normal para o caso de uma esfera sintética, conforme ilustrado nas Figuras em 4.15. Devido à limitação da imagem do campo normal completo, nós ilustramos somente alguns intervalos de vetores para facilitar a visualização.

A aplicação da TWC para diferenciação numérica de $f$ permite controlar a escala analisada, que é equivalente a suavizar a representação do volume original.

Conforme podemos verificar, a Figura 4.16 mostra a versão suavizada, para 


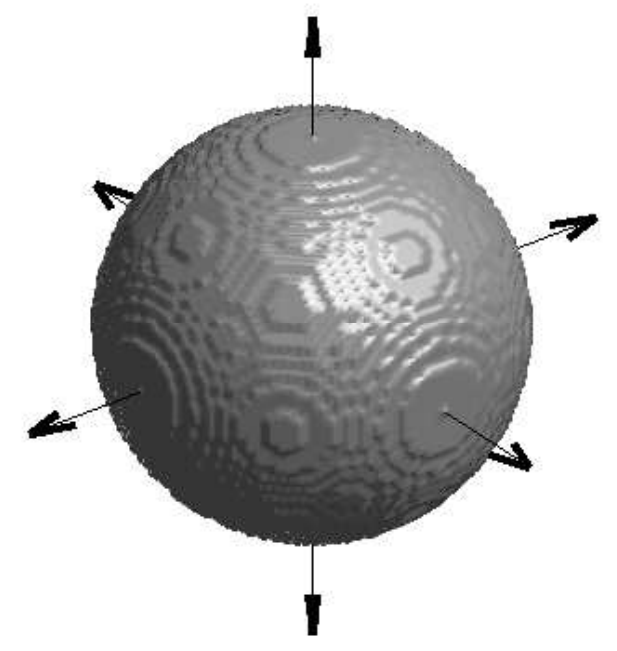

(a)

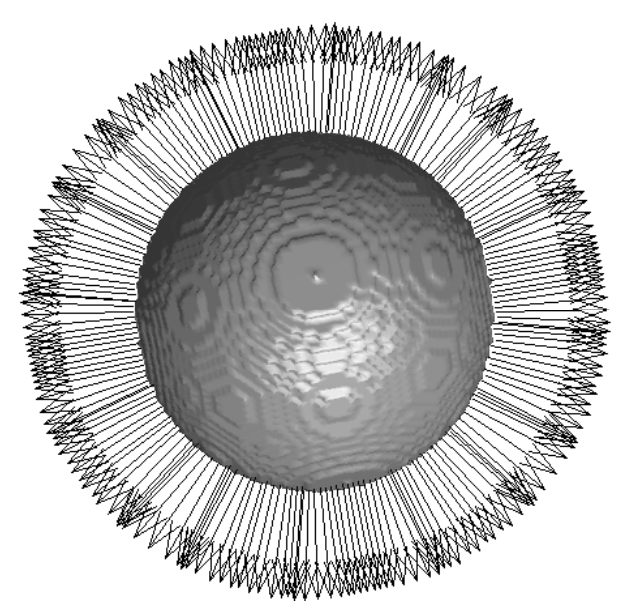

(b)

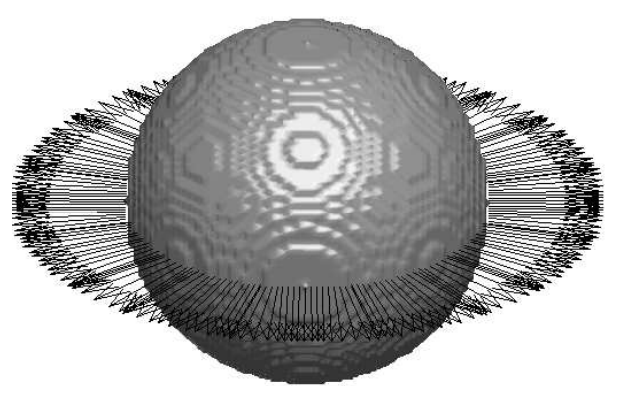

(c)

Figura 4.15: Visualização de alguns intervalos do campo normal de uma esfera sintética em (a)-(c). 
uma determinada escala $a_{0}=0,0005$, da estrutura volumétrica da Figura 4.14, e a Figura 4.17 ilustra o campo normal calculado para este volume.

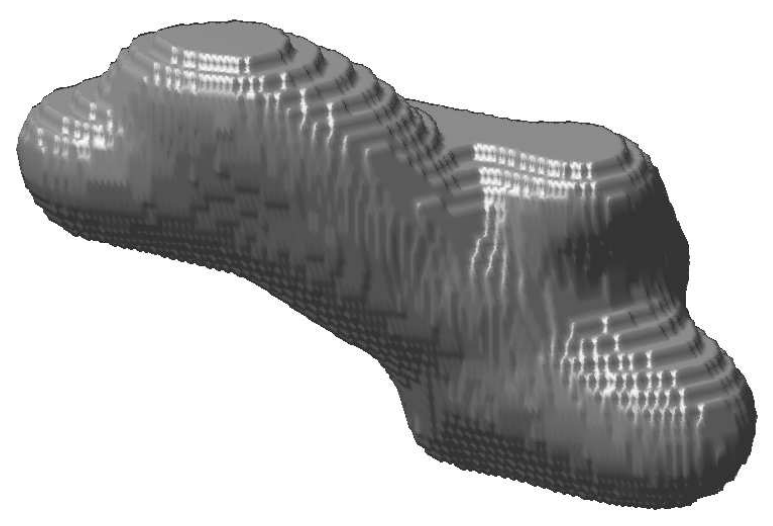

Figura 4.16: Versão suavizada pela aplicação da TWC do volume da Figura 4.14 para uma determinada escala $a_{0}=0,0005$.

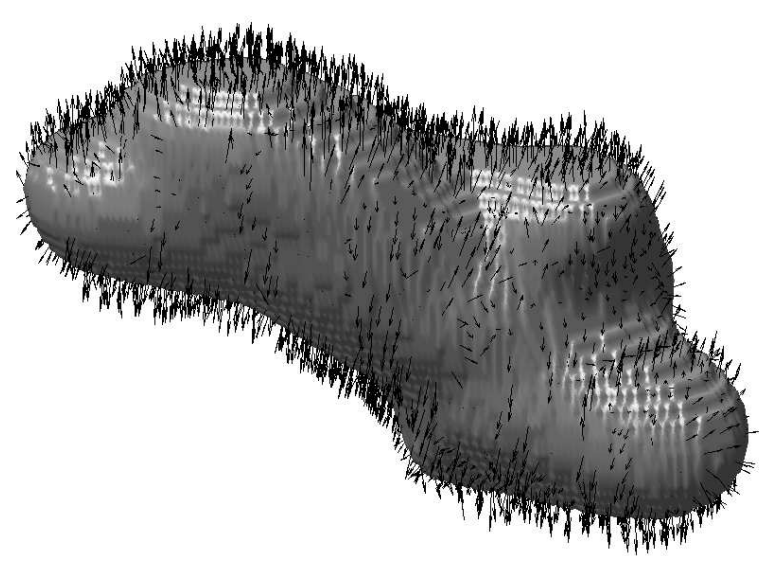

Figura 4.17: Ilustração do campo normal obtido através da versão suavizada da estrutura volumétrica da Figura 4.16.

Uma vez obtido o campo normal, é importante analisar suas propriedades geométricas em termos de um conjunto de características significantes. Neste trabalho, o principal objetivo é caracterizar as diferenças entre as propriedades geométricas de estruturas de interesses nos indivíduos. Parte da variabilidade observada numa estrutura extraída poderia ser devida às diferenças na posição da cabeça dentro do escâner, ou devida à forma da cabeça e diferentes tamanhos entre os sujeitos. No entanto, este tipo de variabilidade é minimizada depois da normalização dada às imagens de ressonância magnética usando técnicas de registro de imagem global. 
Depois da normalização, orientação, translação e mudança de escala, as diferenças da forma ainda prevalecem nas imagens de uma população como parte da variabilidade natural nas estruturas neuroanatômicas nos indivíduos [57].

Então, a fim de focalizar exclusivamente as diferenças das formas, as características selecionadas, levando em conta que elas devem ser invariantes à rotação, translação e mudança de escala, são:

Razões dos auto-eixos: Este método para extrair característica de formas utiliza o conceito de autovalores. Geralmente, existem uma ou mais direções da forma onde ela é mais alongada. Neste caso podemos afirmar que a forma apresenta um eixo maior nesta direção. Perpendicular a este eixo, podemos obter mais outros dois eixos, perpendiculares entre si. Para estes três eixos damos os nomes de eixos principais da forma tridimensional, também chamados auto-eixos da forma. Ou seja, dada uma superfície, a matriz de covariância das coordenadas de cada ponto é estimada pelo método de estatística padrão. Os auto-eixos da forma são então definidos como os autovetores obtidos a partir dos três maiores autovalores da matriz de covariância. A partir disso, obtemos três variâncias (ou seja, $\sigma_{1}^{2}>\sigma_{2}^{2}>\sigma_{3}^{2}$ ). O alongamento das estruturas neuroanatômicas pode então ser convenientemente expresso em termos dos raios $R_{1}=\sigma_{1} / \sigma_{2}, R_{2}=\sigma_{1} / \sigma_{3}$. Observe que estas três características têm naturezas globais e são invariantes à translação, rotação e mudança isotrópica de escala.

Distribuição de orientação local: A fim de expressar as diferenças locais entre as superfícies neuroanatômicas, histogramas da densidade foram obtidos para a orientação dos vetores normais ao longo dos vizinhos de 1 voxel ao redor de cada ponto da superfície (ver Figura 4.18(a)). Mais especificamente, para cada ponto $(x, y, z)$ da superfície, calculamos o valor médio, o máximo e o mínimo do ângulo entre o vetor normal do ponto $(x, y, z)$ e os vetores normais dos voxels de vizinhança-de-1-voxel na superfície (veja a ilustração da Figura 4.18(b)). Em seguida, obtemos os histogramas correspondentes, considerando toda a superfície. Características globais são extraídas dos três histogramas a fim de reduzir a dimensionalidade do espaço de classificação. Estas características incluem o valor médio (eq. (4.9)) e os momentos centrais (eq. (4.10)) da segunda à décima quinta ordem [20].

$$
\mu_{\mathbf{x}}=\int_{-\infty}^{\infty} \mathbf{x} p(\mathbf{x}) d \mathbf{x}
$$




$$
\tilde{M}_{k}[\mathbf{x}]=\int_{-\infty}^{\infty}\left(\mathbf{x}-\mu_{\mathbf{x}}\right)^{k} p(\mathbf{x}) d \mathbf{x}
$$

Observe que essas características preservam a invariância para a translação e rotação dos ângulos entre os vetores normais.

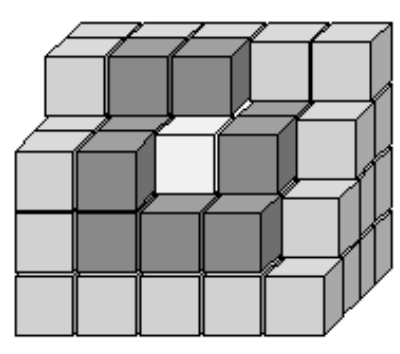

(a)

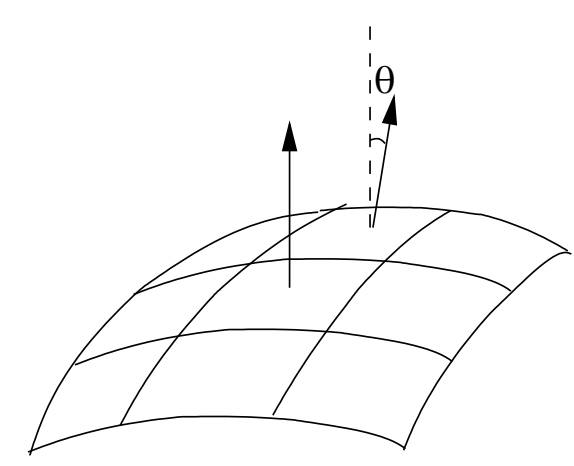

(b)

Figura 4.18: Modelo da distribuição dos voxels vizinhos-de-1-voxel (em cinza escuro) de um ponto $(x, y, z)$ da superfície em (a); e em (b) a medida do ângulo $\theta$ de um dos voxels da vizinhança em relação ao vetor normal do ponto $(x, y, z)$.

No total, teremos um número muito grande de características da forma. Como não há processos universais para a seleção de características, embora a análise de componentes principais e a de correlação possam ser úteis, a seleção de características tem apresentado bom desempenho em relação às demandas específicas impostas por cada aplicação. O ideal, em princípio, seria usar um número pequeno de características capazes de caracterizar e/ou separar os padrões. As dificuldades relacionadas com a escolha de medidas adequadas têm motivado a área de pesquisa conhecida como seleção de características [67].

Optamos por trabalhar com todas as combinações uma a uma, duas a duas e três a três destas características, as quais foram visualmente avaliadas e os melhores resultados em respeito à presente aplicação foram selecionados. Esses resultados são apresentados no Capítulo 5. 


\section{Capítulo 5}

\section{Resultados}

\subsection{Curvas Espaciais Parametrizadas e Wavelet 1D}

O nosso primeiro estudo trata do problema de descrever numericamente a forma do contorno orbital em crânios de coelhos no espaço tridimensional e também documentar as mudanças morfológicas presentes durante o estágio de crescimento da forma. Os dados utilizados são contornos orbitais extraídos de crânios de coelhos. Estes contornos são representados por marcos e foram disponibilizados em uma colaboração com o Professor Pete E. Lestrel (UCLA-EUA) [38, 39].

Os marcos, limitados no espaço tridimensional, são representados por um trio de coordenadas $(x, y, z)$ para cada ponto amostrado. Isto é obtido a partir de duas perspectivas, uma do plano $x y$ e outra do plano $x z$, das quais uma curva no espaço $\mathbb{R}^{3}$ pode ser construída. Adicionalmente, o terceiro plano yz é gerado computacionalmente.

Cada conjunto de marcos foi cuidadosamente extraído colocando o crânio do coelho em um gabarito especial, o qual mantém o crânio do coelho (Figura 5.1) em uma posição padronizada, permitindo ser rotacionado ao longo do maior eixo. Uma régua de $10 \mathrm{~cm}$, com divisões de $1 \mathrm{~mm}$, foi anexada ao gabarito como referência de escala. Os crânios são marcados com pontos (marcos) por uma caneta preta e as fotografias são feitas e mapeadas por um computador, fazendo a digitalização dos marcos. Os detalhes de extração dos dados podem ser obtidos em [38].

A fim de realizar uma avaliação das mudanças da forma conforme o crescimento 


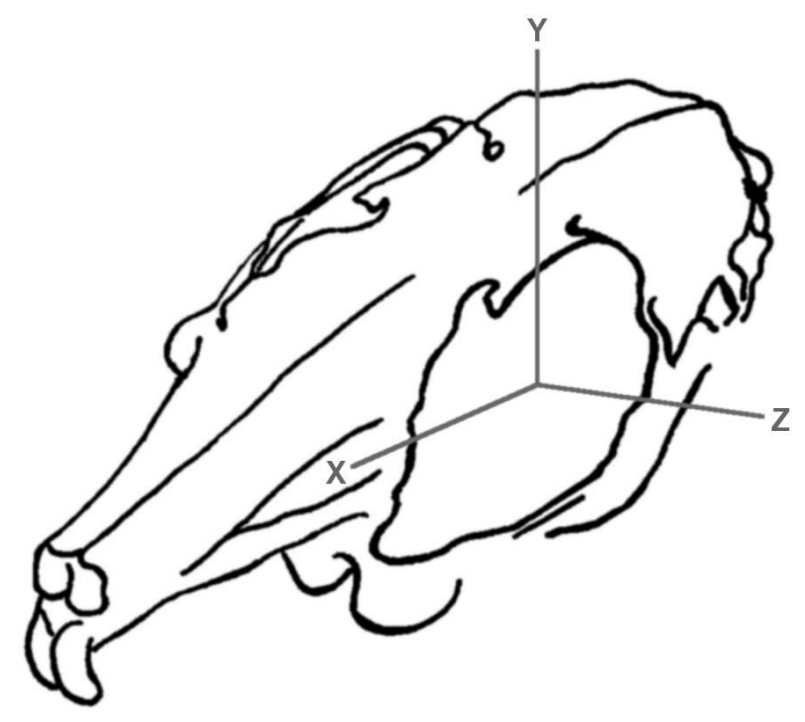

Figura 5.1: O crânio do coelho visualizado por uma perspectiva que mostra a relação da margem orbital e sua orientação no sistema de coordenadas cartesianas. Figura retirada do livro [38].

da órbita do coelho, foi proposta uma padronização do tamanho das órbitas. A partir de um software (Surface Evolver [8]), o qual calcula a área interna de uma curva fechada no espaço tridimensional conforme uma "superfície mínima", o conjunto de 144 marcos contidos na margem orbital foi submetido à padronização por tamanho e pelas coordenadas dos respectivos centróides da forma.

As Figuras 5.2 e 5.3 apresentam as curvas órbitais representadas por marcos, tanto para uma análise relacionada com o tamanho e forma das órbitas quanto para uma análise que leva em consideração somente a forma orbital (com padronização do tamanho), respectivamente. Estas curvas fazem parte de uma representação média de cada classe ${ }^{1}$ para cada tipo de análise, ou seja: 1) infantil (MEANINFC1 e MEANINFC3); (2) juvenil (MEANJUVC1 e MEANJUVC3); e (3) adulto (MEANADUC1 e MEANADUC3). O Apêndice B apresenta estas curvas em diferentes perspectivas visuais.

\footnotetext{
${ }^{1}$ A curva média para cada classe é obtida a partir da média do conjunto de exemplares para casa idade, ou seja: infantil, 14 exemplares, com idade média de 26, $43 \pm 11,75$ meses; juvenil, 9 exemplares, com

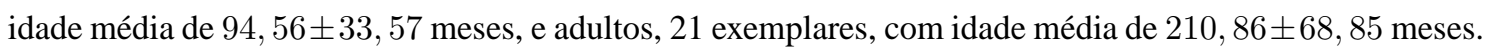




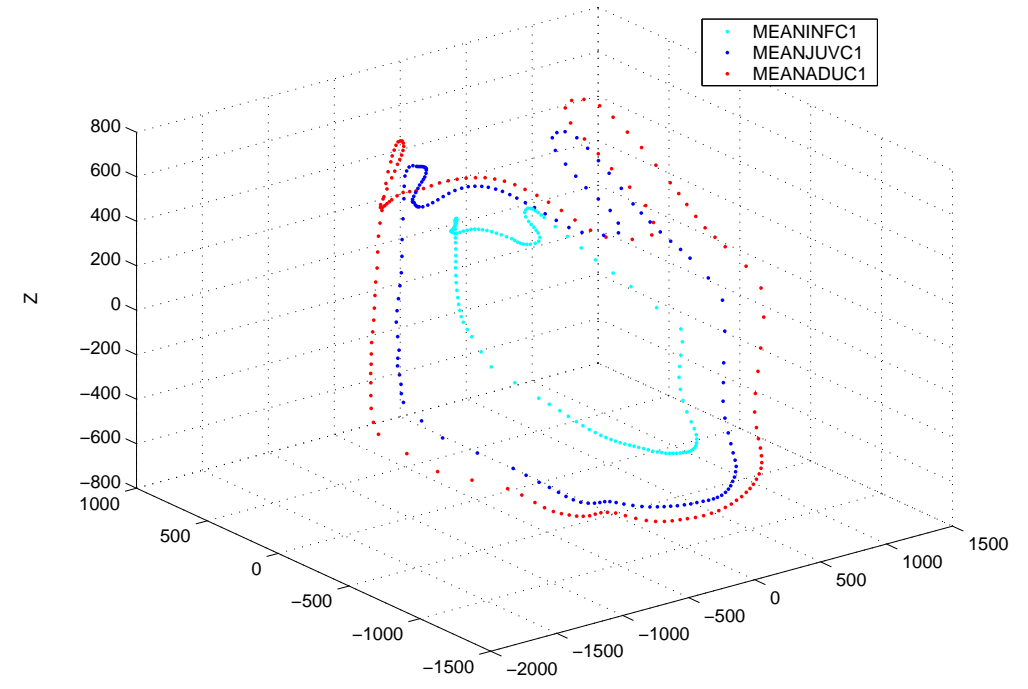

Figura 5.2: Perspectiva 3D da curva orbital do coelho. Os três grupos médios: (1) infantil (MEANINFC3); (2) juvenil (MEANJUVC3); e (3) adulto (MEANADUC3), estão sobrepostos pelo centróide. Ambas diferenças de tamanho e forma estão envolvidas nesta representação.

\subsubsection{Espaço de Características Obtido}

De acordo com a extração de características proposta no Capítulo 4, Seção 4.1.2, foram calculadas a curvatura e torção para cada curva espacial parametrizada a partir dos marcos do contorno orbital. O parâmetro de escala $a$ da transformada wavelet usado foi $a=0,0001$. Estes resultados podem ser conferidos para as duas diferentes análises propostas neste trabalho:

1. Forma e tamanho (gráficos da Figura 5.4);

2. Somente forma (gráficos da Figura 5.5).

Normalizando o resultado da curvatura para as diferentes curvas e análises, podemos observar no gráfico da Figura 5.6 que os picos de máxima curvatura acontecem sempre na mesma região, independentemente das diferentes idades da cobaia. A Figura 5.7 destaca os marcos referentes aos picos de máxima curvatura.

Ao analisarmos os gráficos de torção para a análise de tamanho e forma, Figura 5.4(b), e para a análise que considera apenas a forma, Figura 5.5(b), podemos perceber uma forte semelhança dos gráficos, ou seja, o comportamento do gráfico 


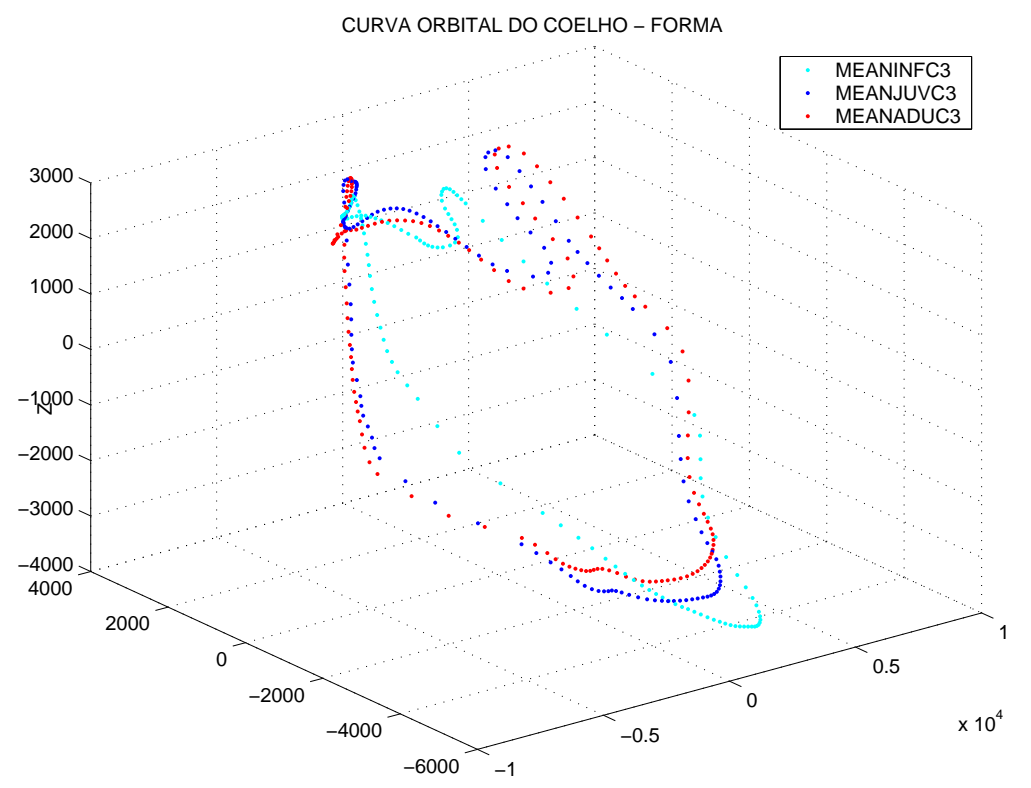

Figura 5.3: Perspectiva 3D da curva orbital do coelho. Os três grupos médios: (1) infantil (MEANINFC1); (2) juvenil (MEANJUVC1); e (3) adulto (MEANADUC1), estão sobrepostos pelo centróide. Apenas as diferenças em relação à forma estão envolvidas nesta representação.

de torção para ambas as curvas está fortemente ligado à forma. De acordo com a Figura 5.8, onde apontamos regiões significativas do gráfico, podemos verificar que a região marcada com o número 1 apresenta um deslocamento em relação a $s$ do pico de máximo em relação às diferentes idades da forma, enquanto as regiões marcadas com os números 2, 3 e 4 apresentam uma alta correlação das órbitas, independentemente da idade.

A Figura 5.9 apresenta as regiões destacadas pelo gráfico da Figura 5.8. 


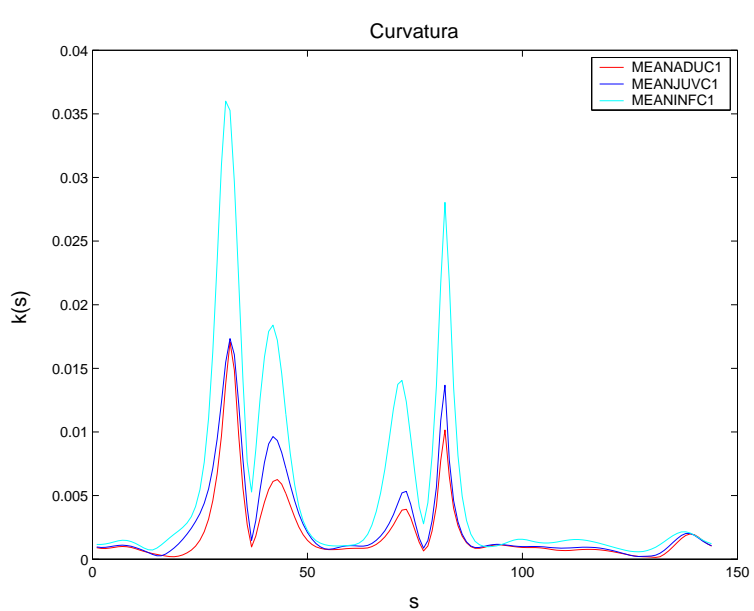

(a)

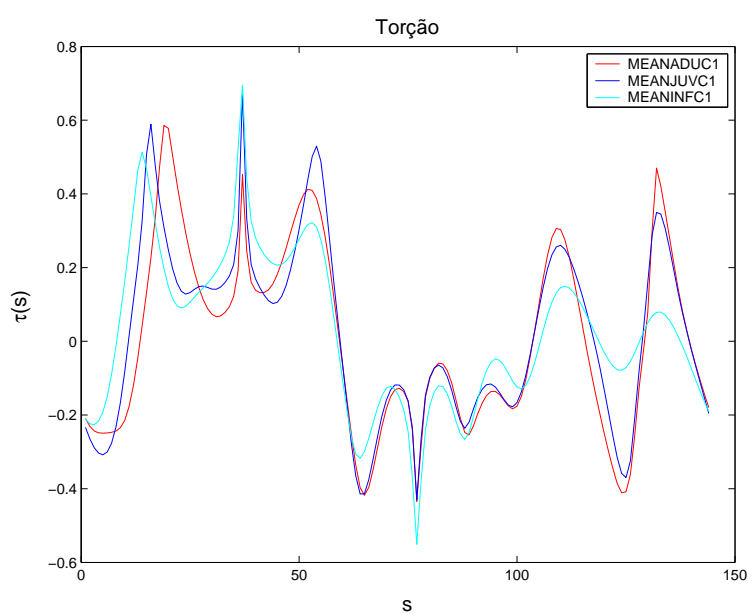

(b)

Figura 5.4: Resultados obtidos para a curvatura em (a) e a torção em (b) para as curvas da Figura 5.2, conforme a análise de forma e tamanho para as diferentes idades do contorno orbital.

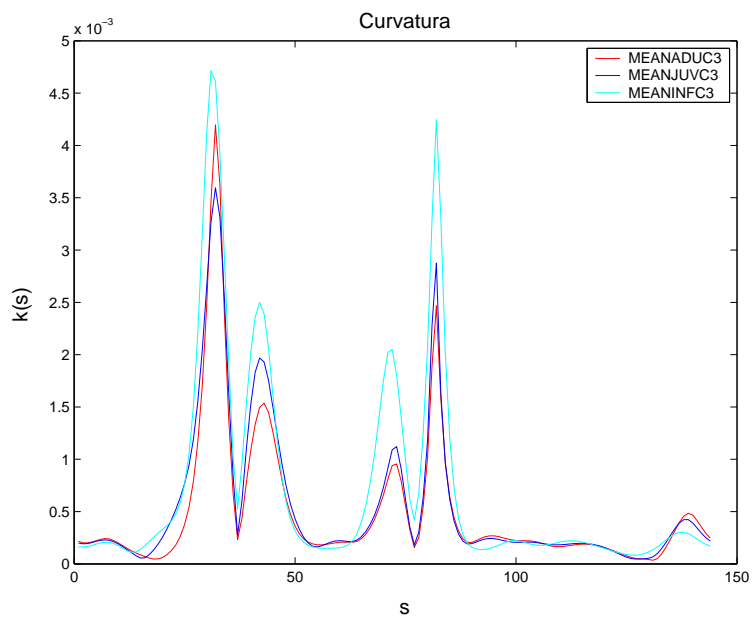

(a)

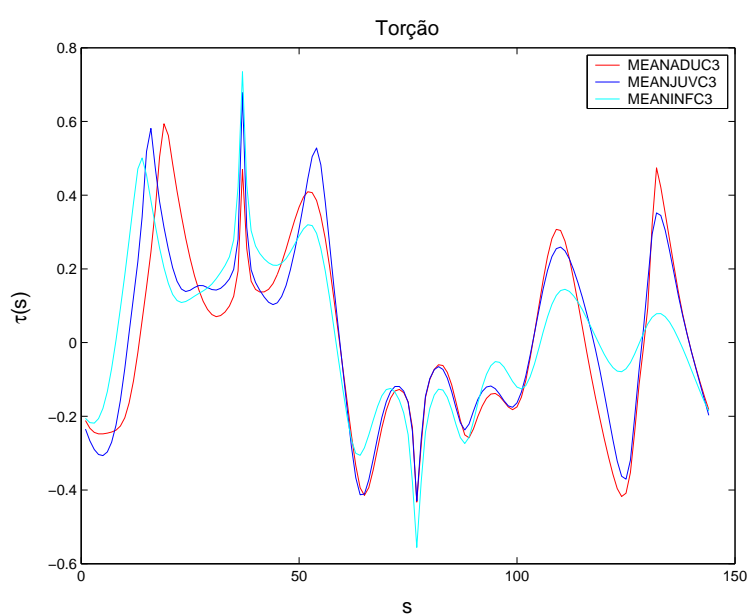

(b)

Figura 5.5: Resultados obtidos para a curvatura em (a) e a torção em (b) para as curvas da Figura 5.2, conforme a análise que considera apenas a forma das diferentes idades do contorno orbital.

\subsection{Superfícies do tipo $z=f(x, y)$ e Wavelet 2D}

Este estudo trata do problema de distinguir duas diferentes estruturas neuroanatômicas, a fissura de Sylvius e o sulco do cíngulo, utilizando as propriedades da trans- 


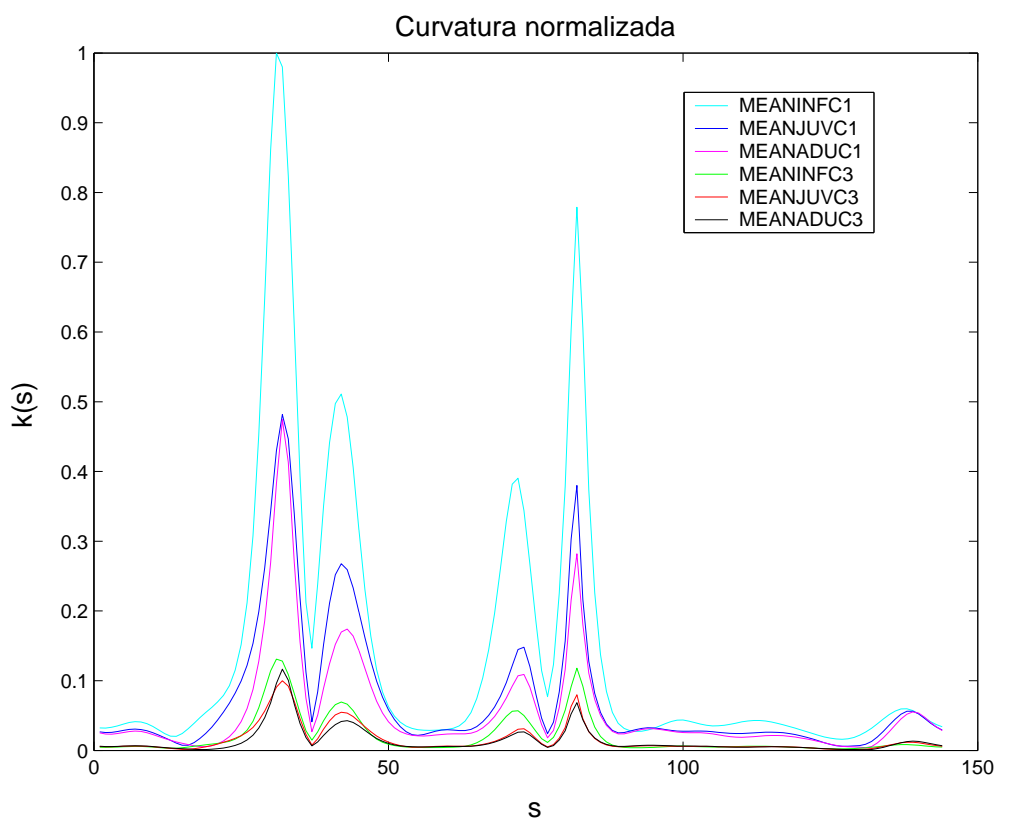

Figura 5.6: Normalização da curvatura para as duas diferentes análises.

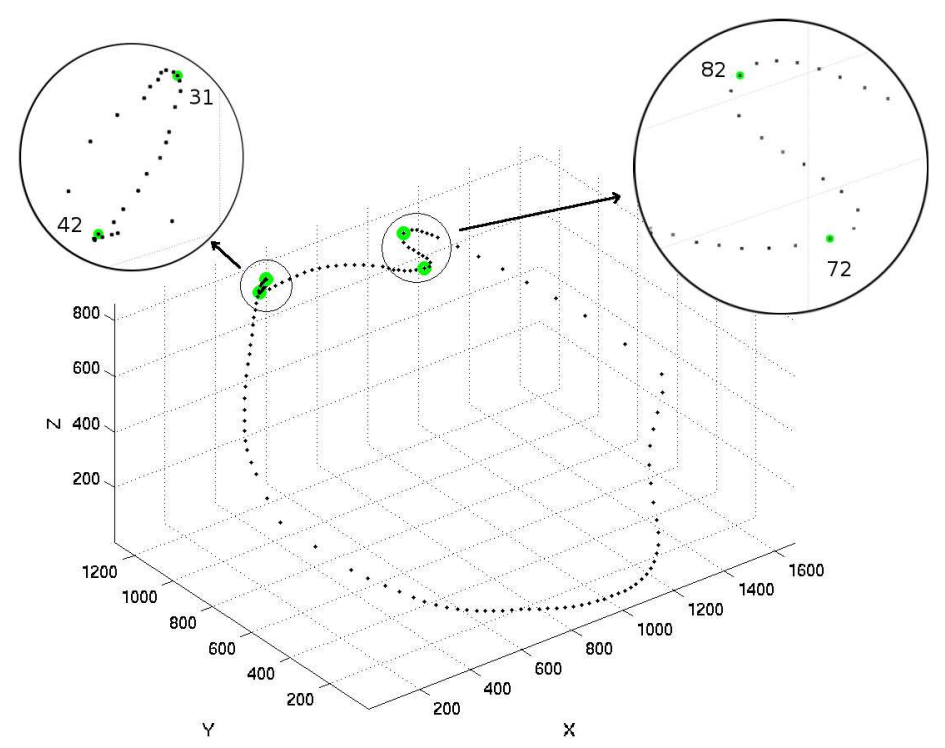

Figura 5.7: Regiões de destaque na curva onde ocorrem os valores de picos no gráfico de curvatura da Figura 5.6.

formada wavelets. Estas duas estruturas foram extraídas por ressonância magnética de 10 sujeitos normais, com idades entre 29 e 51 anos. As diferenças de translação, rotação e escala entre as imagens são resolvidas por um pré-registro dentro de um 


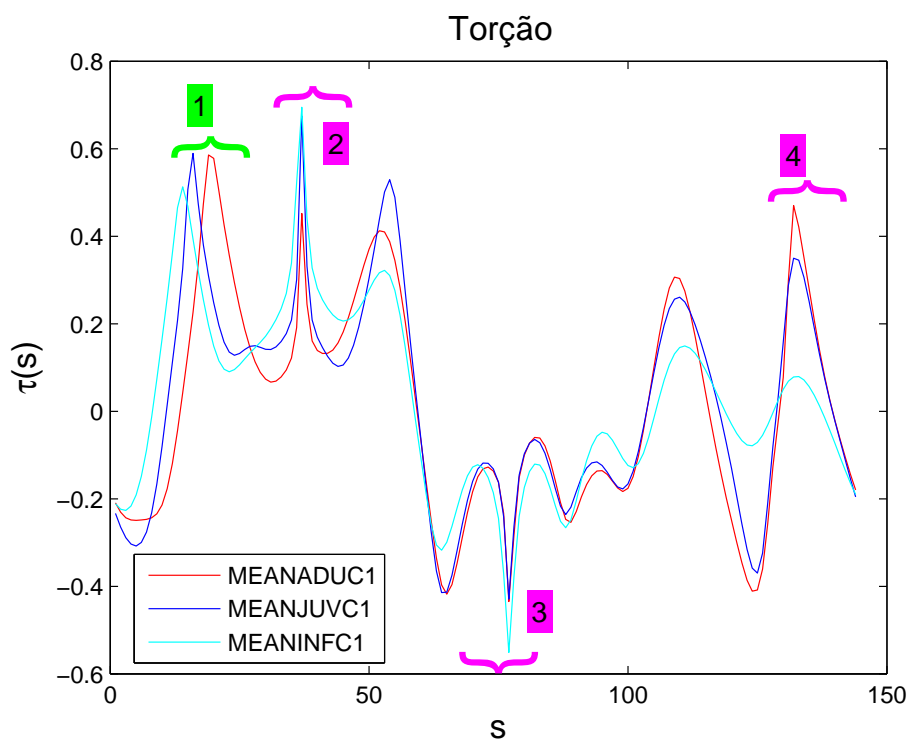

Figura 5.8: Regiões de destaque no gráfico de torção.

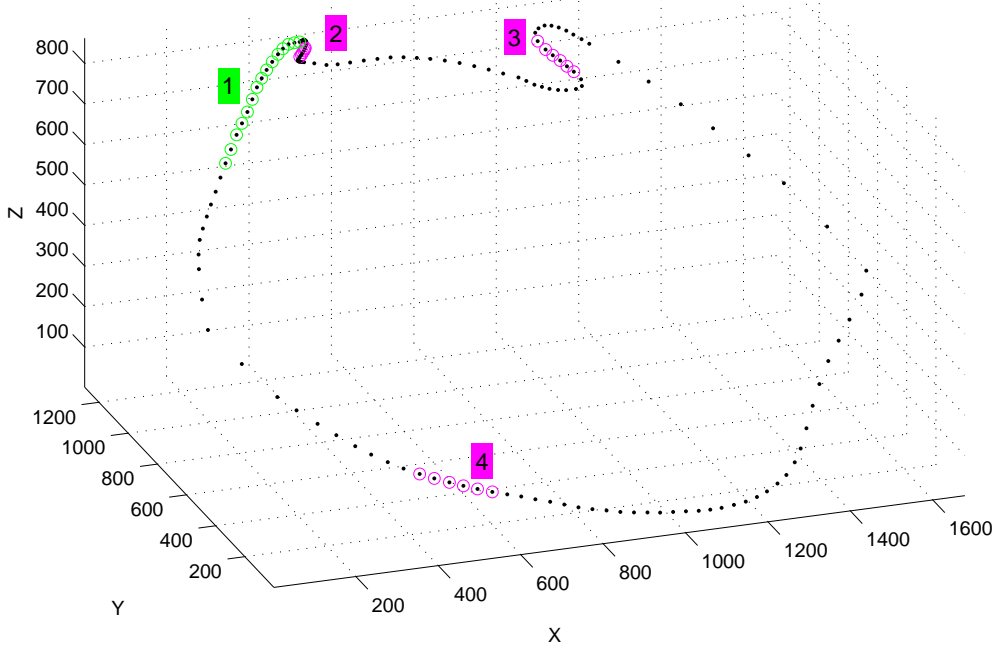

Figura 5.9: Regiões de destaque na curva, conforme o gráfico da Figura 5.8.

espaço de calibração padrão, através da transformação de Talairach [61]. Os detalhes da extração destes dados são encontrados em [26].

Em um corte sagital, observa-se que o sulco do cíngulo (ver Figura 5.11) corre ao longo da face interna (medial) do hemisfério esquerdo desde o lobo frontal, correndo ao longo do lobo parietal e desaparecendo posteriormente. A fissura de Sylvius, que também é conhecida como sulco lateral (ver Figura 5.10), é encontrada na face la- 


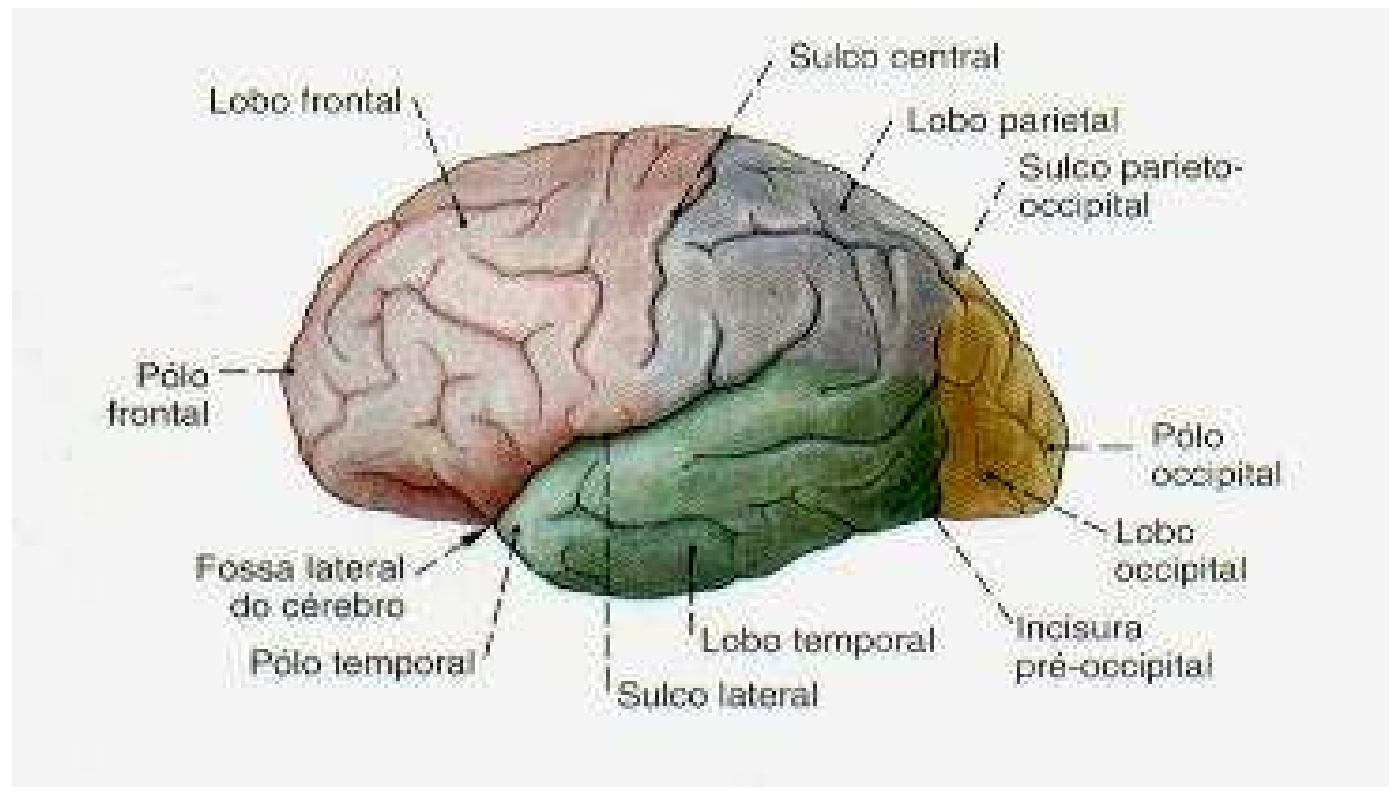

Figura 5.10: Fossa (ou sulco) lateral localizada na visão lateral do Lobos do telencéfalo (Adaptado de [56]).

teral dos hemisférios, separando o lobo temporal dos lobos frontal e parietal. É uma fissura profunda e no seu assoalho encontra-se o lobo insular. Conforme podemos observar qualitativamente nos esboços dos dados originais (ver Figuras C.3 e C.1, apresentadas no Apêndice C), os traços das estruturas revelam que uma das estruturas analisadas, a fissura de Sylvius, tem uma forma mais contínua e amplamente distribuída, enquanto a outra, o sulco de cíngulo, tem um esboço estreito e com algumas interrupções.

De acordo com o que pudemos verificar, estas duas estruturas têm diferenças significativas em relação à sua forma, as quais motivaram a análise proposta, que apresentamos a seguir.

\subsubsection{Espaço de Características Obtido}

As características extraídas, conforme foi explicado no Capítulo 4, Seção 4.2.2, são levadas a uma combinação duas a duas, isto é, a Magnitude $\bar{\nabla}_{W}(a)$ e a Entropia de orientação $\mathbb{E}_{\nabla_{W}}(a)$, para formarem os espaços de características. Os espaços apresentados nas Figuras 5.12(a)-(c) são um exemplo dos resultados obtidos para a separação das duas classes de formas analisadas, isto é, o sulco do cíngulo (representada pela abreviação cing) e a fissura de Sylvius (representada pela abre- 


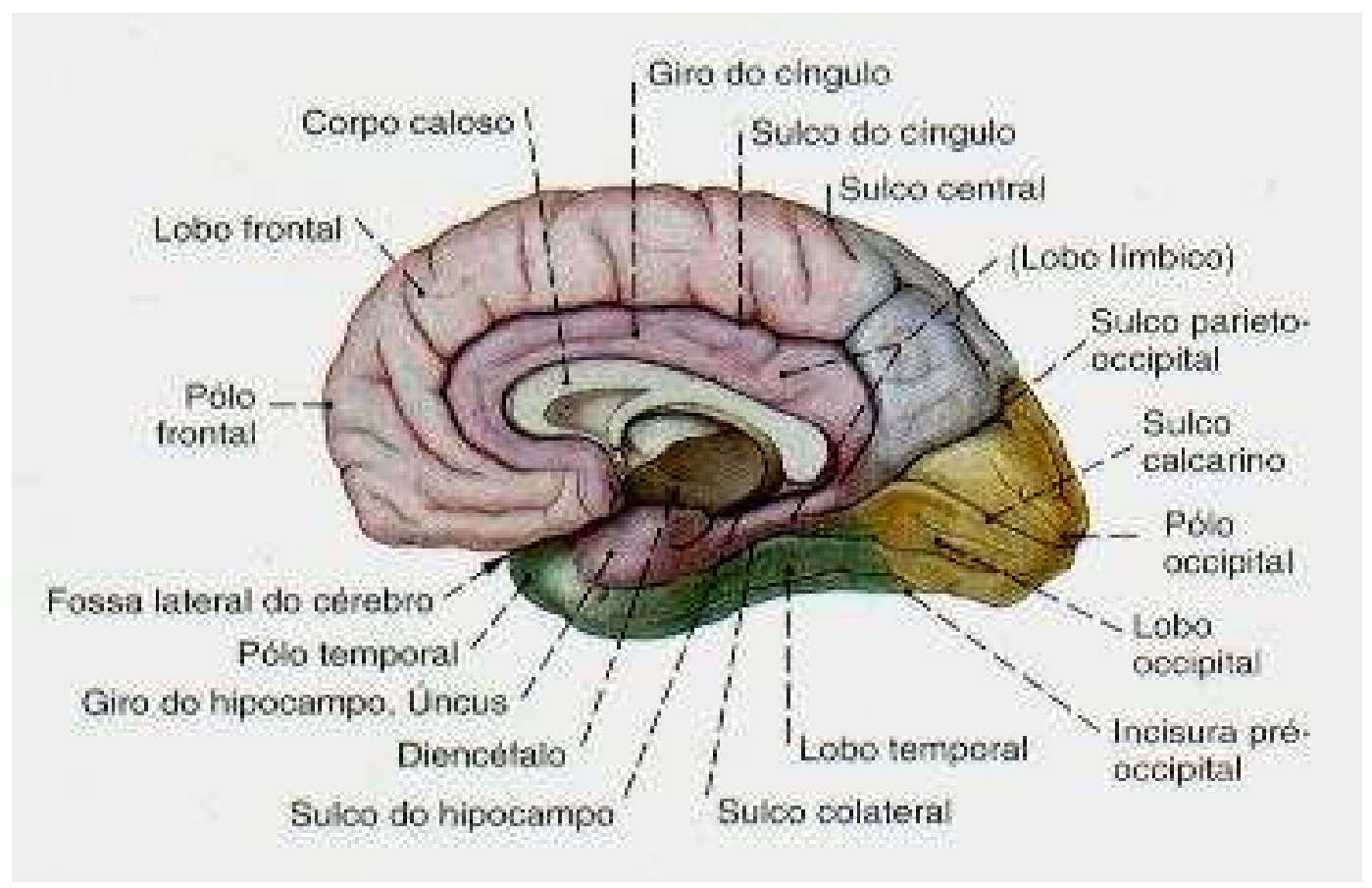

Figura 5.11: Sulco do cíngulo (Adaptado de [56]).

viação $s y l v)$. Os resultados apresentados foram obtidos para as escalas de análise $a=0,00006, a=0,005$ e $a=0,01$.

No intuito de realizar uma comparação entre uma técnica monoescala padrão e o método abordado neste trabalho, estimamos as mesmas características utilizando a máscara de diferenciação de Sobel [20]. O resultado do espaço de características obtido é apresentado na Figura 5.12(d).

Como podemos verificar na Figura 5.12, o espaço de características que melhor separou visualmente as classes analisadas é o que foi obtido pela escala $a=0.005$ (Figura 5.12(b)), conforme mostra a reta posicionada no gráfico.

\subsubsection{Avaliação de Desempenho das Características}

A fim de avaliar o quão eficiente são as características extraídas da forma em discriminação de estruturas 3D, utilizamos algumas medidas de qualidade de separação entre as classes. A idéia é medir o quanto as duas classes analisadas estão separadas em cada espaço de características.

Idealmente, um conjunto de características é considerado eficiente para a dis- 


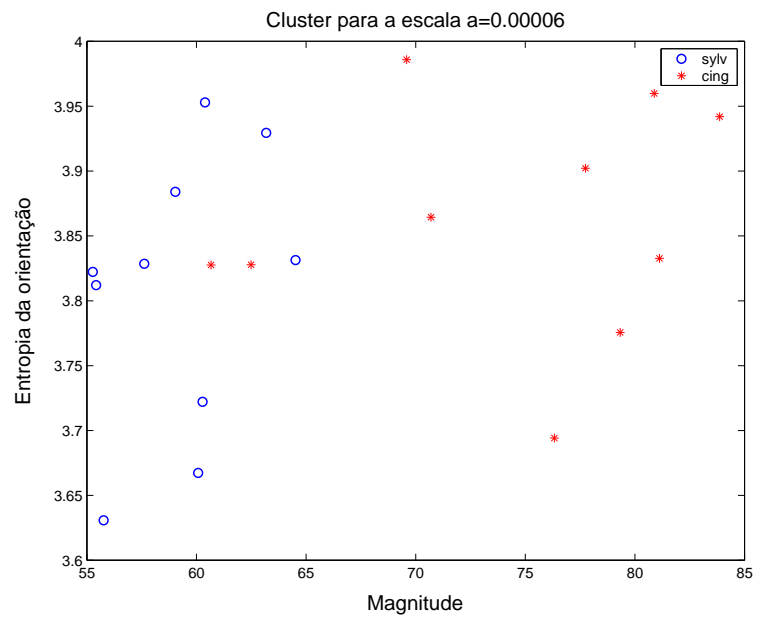

(a)

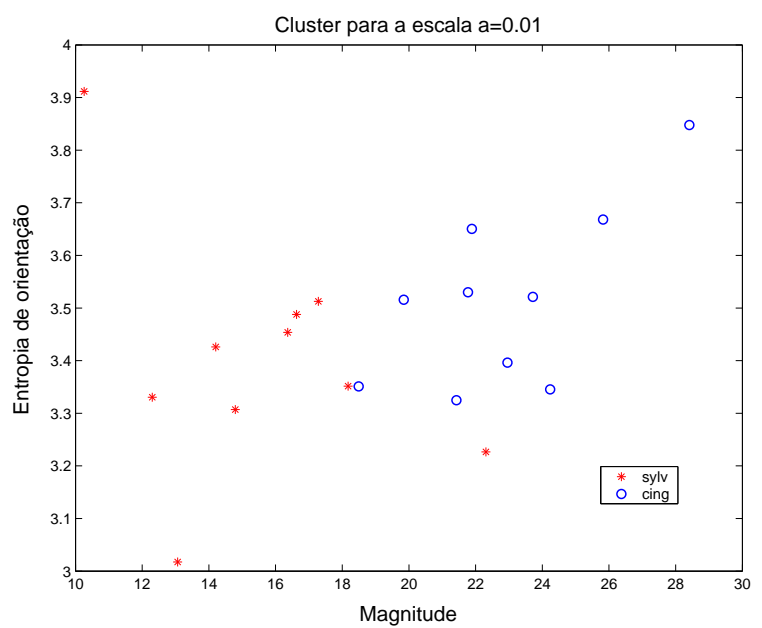

(c)

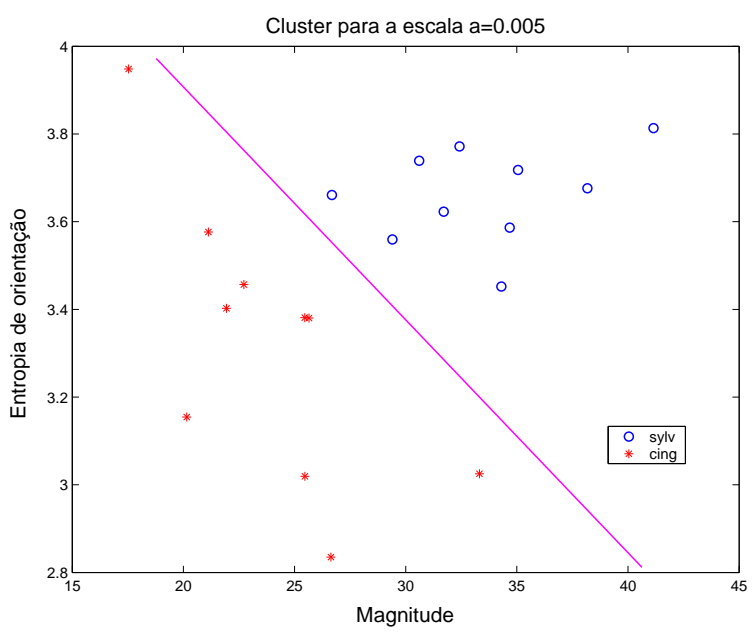

(b)

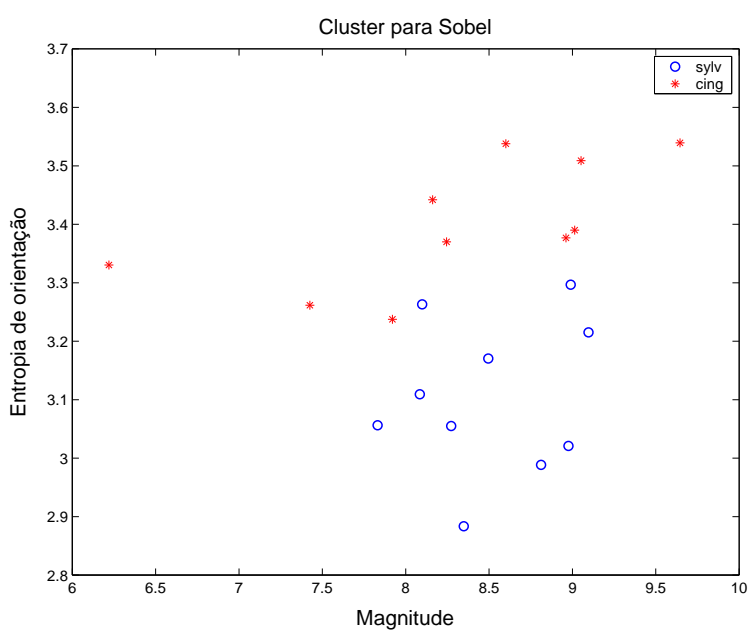

(d)

Figura 5.12: Espaços de características obtidos pelo método que utiliza a transformada wavelet (a)-(c) para as escalas de análise $\mathrm{a}=0.00006, \mathrm{a}=0.005$ e a=0.01, respectivamente; e em (d) o espaço de características obtido pelo método de diferenciação de Sobel.

criminação de classes quando: 1) tem uma representação mais compacta de cada classe; 2) tem uma distância significativa entre classes distintas; e 3) apresenta características descorrelacionadas.

As medidas de qualidade de separação de classes selecionadas para esta avaliação 
foram:

- Distância de Mahalanobis [35];

- Distância de Bhattacharyya [40];

- Dispersão Total entre as classes [20];

- Dispersão Intra classes [20];

- Dispersão Inter classes [20];

- Coeficiente de Correlação [20].

Os detalhes de como são calculadas estas medidas são apresentados no Apêndice A.

Com o objetivo de melhorar o potencial discriminativo da nossa abordagem, investigamos a utilização de um filtro para as superfícies analisadas baseado na Análise dos Componentes Principais [20]. Assim, cada espaço de características pode ser filtrado pela projeção dos componentes principais a partir de um determinado número de auto-valores.

De acordo com os resultados apresentados na Seção 5.2.1, os espaços de características são avaliados para uma série de escalas, e os resultados podem ser verificados na Figura 5.13(a)-(f), onde cada gráfico apresenta duas curvas: uma referente à análise considerando as superfícies representadas pelos seus 1000 auto-vetores (a melhor representação por componentes principais considerando a distância de Mahalanobis, conforme apresenta a Figura 5.14) e a outra considerando todos os seus auto-vetores, isto é, sem a utilização do filtro.

Para avaliar como as medidas de separação de classes da Figura 5.13 se relacionam uma com a outra, os coeficientes de correlação entre cada uma delas foram calculados, conforme apresentado na Tabela 5.1.

Considerando os espaços de características obtidos pelo par de características, ou seja, a magnitude e a entropia de orientação para diferentes escalas (conforme apresentamos na Seção 5.2.1), podemos conferir na Tabela 5.2 os valores da distância de Mahalanobis para as diferentes escalas e comprovar que o espaço de características para a escala $a=0,005$ (Figura 5.12(b)) apresenta a maior distância entre as classes quando comparado com outras escalas. O valor da distância de Mahalanobis entre as classes, obtido pelo método de diferenciação de Sobel (Figura 5.12(d)), é 2,3811. 


\begin{tabular}{|c||c|c|c|c|c|c|}
\hline & Mahal. & Batt. & Dis. Total & Dis. Intra. & Dis. Inter. & Coef. Corr. \\
\hline \hline Mahal. & 1.0000 & 0.4987 & 0.2455 & 0.2804 & 0.2391 & -0.4586 \\
Batt. & 0.4987 & 1.0000 & 0.9548 & 0.9581 & 0.9536 & 0.2491 \\
Dis. Tot. & 0.2455 & 0.9548 & 1.0000 & 0.9972 & 0.9999 & 0.4960 \\
Dis. Intra. & 0.2804 & 0.9581 & 0.9972 & 1.0000 & 0.9961 & 0.5074 \\
Dis. Inter. & 0.2391 & 0.9536 & 0.9999 & 0.9961 & 1.0000 & 0.4936 \\
Coef. Corr. & -0.4586 & 0.2491 & 0.4960 & 0.5074 & 0.4936 & 1.0000 \\
\hline
\end{tabular}

Tabela 5.1: Coeficientes de correlação entre as medidas de qualidade de clusters.

\begin{tabular}{|c|c|}
\hline Escalas & Dist. de Mahalanobis \\
\hline \hline $\mathbf{0 , 0 0 0 0 6}$ & $\mathbf{2 , 3 9 0 8}$ \\
\hline 0,0001 & 2,2561 \\
\hline 0,0005 & 2,1835 \\
\hline 0,0009 & 0,7947 \\
\hline 0,002 & 1,4313 \\
\hline 0,004 & 2,7221 \\
\hline $\mathbf{0 , 0 0 5}$ & $\mathbf{2 , 8 7 8 4}$ \\
\hline 0,006 & 2,7066 \\
\hline 0,008 & 2,7189 \\
\hline $\mathbf{0 , 0 1}$ & $\mathbf{2 , 3 1 2 8}$ \\
\hline 0,05 & 2,2435 \\
\hline
\end{tabular}

Tabela 5.2: Distância de Mahalanobis para diferentes escalas considerando a combinação de características conforme explicado na Seção 5.2.1. Os valores em destaque são referentes aos gráficos da Figura 5.12(a)-(c).

Considerando todas as características obtidas para uma série de escalas espaciais, nós as combinamos uma a uma, duas a duas, e três a três, levando em conta a distância de Mahalanobis entre elas, e os resultados para os melhores espaços de características são apresentados nas Figuras 5.15(a)-(c). A Tabela 5.3 apresenta os valores da distância de Mahalanobis para as respectivas figuras. 


\begin{tabular}{|c|c|}
\hline Número de características & Dist. de Mahalanobis \\
\hline \hline 1 & 3,2035 \\
\hline 2 & 12,7112 \\
\hline 3 & 64,7470 \\
\hline
\end{tabular}

Tabela 5.3: Distância de Mahalanobis para os espaços de características apresentados na Figura 5.15.

\subsection{Superfícies do tipo $w=f(x, y, z)$ e Wavelet 3D}

Nosso terceiro estudo trata de separar estruturas neuroanatômicas, mais especificamente traços de uma estrutura, a giro de Heschl. Ele é obtido de um hemisfério de 14 pessoas, usando a metodologia de traço de [37]. Estas 14 pessoas são classificadas por um anatomista especializado em três categorias de formas:

- Classe 1 - Giros de Heschl simples: nesta classe, a forma de giro de Heschl consiste de uma saliência simples como porções latero-mediais.

- Classe 2 - Giros de Heschl com hastes em comum: nesta, o giro de Heschl começa como duas protuberâncias laterais, que convergem gradativamente em uma protuberância conforme avançam medialmente;

- Classe 3 - Giros de Heschl posteriormente duplicados: A forma do giros de Heschl consiste de duas saliências conforme as fatias continuam lateromedialmente.

Segundo o especialista em anatomia, geralmente há uma continuidade da variabilidade da forma ao longo desta três classes, indicando que a Classe 1 é mais similar à Classe 2, e a Classe 2 é mais similar à Classe 3. Assim, se as características selecionadas são quantitativamente representadas, as distribuições espaciais das classes no espaço de características deveriam ser vizinhas de acordo com esta similaridade.

\subsubsection{Espaço de Características Obtido}

Os espaços de características na Figura 5.16(a)-(c) foram obtidos a partir da aplicação da análise de formas proposta para estruturas após o pré-processamento, ou seja, alteradas em relação às classes explicadas acima. 
Conforme podemos verificar nos gráficos da Figura 5.16, as classes consideradas similares são de fato vizinhas no espaço de características, quando pares de características são projetados no gráfico.

Assim, podemos concluir que o método de caracterização aplicado nestas formas captura as variações nos giros de Heschl satisfatoriamente. Neste ponto, a correlação entre estas características - as quais refletem propriedades da forma - com características comportamentais - as quais refletem funcionalidade do cérebro — ainda precisam ser exploradas.

Neste caso, mostramos que a quantificação das propriedades morfológicas complexas de estruturas anatômicas usando as técnicas de análise de formas é possível. Para observar quão eficientes são as características calculadas para discriminar as classes de formas analisadas, avaliamos visualmente todas as combinações uma à uma, duas à duas, e três à três das características, e os espaços que obtiveram melhores resultados são apresentados na Figura 5.16. O parâmetro de escala $a$ da transformada wavelet pelo qual obtivemos os melhores resultados foi $a=0,0005$. 


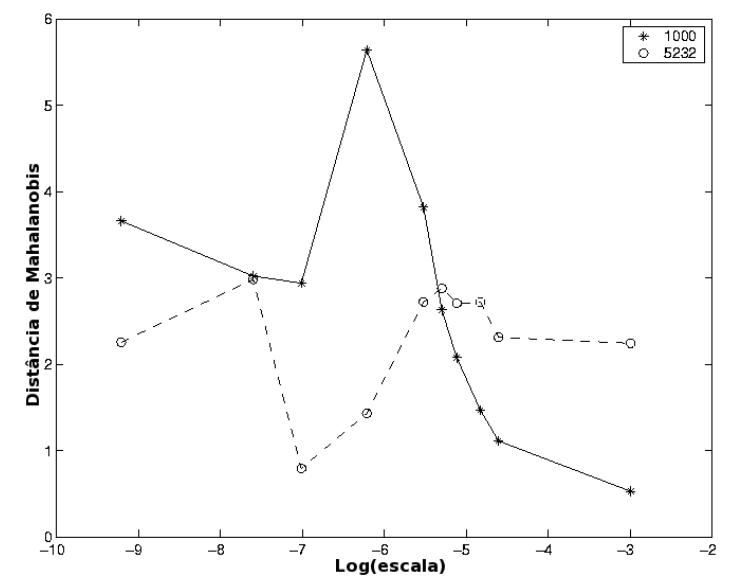

(a)

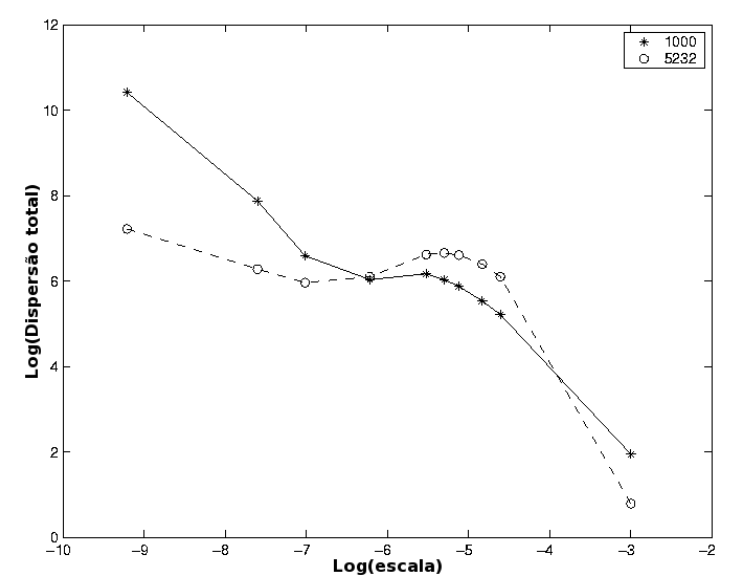

(c)

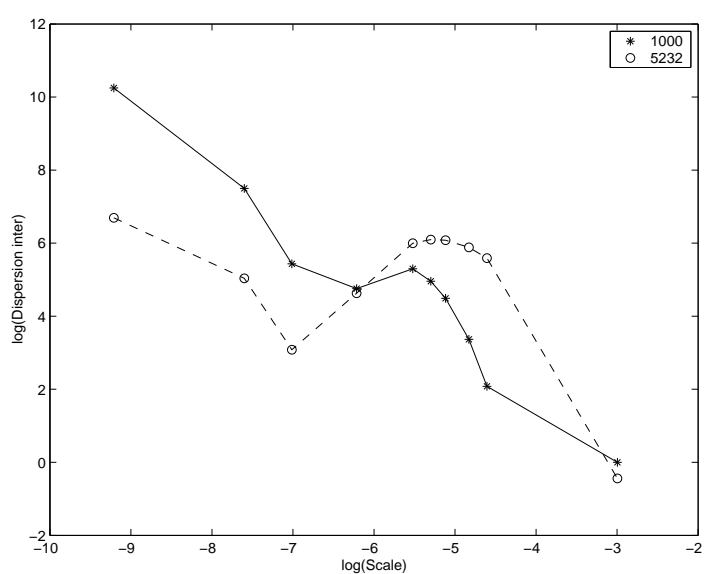

(e)

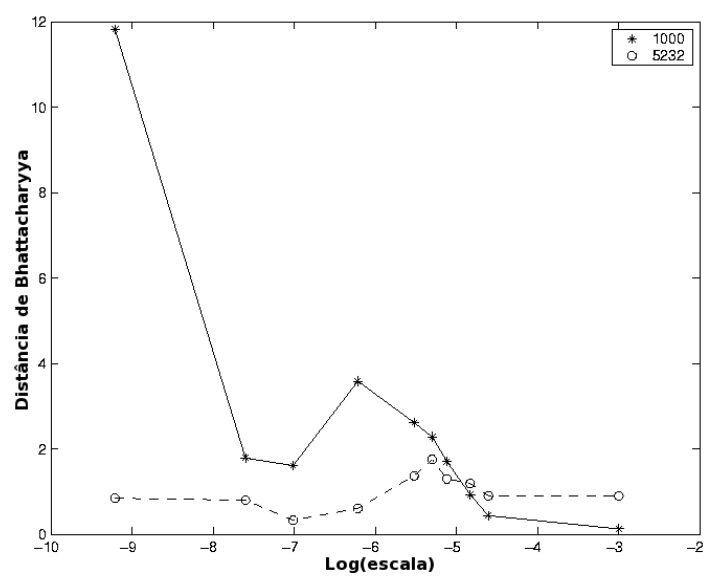

(b)

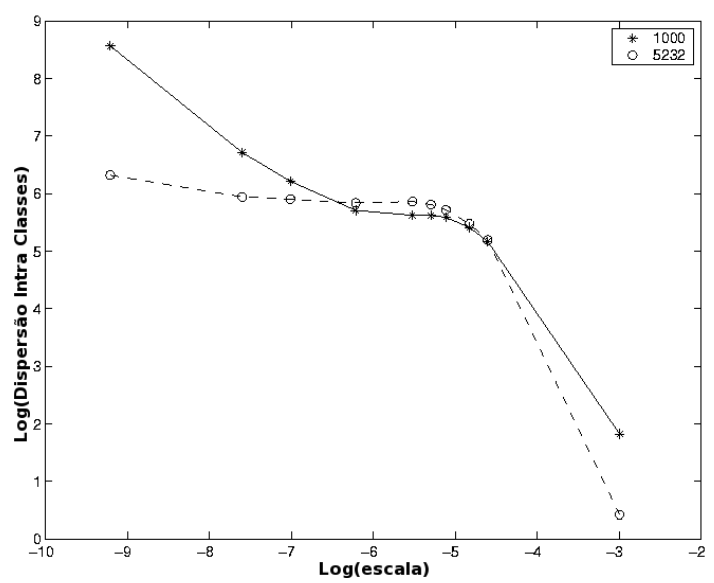

(d)

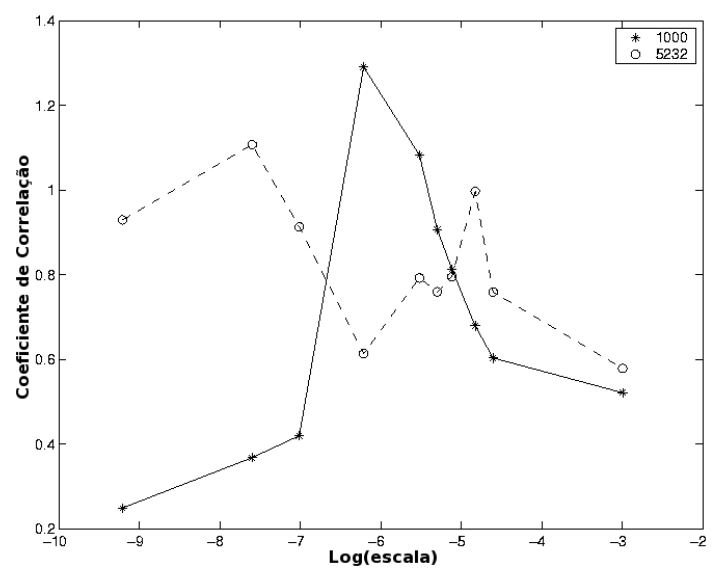

(f)

Figura 5.13: Medidas de qualidade dos espaços de características para uma série de escalas: (a) Distância de Mahalanobis; (b) Distância de Battacharyya; (c) Dispersão total; (d) Dispersão Intra classes; (e) Dispersão Inter classes; (f) Coeficiente de Correlação (valores deslocados para o eixo positivo do gráfico). 


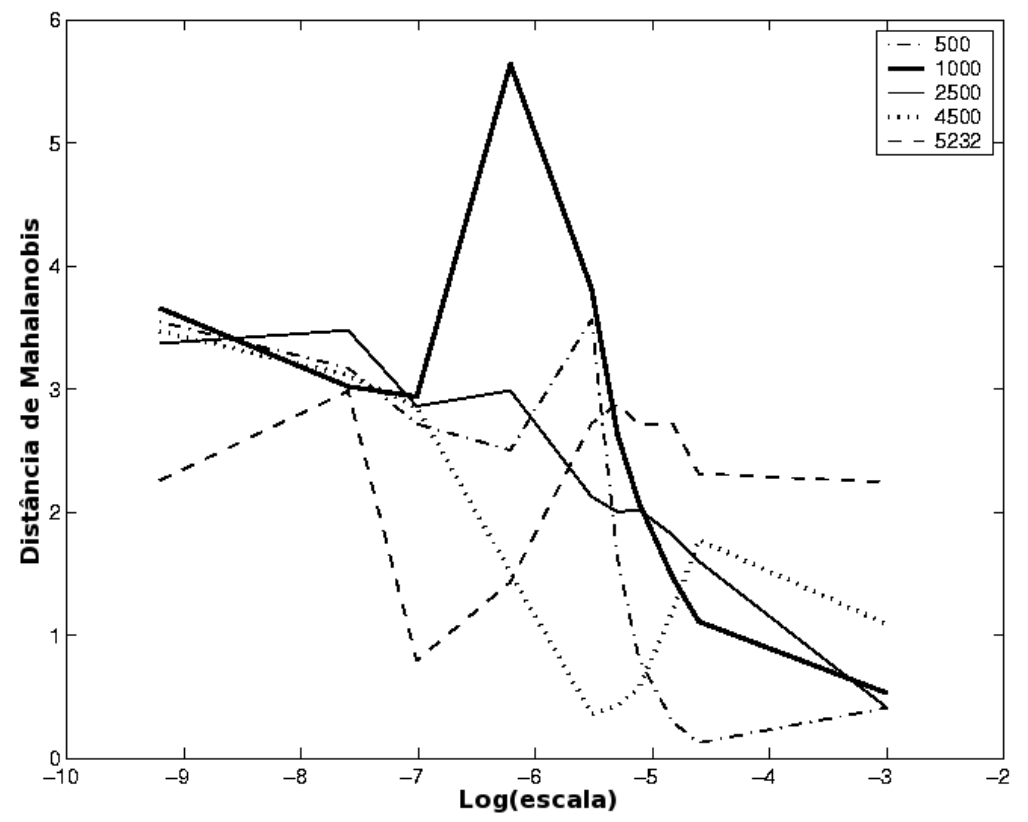

Figura 5.14: A distância de Mahalanobis em relação às escalas espaciais, considerando várias reconstruções a partir dos auto-vetores na Análise dos Componentes Principais. 


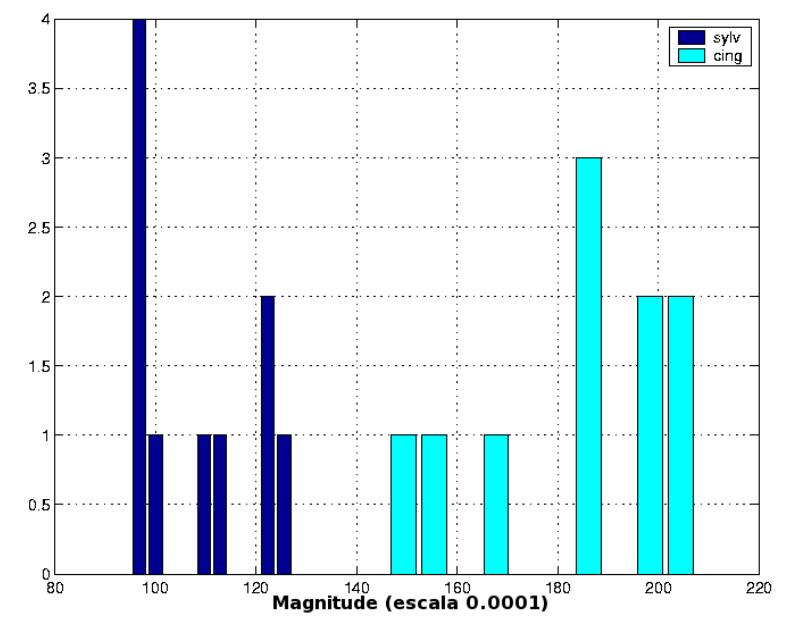

(a)

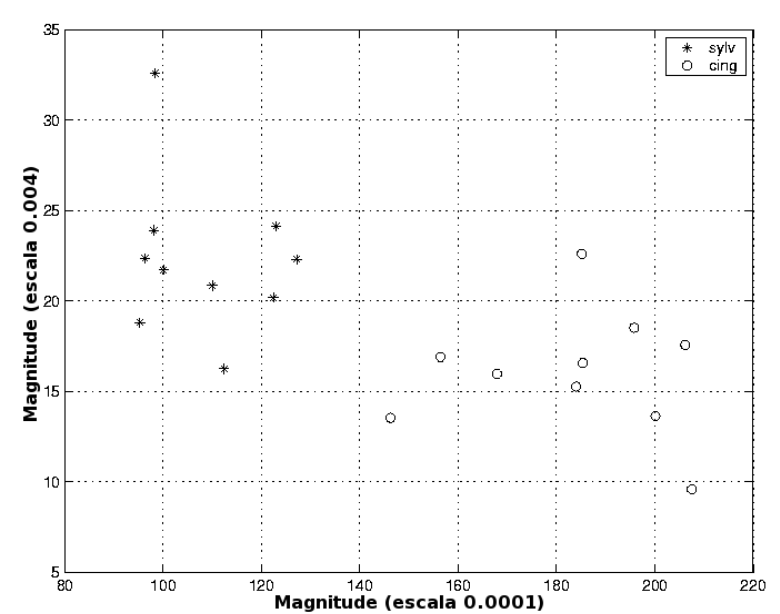

(b)

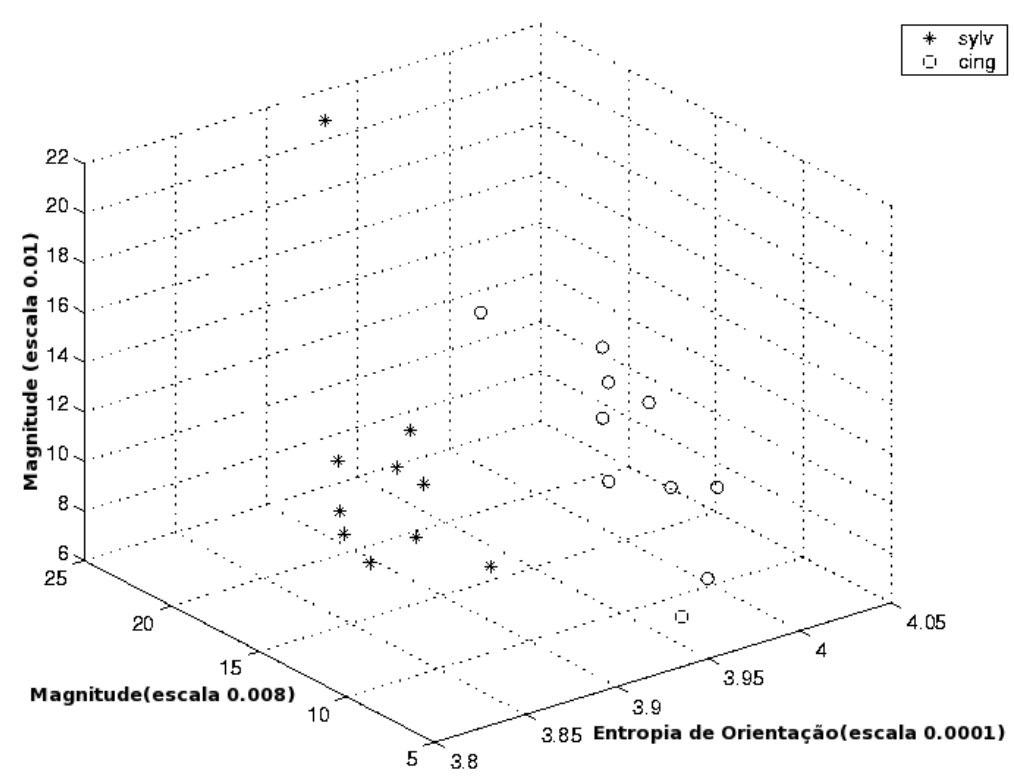

(c)

Figura 5.15: Melhor combinação de uma (a), duas (b) e três (c) características considerando o valor da distância de Mahalanobis. 


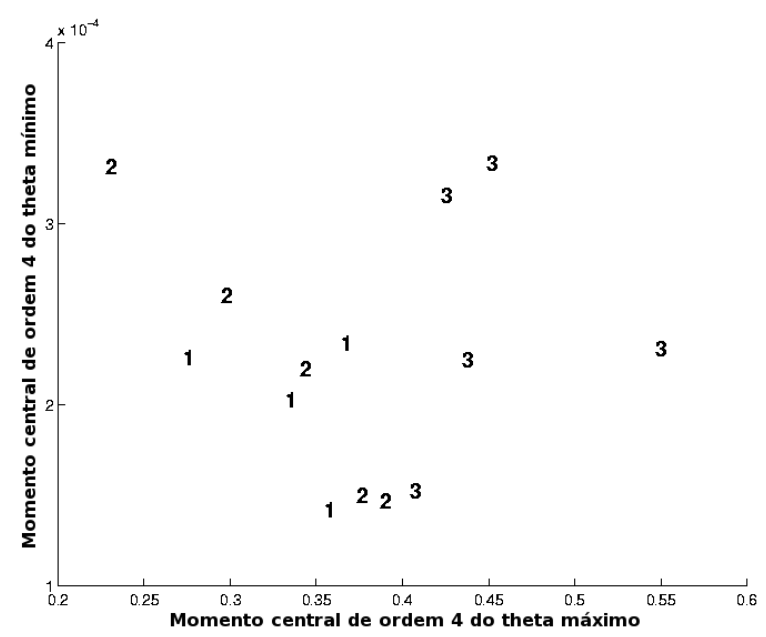

(a)

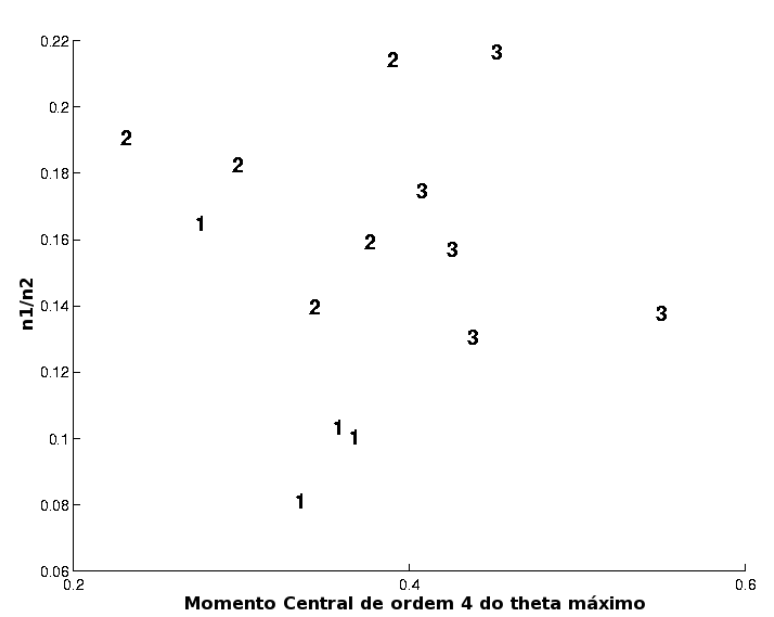

(b)

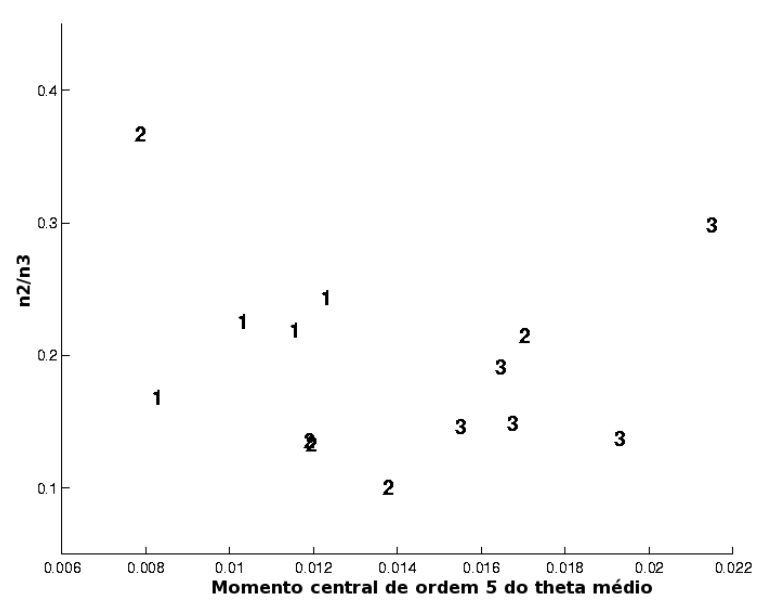

(c)

Figura 5.16: Três espaços de características obtidos pela análise visual entre todas as combinações de 1,2 e 3 características. 


\section{Capítulo 6}

\section{Conclusão}

\subsection{Considerações Finais}

De acordo com o trabalho realizado neste doutorado, foram desenvolvidos métodos para extração e análise de características de formas tridimensionais levando em consideração a propriedade da transformada wavelet de realizar uma análise multiescala.

Este trabalho pode ser considerado como uma extensão do trabalho realizado na tese de doutorado Análise Multi-escala em Formas Bidimensionais [12], cuja tese introduziu a wavelet como ferramenta para a análise multi-escala de formas bidimensionais.

No trabalho atual, pudemos realizar uma análise multi-escala de características para três abordagens com representações diferentes para a forma tridimensional, ou seja,

- Curvas espaciais parametrizadas do tipo $f(t)=(x(t), y(t), z(t))$;

- Superfície do tipo $f(x, y)=z$;

- Superfície do tipo $f(x, y, z)=w$.

Estas três abordagens foram aplicadas em formas biomédicas, as quais foram disponibilizadas por meio da colaboração com outros pesquisadores, conforme citado anteriormente nesta tese. 
A proposta da não-necessidade de trabalhar com formas parametrizadas foi cumprida em relação à aplicação dos métodos propostos nas superfícies analisadas. Ao contrário da maior parte das técnicas da bibliografia encontrada nesta área, as quais utilizam técnicas de triangularização ou outros métodos de parametrização, foram adotados conceitos da geometria diferencial e desenvolvidos métodos de extração de características a partir da análise multi-escala das formas, conforme pôde ser verificado no Capítulo 4, Seções 4.2.2 e 4.3.2.

A partir dos resultados obtidos na aplicação da transformada wavelet, a escolha das características para a análise das formas estudadas levou em consideração medidas que fossem invariantes à rotação e translação das formas, isto é: a curvatura e a torção para a curva espacial $f(t)=(x(t), y(t), z(t))$; a magnitude e a entropia da distribuição dos vetores do gradiente para uma superfície do tipo $f(x, y)=z$; e as razões dos auto-eixos, a média e os momentos centrais dos vetores normais para uma superfície do tipo $f(x, y, z)=z$.

A idéia de realizar medidas em formas 3D, utilizando a transformada wavelet, tem mostrado bons resultados devido à possibilidade de caracterizarmos estas formas do ponto de vista multi-escala. Pudemos perceber, a partir de alguns resultados já obtidos, que o nosso método proporcionou uma melhor separação entre as classes em relação a alguns métodos tradicionais de diferenciação como, por exemplo, o método de Sobel, conforme pôde ser verificado na Figura 5.12, do Capítulo 5.

Conforme as contribuições propostas neste trabalho, apresentadas no Capítulo 1, Seção 1.3, os resultados obtidos, apresentados no Capítulo 5, foram satisfatórios.

\subsubsection{Desenvolvimentos Futuros}

Apresenta-se como proposta de trabalho futuro a continuação da investigação das propriedades da transformada wavelet na extração de características de formas em diferentes aplicações como, por exemplo:

- Análise fractal multi-escala para detectar auto-similaridade em problemas de geração de padrões;

- Análise de texturas em reconhecimento de padrões em vídeo;

- Reconhecimento de padrões em faces como, por exemplo, expressões faciais. 
Outra possibilidade de trabalho é a aplicação dos métodos desenvolvidos em outros tipos de imagens e formas como, por exemplo, análise de imagens de microscopia de tunelamento e por força atômica, análise de imagens de tomografia e ultra-som 3D, análise de imagens de neurônios, etc.

Outra oportunidade de pesquisa é o estudo da verificação de como medidas de um certo objeto, a partir de uma representação numa certa dimensão, digamos 3D, modificam-se ao serem projetadas em espaços de dimensão inferior, por exemplo 2D. Tal estudo é considerado fundamental como uma possibilidade para o abrangente conhecimento de degenerações das medidas, quando tomadas em espaços projetados. Este conhecimento é essencial para podermos compreender as vantagens e desvantagens de medidas específicas de formas. 


\section{Bibliografia}

[1] N. Amenta, S. Choi, T. K. Dey, and N. Leekha. A simple algorithm for homeomorphic surface reconstruction. Int. J. Comput. Geometry Appl., 12(1-2):125$141,2002$.

[2] J-P. Antoine, D. Barache, R. M. Cesar-Jr., and L. da F. Costa. Shape characterization with the wavelet transform. Signal Processing, 62(3):265-290, 1997.

[3] J-P. Antoine and R. Murenzi. Two-dimensional wavelet analysis in image processing. Physicalia Magazine, 16:105-134, 1994.

[4] J-P. Antoine, P. Vandergheynst, and R. Murenzi. Two-dimensional directional wavelets in image processing. Int. J. Imag. Syst. Tech., 7:152-165, 1996.

[5] A. Arnéodo, N. Decoster, and S. G. Roux. A wavelet-based method for multifractal image analysis. i. methodology and test applications on isotropic and anisotropic random rough surfaces. The European Physical Journal B, 15:567$600,2000$.

[6] D. H. Ballard and C. M. Brown. Computer Vision. Prentice-Hall, Englewood Cliffs, NJ, 1982.

[7] H. Blum. Biological shape and visual sciences. J. theor. Biol., 38:205-287, 1973.

[8] K. Brakke. The Surface Evolver. http://www.susqu.edu/facstaff/b/brakke/evolver/, Consultado em 2005.

[9] M. F. Carmo. Differential geometry of curves and surfaces. Prentice-Hall, Englewood Cliffs, N.J., 1976.

[10] K.R. Castleman. Digital Image Processing. Prentice-Hall, Englewood Cliffs, NJ, 1996. 
[11] R. M. Cesar-Jr. Reconstrução tridimensional por ajuste de superfícies paramétricas. Master's thesis, FEE-UNICAMP, 1993.

[12] R. M. Cesar-Jr. Análise Multi-Escala de Formas Bidimensionais. PhD thesis, IFSC - USP, São Carlos, 1997.

[13] R. M. Cesar-Jr. and L. da F. Costa. Piecewise linear segmentation of digital contours in $\mathrm{O}(\mathrm{N} \cdot \log (\mathrm{N}))$ through a technique based on effective digital curvature estimation. Real-Time Imaging, 1:409-417, 1995.

[14] R. M. Cesar-Jr. and L. da F. Costa. Neural cell classification using wavelets and multiscale curvature. Biological Cybernetics, 79(4):347-360, 1998.

[15] A. K. Chan and S. J. Liu. Wavelet Toolware: Software for Wavelet Training. Academic Press, 1998.

[16] M. M. S. Chong, R. K. Gay, H. N. Tan, and J. Liu. Automatic representation of fingerprints for data compression by b-spline functions. Pattern Recognition, 25(10):1199-1210, 1992.

[17] F. S. Cohen and C. Pintavirooj. Invariant surface alignment in the presence of affine and some nonlinear transformations. In IEEE Workshop on Mathematical Methods in Biomedical Image Analysis, pages 78 -85, 2000.

[18] B. Crosson, J. R. Sadek, J. A. Bobholz, D. Gokcay, C. M. Mohr, C. M. Leonard, L. Maron, E. J. Auerbach, S. R. Browd, A. J. Freeman, and R. W. Briggs. Activity in the paracingulate and the cingulate sulci during word generation: An fmri study of functional anatomy. Cerebral Cortex, 9(4):307-316, 1999.

[19] L. da F. Costa. Small camera movements as a means of reducing the amount of broken and false detected lines in Hough transform. Real-Time Imaging, 1996.

[20] L. da F. Costa and R. M. Cesar-Jr. Shape Analysis and Classification: Theory and Practice. CRC Press, 2001.

[21] L. da F. Costa, R. M. Cesar-Jr., R. C. Coelho, and J. S. Tanaka. Perspective on the analysis and synthesis of morphologically realistic neural networks. In R. Poznanski, editor, Modeling in the Neurosciences: From Ionic Channels to Neural Networks, pages 505-528. Gordon and Breach Science Publishers, 1999.

[22] L. da F. Costa and T. Velte. Automatic characterization and classification of ganglion cells from the salamander retina. J. Comp. Neurol., 404:33-51, 1999. 
[23] R. J. Ferrari, R. M. Rangayyan, J. E. L. Desautels, and A. F. Frére. Analysis of asymmetry in mammograms via directional filtering with Gabor wavelets. IEEE Transaction on Medical Imaging, 9(20):953-964, 2001.

[24] J. D. Foley, A. Van Dam, S. K. Freiner, and J. F. Hughes. Fundamentals of Interactive Computer Graphics. Addison Wesley Publishing Company, 2nd edition, 1990.

[25] K. S. Fu. Syntactic Pattern Recognition and Applications. Prentice-Hall, Englewood Cliffs, NJ, 1982.

[26] D. Gokcay. Self-organizing features for regularized image standardization. University of Florida, 2001. Doctoral dissertation.

[27] G. H. Granlund. Fourier preprocessing for hand print character recognition. IEEE Transactions on Computers, C-21(2):195-201, 1972.

[28] A. Grossmann. Wavelet transforms and edge detection. In S. Albeverio, Ph. Blanchard, M. Hazewinkel, and L. Streit, editors, Stochastic Processes in Physics and Engineering. Reidel Publishing Company, Dordrecht, 1988.

[29] A. Grossmann, R. Kronland-Martinet, and J. Morlet. Reading and understanding continuous wavelet transform. In [31], 1989.

[30] X. Han, C. Xu, and J. L. Prince. A topology preserving level set method for geometric deformable models. IEEE Transactions on Pattern Analysis and Machine Intelligence, 25(6):755-768, 2003.

[31] M. Holschneider, R. Kronland-Martinet, J. Morlet, and A. Grossmann. A realtime algorithm for signal analysis with the help of the wavelet transform. In J. M. Combes, A. Grossmann, and Ph. Tchamitchian, editors, Wavelets, TimeFrequency Methods and Phase Space, pages 286-297. Springer-Verlag, 1989.

[32] L. Jacques, A. Coron, A. Rivoldini, P. Vandergheynst, and L. Demanet. Yawtb's homepage. http://www.fyma.ucl.ac.be/projects/yawtb/index.php, Consultado em 2003.

[33] S. Joshi, J. Wang, M. I. Miller, D. C. Van Essen, and U. Grenander. On the differential geometry of the cortical surface. In Proceedings of the SPIE's 1995 International Symposium on Optical Science, Engineering, and Instrumentation San Diego, CA,, pages 304-311, 1995. 
[34] R. S. Kashi, P. Bhoi-Kavde, R. S. Nowakowski, and T. V. Papathomas. 2d shape representation and averaging using normalized wavelet descriptors. Simulation, 66(3):164-178, 1996.

[35] A. F. Kohn. Reconhecimento de padrões, uma abordagem estatística. Apostila, Escola Politécnica, USP, 1998.

[36] C. M. Leonard, M. A. Eckert, L. J. Lombardino, T. Oakland, K. Kranzler, C. M. Mohr, W. M. King, and A. Freeman. Anatomical risk factors for phonological dyslexia. Cerebral Cortex, 11(2):148-157, 2001.

[37] C. M. Leonard, C. Puranik, J. M. Kuldau, and L. J. Lombardino. Normal variation in the frequency and location of human auditory cortex landmarks. Heschl's gyrus: Where is it? Cerebral Cortex, 8:397-406, 1998.

[38] P. E. Lestrel. Fourier Descriptors and Their Applications in Biology. Cambridge University Press, 1997.

[39] P. E. Lestrel. Morphometrics for the Life Sciences. World Scientific, 2000.

[40] B. Mak and E. Barnard. Phone clustering using the Bhattacharyya distance. In In The Fourth International Conference on Spoken Language Processing (ICSLP96), volume 4, 1996.

[41] S. Mallat and W. L. Hwang. Singularity detection and processing with wavelets. IEEE Transactions on Information Theory, 38(2):617-643, 1992.

[42] S. Mallat and S. Zhong. Characterization of signals form multiscale edges. IEEE Trans. Pattern Analysis and Machine Intelligence, 14(7):710-732, July 1992.

[43] D. Marr. Vision. W.H. Freeman and Company, 1982.

[44] P. A. Morettin. Onda e Ondaletas: Da Análise de Fourier à Análise de Ondalets. Edusp, 1999.

[45] J. M. Morvan and B. Thibert. Smooth surface and triangular mesh : Comparison of the area, the normals and the unfolding. In SIGGRAPH - ACM Special Interest Group on Computer Graphics and Interactive Techniques - Solid Modeling, pages 147 - 158, June 2002. 
[46] S. C. D. Pinto, R. M. Cesar-Jr, D. Gokcay, and L. da F. Costa. 3d morphological analysis of brain MRI using wavelets. In Proceedings of DSP 2002 14th International Conference on Digital Signal Processing, volume 1, pages 399-402, Greece, 2002.

[47] S. C. D. Pinto, R. M. Cesar-Jr, D. Gokcay, and L. da F. Costa. Characterization of neuroanatomic structures using $3 \mathrm{~d}$ wavelet-based normal fields. In Proceedings of ISSPA 2003 - The Seventh International Symposium on Signal Processing and its Applications, pages 479-482, Paris, France, 2003.

[48] S. C. D. Pinto, R. M. Cesar-Jr, D. Gokcay, and L. da F. Costa. Feature generation and assessment of $3 \mathrm{~d}$ morphological analysis of brain MRI. In ICoBiCoBi'03 - International Conference on Bioinformatics and Computacional Biology, Ribeirão Preto, Brasil, 2003.

[49] S. C. D. Pinto, R. M. Cesar-Jr, D. Gokcay, and L. da F. Costa. Morphological analysis of brain structures using 3d wavelet. In SIBGRAPI 2003 - XVI Brazilian Symposium on Computer Graphics and Image Processing, São Carlos, Brasil, 2003.

[50] S. C. D. Pinto, R. M. Cesar-Jr, Pete E. Lestrel, and L. da F. Costa. Shape feature extraction from a contour-based 3-d landmark representation using 3d wavelet transforms. In SIBGRAPI 2004 - XVII Brazilian Symposium on Computer Graphics and Image Processing, Curitiba, Brasil, 2004.

[51] S. C. D. Pinto, R. M. Cesar-Jr, Pete E. Lestrel, and L. da F. Costa. Features extraction from a 3d morphological structure using wavelets. In SIBGRAPI 2005 - XVIII Brazilian Symposium on Computer Graphics and Image Processing, Natal, Brasil, 2005.

[52] I. Pitas and A. N. Venetsanopoulos. Morphological shape decomposition. IEEE Transactions on Pattern Analysis and Machine Intelligence, 12(1):38-45, 1990.

[53] I. Pitas and A. N. Venetsanopoulos. Morphological shape representation. Pattern Recognition, 25(6):555-565, 1992.

[54] P. Schneider, M. Scherg, H. G. Dosch, H. J. Specht, A. Gutschalk, and A. Rupp. Morphology of Heschl's gyrus reflects enhanced activation in the auditory cortex of musicians. Nature Neuroscience, 5(7):688-694, 2002. 
[55] M. Schonwiesner, D. Y. von Cromon, and R. Rubsamen. Is it tonotopy after all? Neuroimage, 17:1144-1161, 2002.

[56] J. Sobotta. Atlas de Anatomia Humana, volume 1. Guanabara Koogan, Rio de Janeiro, 20a edition, 1997.

[57] H. Steinmetz, G. Furst, and H-J. Freund. Cerebral cortical localization: Application and validation of the proportional grid system in MR Imaging. Journal of Computer Assisted Tomography, 13(1):10-19, 1989.

[58] E. J. Stollnitz, T. D. DeRose, and D. H. Salesin. Wavelets for computer graphics: A primer, part 1. IEEE Computer Graphics and Applications, 15(3):76-84, 1995.

[59] M. Styner and G. Gerig. Medial models incorporating object variability for 3d shape analysis. In Information Processing in Medical Imaging. 17th International Conference. IPMI 2001, pages 502-516, 2001.

[60] C. M. Takemura, R. M. Cesar-Jr, R. A. T. Arantes, L. da F. Costa, E. HingstZaher, V. Bonato, and S. F. dos Reis. Morphometrical data analysis using wavelets. Journal of Real-Time Imaging, 10(4):239-250, Aug. 2004.

[61] J. Talairach and P. Tournoux. Co-planar stereotaxic Atlas of the Human Brain. Stuttgart, 1988.

[62] K. Tenenblat. Introdução à geometria diferencial. Editora Universidade de Brasília, Brasília, D.F., 1988.

[63] M. Vaillant and C. Davatzikos. Finding parametric representations of the cortical sulci using an active contour model. Medical Image Analysis, 1(4):295-315, 1997.

[64] J. Wang and M. M. Oliveira. A hole-filling strategy for reconstruction of smooth surfaces in range images. In SIBGRAPI, pages 11-18, 2003.

[65] E. W. Weisstein. "euler angles" from Mathworld-a Wolfram web resource. http://mathworld.wolfram.com/EulerAngles.html, Consultado em 2003.

[66] E. W. Weisstein. "rotation group" from Mathworld-a Wolfram web resource. http://mathworld.wolfram.com/RotationGroup.html, Consultado em 2003. 
[67] I. H. Witten and E. Frank. Data Mining: Practical Machine Learning Tools and Techniques. Morgan Kaufmann, second edition, 2005.

[68] I. T. Young, J. E. Walker, and J. E. Bowie. An analysis technique for biological shape. I. Information and Control, 25:357-370, 1974. 


\section{Apêndice A}

\section{Rotinas Aplicadas no}

\section{Pré-processamento das Imagens}

\section{Algoritmo de Bresenham}

O algoritmo de linha de Bresenham é um dos mais eficientes para se determinar a posição dos pixels intermediários entre dois pixels inicialmente definidos a fim de ligá-los por uma linha reta usando somente inteiros aritméticos.

O algoritmo é definido [24] da seguinte maneira:

1. Entre com os dois pontos iniciais e que serão as pontas da curva. Guarde o ponto da esquerda em $\left(x_{1}, y_{1}\right)$ e o ponto da direita em $\left(x_{2}, y_{2}\right)$.

2. O primeiro ponto a ser selecionado pela tela é o ponto da esquerda $\left(x_{1}, y_{1}\right)$.

3. Calcule $\Delta_{x}=x_{2}-x_{1}, \Delta_{y}=y_{2}-y_{1}$, e $p_{1}=2 \Delta_{y}-\Delta_{x}$. Se $p_{1}<0$, o próximo ponto a ser marcado é $\left(x_{1}+1, y_{1}\right)$. Caso contrario, o próximo ponto é $\left(x_{1}+1, y_{1}+1\right)$.

4. Continue incrementando a coordenada $x$ pelos passos de unidade. Na posição $x_{i}+1$, a coordenada a ser selecionada, $y_{i}+1$, ou é $y_{i}$ ou $Y-i+1$, dependendo se $p_{i}<0$ ou $p_{i} \geq 0$. Os cálculos para cada parâmetro $p$ depende do último 
pixel calculado. Se $p_{i}<0$, a fórmula para o próximo parâmetro é

$$
p_{i+1}=p_{i}+2 \Delta_{y}
$$

Mas se $p_{i} \geq 0$, o próximo parâmetro é

$$
p_{i+1}=p_{i}+2\left(\Delta_{y}-\Delta_{x}\right)
$$

Então, se $p_{i+1}<0$, a próxima coordenada $y$ a ser selecionada é $y_{i+1}$. Caso contrário, selecione $y_{i+1}+1$. (A coordenada $y_{i+1}$ foi então determinada para ser ou $y_{i}$ ou $y_{i+1}$ para o parâmetro $p_{i}$ no passo 3 .)

5. Repita os procedimentos do passo 4 até a coordenada $x$ alcançar $x_{2}$.

\section{Método para tornar uma imagem periódica}

Dada uma imagem inicial $I$ de tamanho $\mathrm{MxN}$ é criada uma matriz de tamanho $(\mathrm{M}+2) \mathrm{x}(\mathrm{N}+2)$. A partir disso nós preenchemos a matriz com a imagem, obedecendo o seguinte critério:

- A primeira linha da imagem é colocada na segunda linha da matriz e a partir da segunda coluna, a segunda linha da imagem é colocada na terceira linha da matriz e a partir da segunda coluna, e assim por diante. O resultado então é uma nova imagem $J$ cuja borda têm pixels "vazios".

A atribuição de valores para estes pixels se dá seguinte maneira:

1. Ignore os pixels que estão nas arestas da imagem $J$;

2. As linhas superior e inferior da imagem $J$ são preenchidas com o valor médio dos pixels das linhas superior e inferior da imagem $I$;

3. A primeira e última coluna da imagem $J$ são preenchidas com o valor médio dos pixels da primeira e última coluna da imagem $I$;

4. Os pixels pertencentes ás arestas da imagem $J$ são preenchidos com o valor médio dos pixels pertencentes ás arestas da imagem $I$. 


\section{Medidas de Qualidade na Separação de Classes}

Dada duas classes num espaço de características, definidas como $C_{1}$ e $C_{2}$, temos que $\mathbf{r}_{i}$ é o vetor de características representando a $i$-ésima amostra no conjunto de treinamento. Se a $i$-ésima amostra pertence a classe $C_{j}$, sendo $j=1,2, \ldots$, então nos assumimos que $i \in C_{j}$. Nos também assumimos que o vetor de características médio para a $j$-ésima classe é dado como:

$$
\mu_{j}=\frac{1}{N_{j}} \sum_{i \in C_{j}} \mathbf{r}_{i}
$$

sendo que $N_{j}$ é o número de amostras da classe $C_{j}$ no conjunto de treinamento. $\mathrm{O}$ vetor de características médio global $M$ é definido como a média de todos os vetores de características de todas classes no conjunto de treinamento. Nos definimos a matriz covariante de $\mathbf{r}$, a qual pode ser estimada das amostras do conjunto de treinamento, como $\Sigma$. Similarmente, a matriz de covariância para cada classe é definida como $\sigma_{j}$.

A parti destas definições, nos calculamos as seguintes medidas de qualidade na separação de classes:

- Distância de Mahalanobis: A distância de Mahalanobis [35] entre as classes $C_{1}$ e $C_{2}$ é definida como:

$$
d_{M}\left(C_{1}, C_{2}\right)=\left[\left(\mu_{1}-\mu_{2}\right)^{T} \Sigma^{-1}\left(\mu_{1}-\mu_{2}\right)\right]^{\frac{1}{2}} .
$$

- Distância de Bhattacharyya: A distância de Bhattacharyya [40] entre as classes $C_{1}$ e $C_{2}$ é definida como:

$$
d_{B}\left(C_{1}, C_{2}\right)=-\ln \int\left[p\left(\mathbf{r} \mid C_{1}\right)\left(\mathbf{r} \mid C_{2}\right)\right]^{\frac{1}{2}} d \mathbf{r}
$$

Em nossa implementação, nos assumimos funções de densidade condicional normal $p\left(\mathbf{r} \mid C_{1}\right)$ e $p\left(\mathbf{r} \mid C_{2}\right)$ com as médias e matrizes de covariâncias dos parâmetros de classes entre a estimação do conjunto de treinamento.

- Medidas de Dispersão entre Classes: A matriz de dispersão da classe $C_{j}$ é definida como:

$$
S_{j}=\sum_{i \in C_{j}}\left(r_{i}-\mu_{i}\right)\left(r_{i}-\mu_{i}\right)^{T}
$$


e a matriz de dispersão intra classe é definida como $S_{\text {intra }}=S_{1}+S_{2}$. A matriz de dispersão inter classe é definida como $S_{\text {inter }}=\sum_{i=1,2} N_{i}\left(\mu_{i}-M\right)\left(\mu_{i}-M\right)^{T}$. Existem diferentes medidas de qualidade que podem ser extraídas de $S_{\text {intra }}$ e $S_{\text {inter }}[20]$. Neste trabalhos nos trabalhamos com o traço de cada matriz para definir duas medidas, isto é, dispersão intra classe definida como $D_{\text {intra }}=\operatorname{traço}\left(S_{\text {intra }}\right)$ e a dispersão inter classe definida como $D_{\text {inter }}=\operatorname{traço}\left(S_{\text {inter }}\right)$. Com a soma destas duas dispersões obtemos a dispersão total $D_{\text {total }}$. $D_{\text {intra }}$ é a medida que calcula o quão compacto estão as classes no espaço de características, enquanto que $D_{\text {inter }}$ calcula o quão distantes elas estão.

- Coeficiente de Correlação: O Coeficiente de Correlação [20] entre os vetores de características $r$ quantificam o quão correlacionados estão as características correspondentes.

$$
\operatorname{CoefCorr}\left(C_{1}, C_{2}\right)=E\left[\left(\frac{C_{1}-\mu_{1}}{\sigma_{C_{1}}}\right)\left(\frac{C_{2}-\mu_{2}}{\sigma_{C_{2}}}\right)\right]=\frac{\Sigma}{\sigma_{C_{1}} \sigma_{C_{2}}} .
$$

sendo $E$ o operador esperança. 


\section{Apêndice B}

\section{Conjunto das Curvas Espaciais}

Nesta seção, apresentamos as curvas originais representadas por landmarks, em diferentes perspectivas, para as duas análises propostas neste trabalho:

- 1. Forma e tamanho;

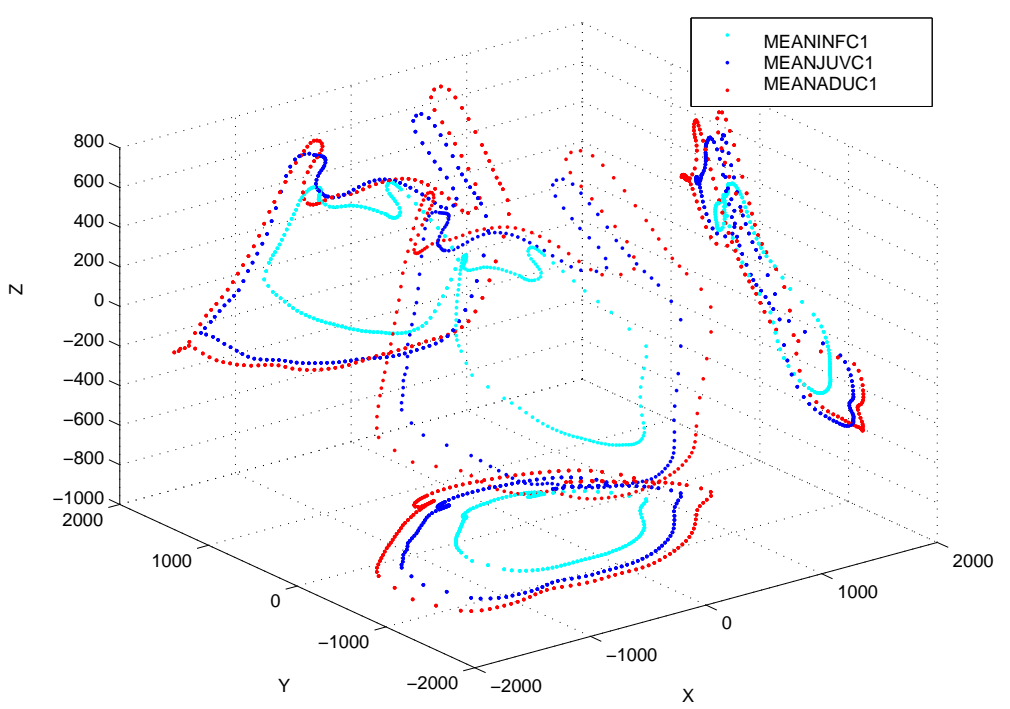

Figura B.1: Perspectivas 3D da curva orbital do coelho. Os três grupos médios: (1) infantil (MEANINFC1); (2) juvenil (MEANJUVC1); e (3) adulto (MEANADUC1), estão sobrepostos pelo centróide. Também são apresentadas as projeções ortogonais nos planos xy, xz e yz. Ambas diferenças de tamanho e forma estão envolvidas nesta representação. 


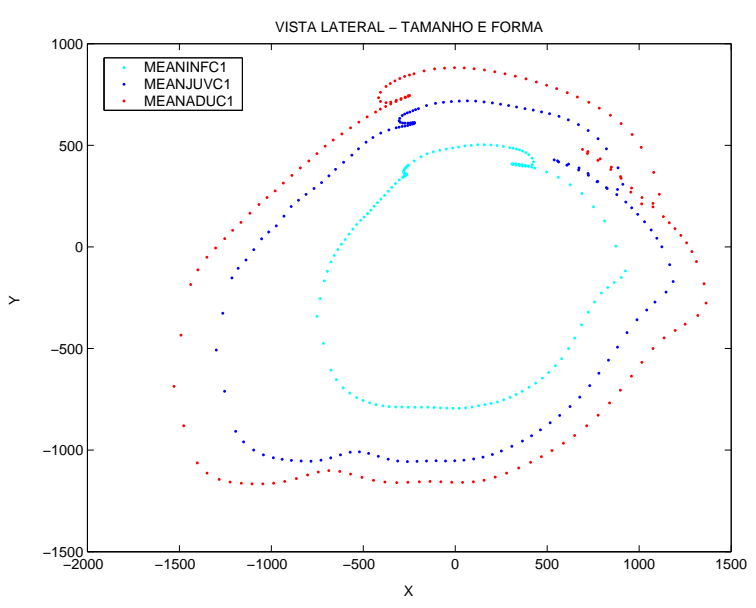

(a)

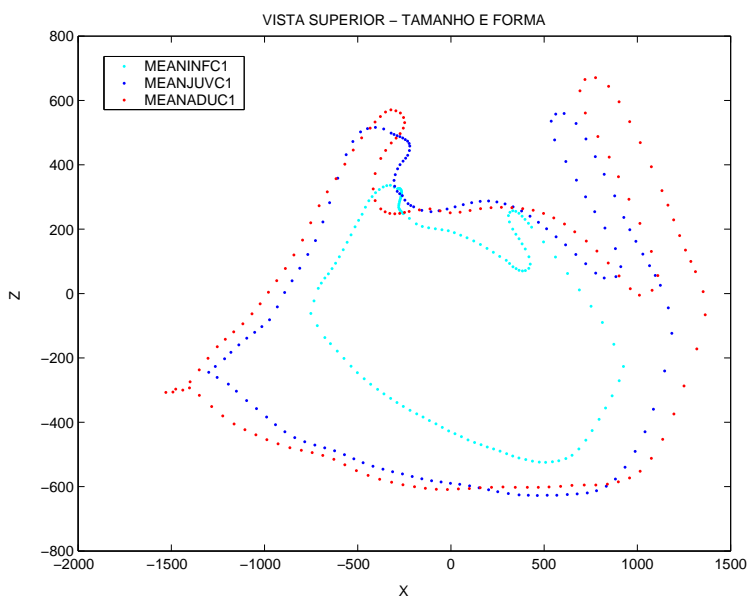

(b)

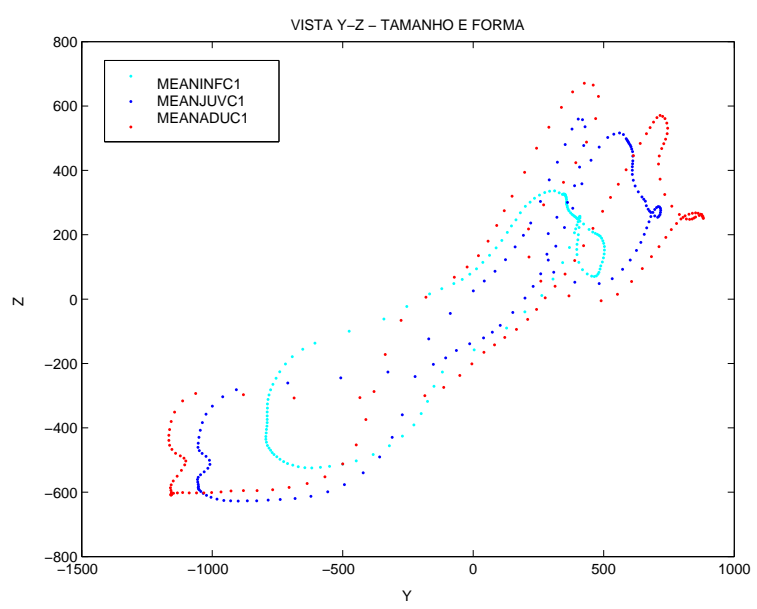

(c)

Figura B.2: Perspectiva 2D das três vistas da curva orbital para os três grupos médios: (1) infantil (MEANINFC1); (2) juvenil (MEANJUVC1); e (3) adulto (MEANADUC1), que estão sobrepostos pelo centróide. Em (a) vista lateral ou plano xy; em (b) vista superior ou plano xz; e (c) plano yz, respectivamente, conforme as projeções das curvas orbitais apresentadas na Figura 5.2 no Capítulo 5. Ambas diferenças de tamanho e forma estão envolvidas nestas representações.

- 2. Somente forma. 


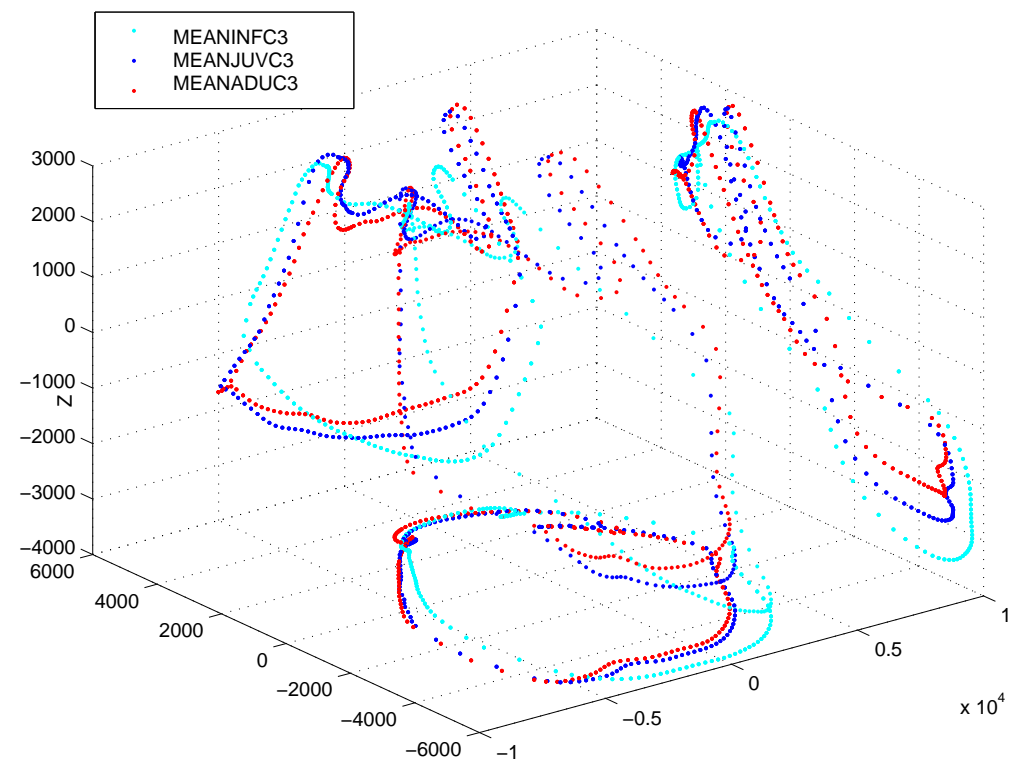

Figura B.3: Perspectivas 3D da curva orbital do coelho. Os três grupos médios: (1) infantil (MEANINFC3); (2) juvenil (MEANJUVC3); e (3) adulto (MEANADUC3), estão sobrepostos pelo centróide. Também são apresentadas as projeções ortogonais nos planos xy, xz e yz. Apenas as diferenças em relação à forma estão envolvidas nesta representação. 


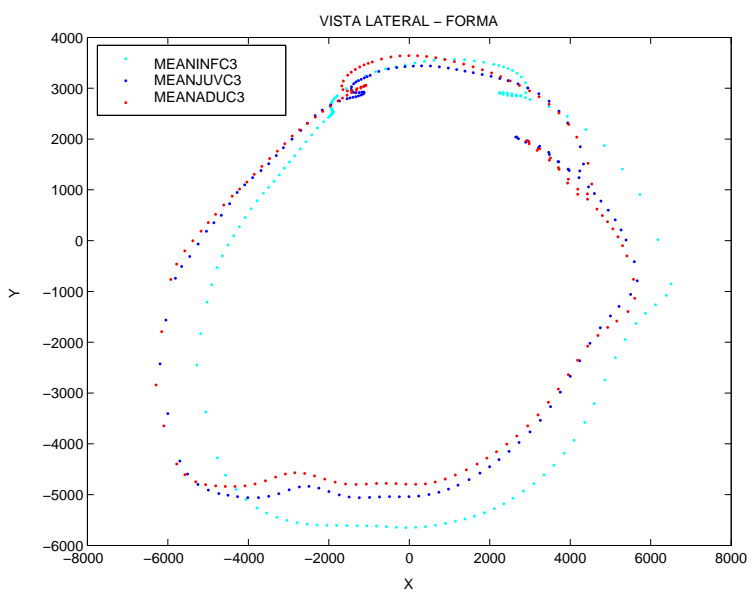

(a)

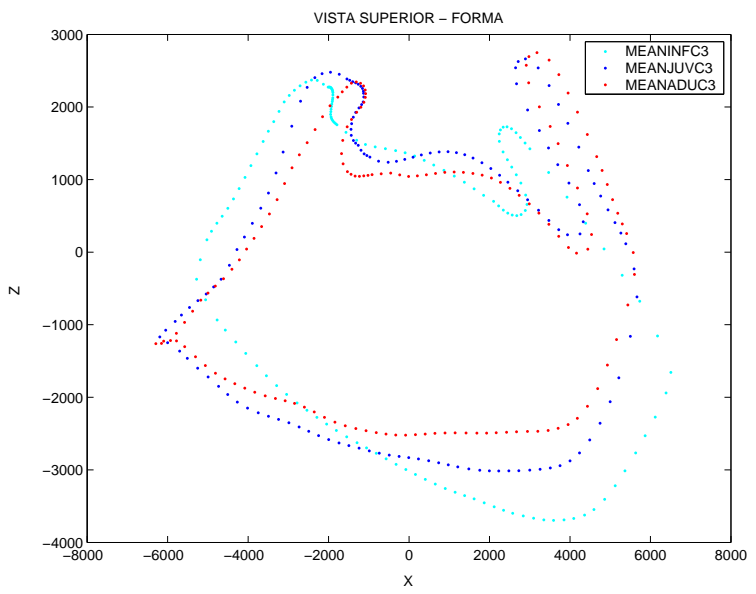

(b)

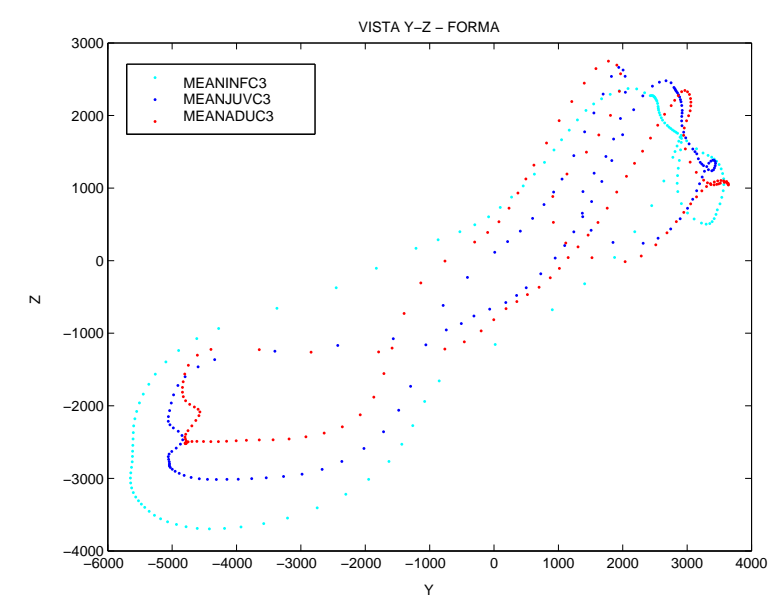

(c)

Figura B.4: Perspectiva 2D das três vistas da curva orbital para os três grupos médios: (1) infantil (MEANINFC3); (2) juvenil (MEANJUVC3); e (3) adulto (MEANADUC3), que estão sobrepostos pelo centróide. Em (a) vista lateral ou plano xy; em (b) vista superior ou plano xz; e (c) plano yz, respectivamente, conforme as projeções das curvas orbitais apresentadas na Figura 5.3 no Capítulo 5. Apenas as diferenças em relação à forma estão envolvidas nesta representação. 


\section{Apêndice C}

\section{Conjuntos das Superfícies do tipo \\ $z=f(x, y)$}

Nesta seção, apresentamos as estruturas originais e as mesmas mostradas depois da rotina de pré-processamento, as quais sofreram a aplicação do proposto neste trabalho. 

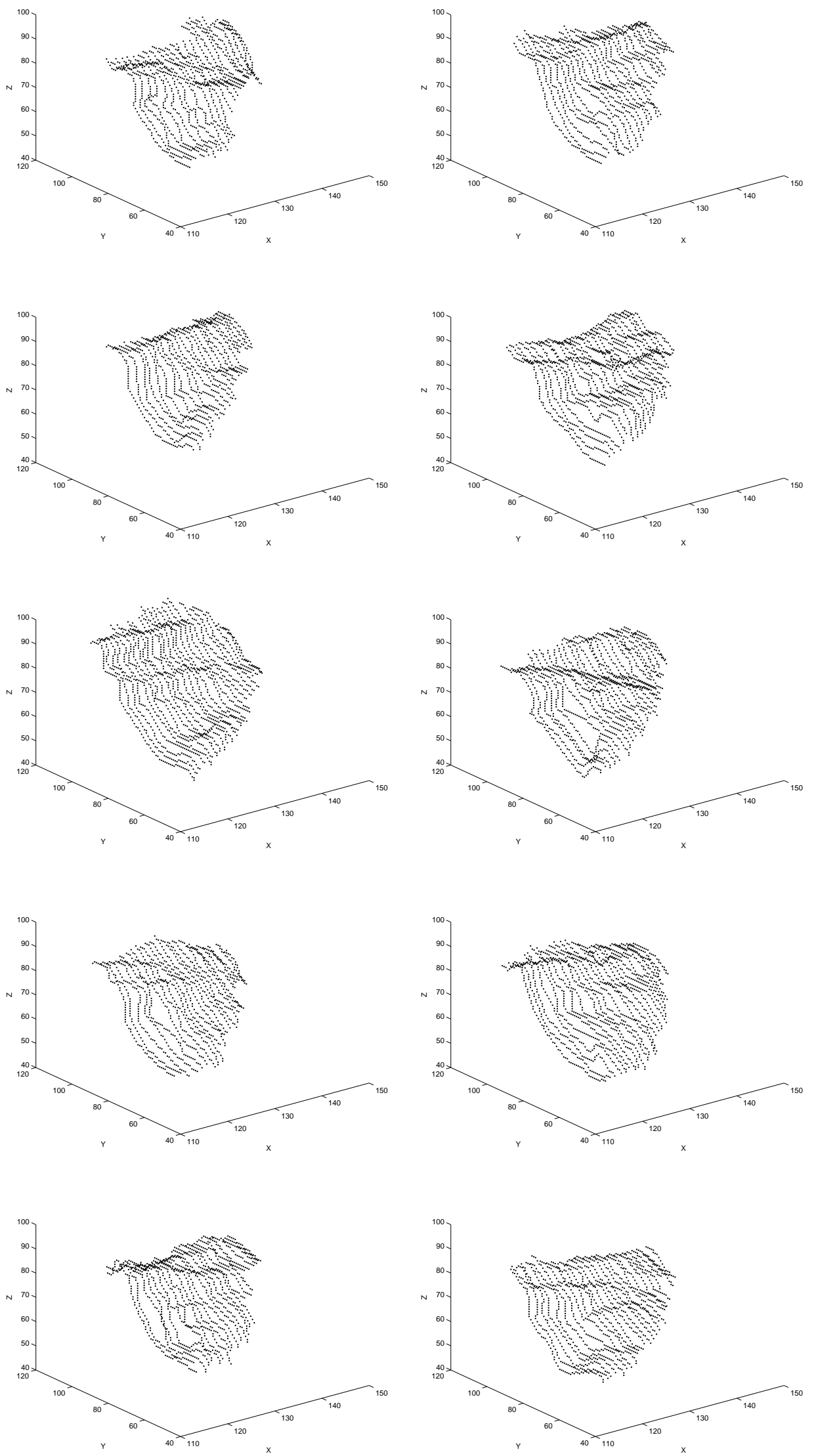

Figura C.1: Estruturas do tipo fissura de Sylvius. 

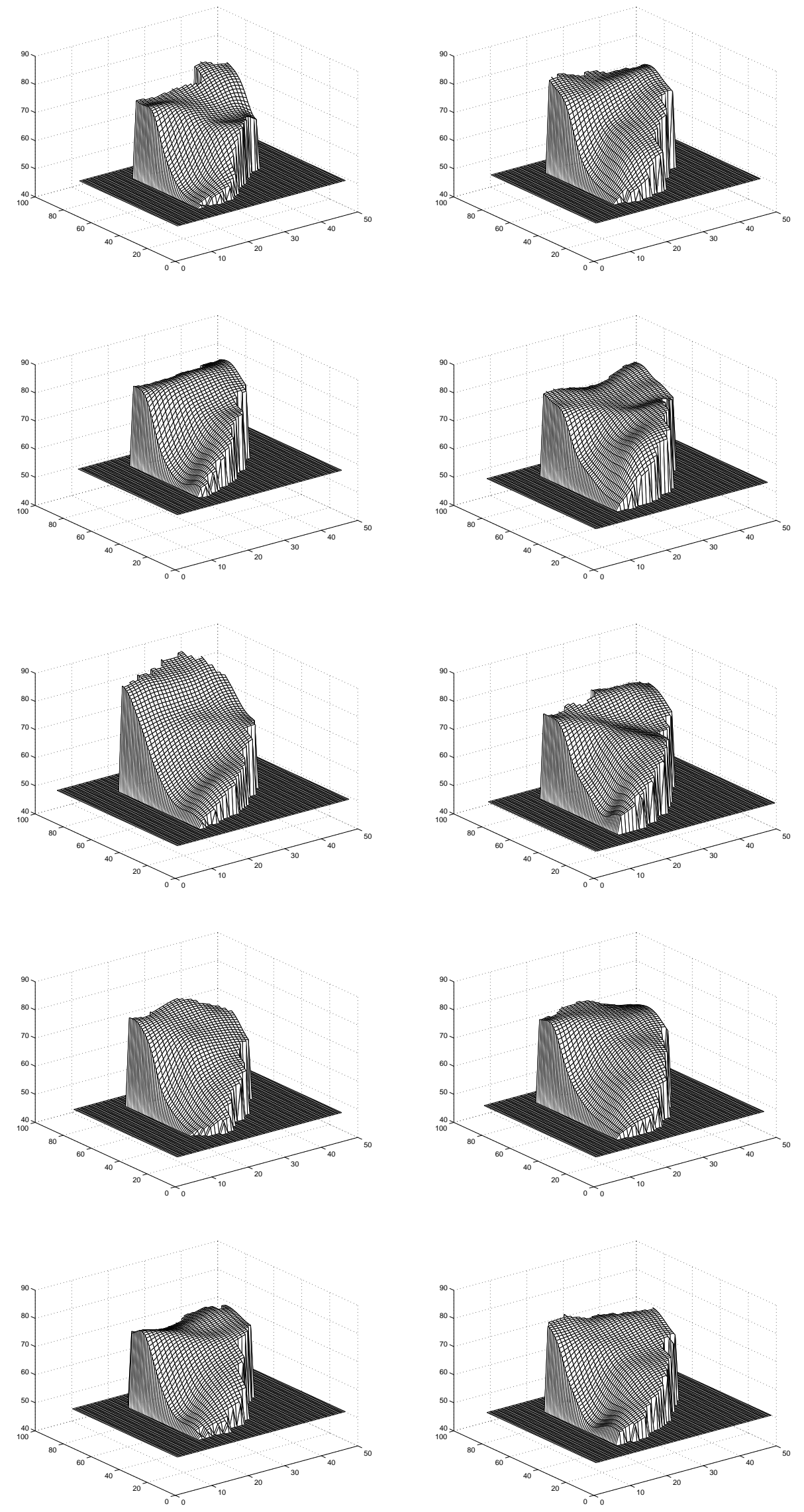

Figura C.2: Superfícies suavizadas das estruturas referentes à figura C.1 para $a=5 \cdot 10^{-4}$. 

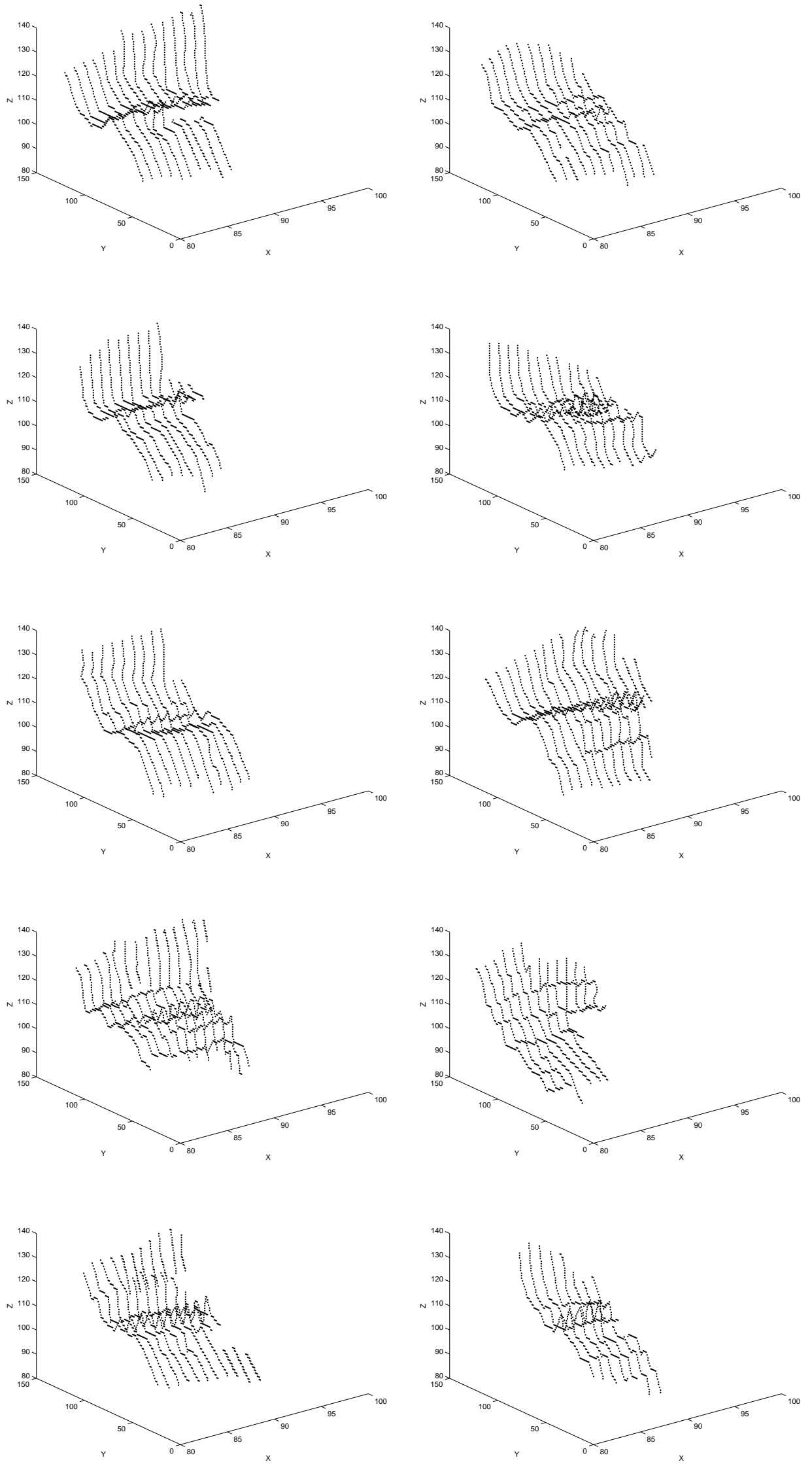

Figura C.3: Estruturas do tipo sulco de cíngulo. 

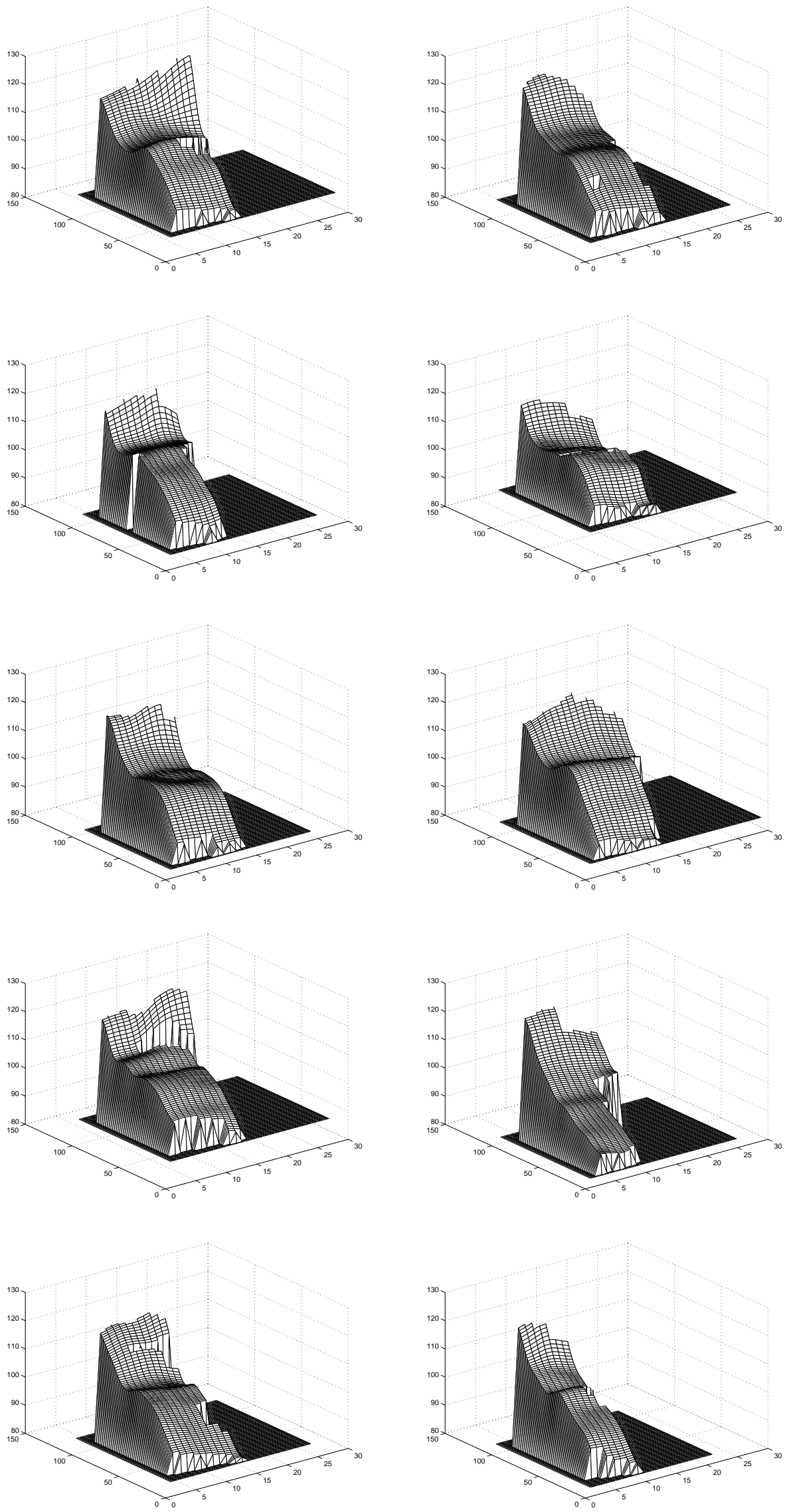

Figura C.4: Superfícies suavizadas das estruturas referentes à figura C.3 para $a=5.10^{-4}$. 


\section{Apêndice D}

\section{Conjunto das Superfícies do tipo}

$w=f(x, y, z)$

Nesta seção, apresentamos as superfícies analisadas, as quais foram obtidas após a aplicação da rotina de pré-processamento nas estruturas originais. 

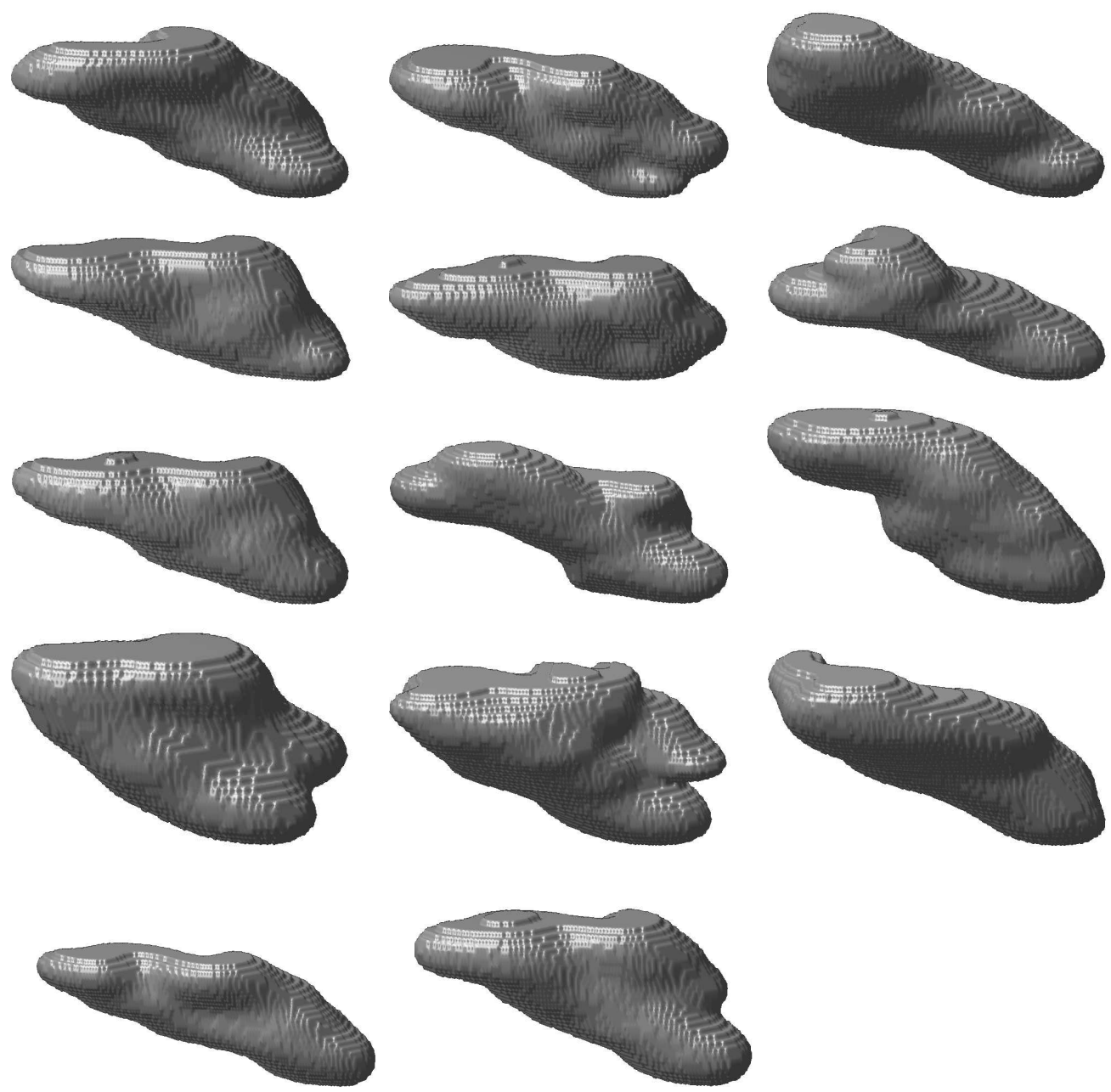

(a)

(b)

(c)

Figura D.1: Superfícies analisadas: as superfícies da coluna (a) pertencem à classe de Giros de Heschl de hastes em comum; as superfícies da coluna (b) pertencem à classe de Giros de Heschl posteriormente duplicado; e as superfícies da coluna (c) pertencem à classe de Giros de Hesch simples. 


\section{Apêndice E}

\section{Trabalhos Produzidos durante o Programa de Doutorado}

Lista-se abaixo, os trabalhos submetidos (todos aceitos):

1 Artigo (Full Paper): S. C. D. Pinto, R. M. Cesar-Jr, D. Gokcay and L. da F. Costa, 3D Morphological Analysis of Brain MRI using Wavelet, Proceedings of DSP 2002 - 14th International Conference on Digital Signal Processing, 1:399-402, Greece, 2002;

2 Resumo (Poster): S. C. D. Pinto, R. M. Cesar-Jr, D. Gokcay and L. da F. Costa, Feature Generation and Assessment of 3D Morphological Analysis of Brain MRI, ICoBiCoBi'03 - International Conference on Bioinformatics and Computacional Biology, Ribeirão Preto, Brasil, 2003;

3 Artigo (Full Paper): S. C. D. Pinto, R. M. Cesar-Jr, D. Gokcay and L. da F. Costa, Characterization of Neuroanatomic Structures using 3D Wavelet-Based Normal Fields, Proceedings of ISSPA 2003 - 14th International Conference on Digital Signal Processing, 479-482, Paris, France, 2003;

4 Resumo (Poster): S. C. D. Pinto, R. M. Cesar-Jr, D. Gokcay and L. da F. Costa, Morphological Analysis of Brain Structures using 3D Wavelet, SIBGRAPI 2003 - XVI Brazilian Symposium on Computer Graphics and Image Processing, São Carlos, Brasil, 2003; 
5 Resumo (Poster): S. C. D. Pinto, R. M. Cesar-Jr, Pete E. Lestrel and L. da F. Costa, Shape feature extraction from a contour-based 3-D landmark representation using 3-D wavelet transforms, SIBGRAPI 2004 - XVII Brazilian Symposium on Computer Graphics and Image Processing, Curitiba, Brasil, 2004 ;

6 Resumo (Poster): S. C. D. Pinto, R. M. Cesar-Jr, Pete E. Lestrel and L. da F. Costa, Features Extraction from a 3D Morphological Structure using Wavelets, SIBGRAPI 2005 - XVIII Brazilian Symposium on Computer Graphics and Image Processing, Natal, Brasil, 2005. 